\title{
Hydrometallurgical Processes for the Recovery of Metals from Steel Industry By-Products: A Critical Review
}

\author{
Koen Binnemans ${ }^{1}\left[\mathbb{D} \cdot\right.$ Peter Tom Jones ${ }^{2}\left[\right.$ [ $\cdot$ Álvaro Manjón Fernández ${ }^{3} \cdot$ Victoria Masaguer Torres $^{3}$
}

Received: 20 April 2020 / Accepted: 14 October 2020 / Published online: 13 November 2020

(c) The Author(s) 2020

\begin{abstract}
The state of the art for the recovery of metals from steel industry by-products using hydrometallurgical processes is reviewed. The steel by-products are different slags, dusts, and sludges from a blast furnace (BF), basic oxygen furnace (BOF), electric arc furnace (EAF), and sinter plant, as well as oily mill scale and pickling sludge. The review highlights that dusts and sludges are harder to valorize than slags, while the internal recycling of dusts and sludges in steelmaking is inhibited by their high zinc content. Although the objectives of treating BF sludges, BOF sludges, and EAF dust are similar, i.e., the removal of zinc and the generation of an Fe-rich residue to be returned to the steel plant, these three classes of by-products have specific mineralogical compositions and zinc contents. Because wide variations in the mineralogical composition and zinc content occur, it is impossible to develop a one-size-fits-all flow sheet with a fixed set of process conditions. The reason for the interest in EAF dust is its high zinc content, by far the highest of all steel by-products. However, EAF dust is usually studied from the perspective of the zinc industry. There are not only different concentrations of zinc, but also variations in the all-important $\mathrm{ZnO} / \mathrm{ZnFe}_{2} \mathrm{O}_{4}$ (zincite-to-franklinite) ratio. In many chemical processes, only the $\mathrm{ZnO}$ dissolves, while the $\mathrm{ZnFe}_{2} \mathrm{O}_{4}$ is too refractory and reports to the residue. It only dissolves in concentrated acids, or if the dust is pre-treated, e.g., with a reductive roasting step. The dissolution of $\mathrm{ZnFe}_{2} \mathrm{O}_{4}$ in acidic solutions also brings significant amounts of iron in solution. Finally, due to its high potassium chloride content, sinter-plant dust could be a source of potassium for the fertilizer industry.
\end{abstract}

\section{Graphical Abstract}

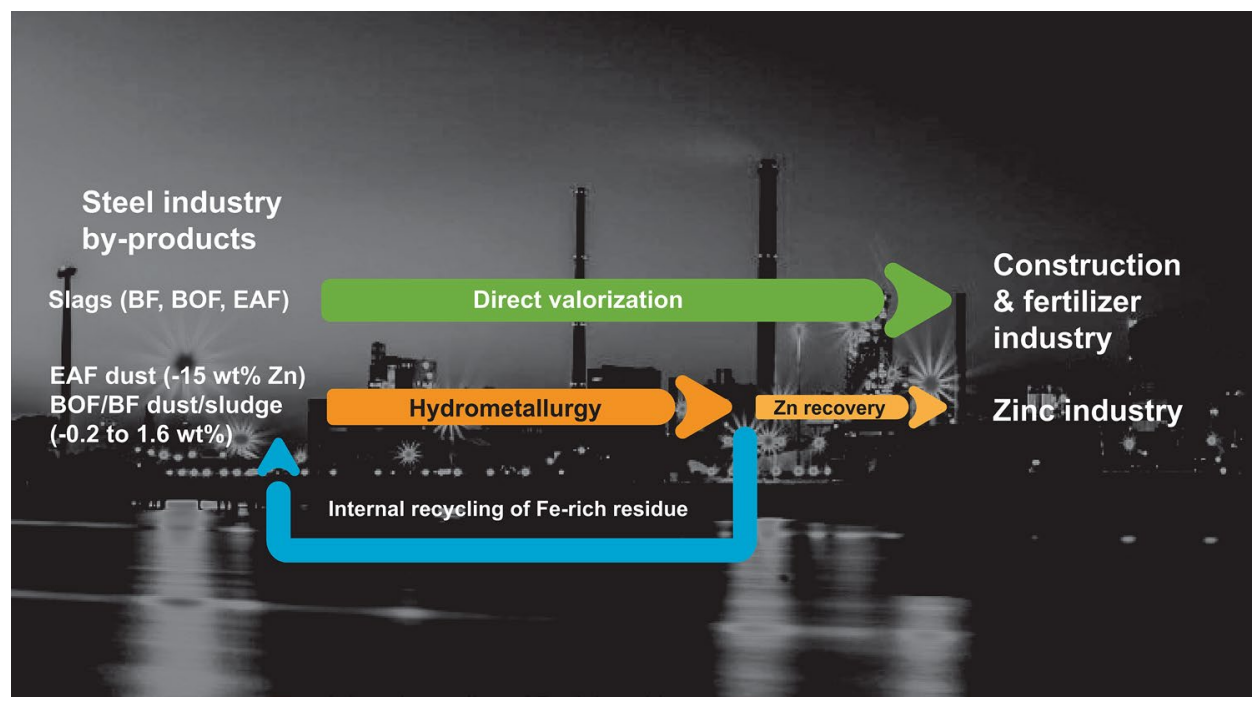

Keywords Hydrometallurgy $\cdot$ Iron $\cdot$ Industrial process residues $\cdot$ Steel $\cdot$ Recycling $\cdot$ Zinc

The contributing editor for this article was Markus Reuter.

Extended author information available on the last page of the article 


\section{Introduction}

Producing one ton of steel in an integrated steel plant generates about half a ton of by-products, i.e., slags $(90 \%$ by mass), dusts, and sludges. A blast furnace (BF) produces the most slag, with smaller amounts generated in a basic oxygen furnace (BOF) and an electric arc furnace (EAF). Dusts and sludges originate from the off-gas produced in $\mathrm{BF}, \mathrm{BOF}$, and EAF installations. Minor by-products include sinter-plant dust, oily mill scale, and pickling sludge. Although most steel slags have applications, dusts and sludges are often seen as waste. Research is turning to the valorization of those steel by-products that have no applications yet.

The motivation can be the valorization of the metal content. However, in most cases the removal of metals inhibits the recycling of by-products. For instance, the zinc content of $\mathrm{BF}$ and $\mathrm{BOF}$ sludges is too low for zinc recovery, but too high to recycle the by-products to the $\mathrm{BF}$ via the sinter plant. Stewart and Barron suggested the reason for the sensitivity to zinc is that, once charged into a blast furnace, any zinc component is reduced to elemental zinc [1]. Due to its low boiling point $\left(907{ }^{\circ} \mathrm{C}\right)$ compared to the blast furnace (1600-1650 $\left.{ }^{\circ} \mathrm{C}\right)$, the vapor re-condenses, leading to the condensation of zinc scaffolds (accretions) on the blast-furnace walls. These deposits affect the solid and gas flows through the furnace, so damaging the lining through burden slips. Zinc is also known to attack refractories in the upper stack of the furnace, thus shortening its operating life. Therefore, landfilling (or internal stockpiling) is often the only option. Despite this, with partial removal ("bleeding") of the zinc, these sludges can be recycled and their iron content recovered in the BF.

Most studies were performed on dusts and sludges (with only a few references to slags), primarily on EAF dust, because it is sufficiently $\mathrm{Zn}$-rich to be a secondary resource, making extraction economically attractive.

With respect to pyrometallurgical processes, hydrometallurgical routes have several advantages. First, the capital expenditure (CAPEX) required is lower, making them more suitable for small-scale operations. As a result, the by-products do not require transport over long distances to large processing plants, such as Waelz kilns. Second, the operating expenses (OPEX) can be lower, because less energy is used. Third, hydrometallurgical processes are often more selective, so they can be more efficient.

This paper reviews the state of the art for the recovery of metals from steel-industry by-products using hydrometallurgical processes. The steel by-products are different types of slags, dusts, and sludges from a blast furnace (BF), basic oxygen furnace (BOF), electric acid furnace (EAF), and sinter plant, as well as the oily mill scale and pickling sludge. The literature covers the period to March 2020, and this review complements others on the valorization of steelindustry by-products [2-10].

\section{Slags}

\section{Blast Furnace Slag (BF Slag)}

Almost $100 \%$ of BF slag is recovered, either internally or externally [11]. Its main use is in the cement industry (75\%), as a hydraulic binder, or as a raw material for clinker kilns. About $18 \%$ of BF slags are used as aggregates in construction: for concrete, asphalt pavements, roads, and waterways. The slag is crushed and screened (air-cooled slags) or granulated. The remainder is reused internally by steel plants for roadmaking and landfills. There are currently no technical limitations on the use of BF slags. Granulation is becoming the standard route, with cement being the high-value application. In other words, BF slag has been promoted from a by-product to a co-product.

Because there are no toxic or valuable metals, there is no need to hydrometallurgically treat BF slag to remove and recover metals. An exception are the slags produced from Tirich iron ores. These also contain vanadium and chromium, which are reduced by the coke in the BF and report to the hot metal. In contrast, vanadium and chromium are oxidized in a BOF, where they are enriched in the BOF slag, usually called vanadium slag [12]. Titanium is not reduced in a $\mathrm{BF}$ and is enriched in the form of $\mathrm{TiO}_{2}$ in a BF slag. The grade of Ti-bearing slags is too low to recover the titanium and produce $\mathrm{TiCl}_{4}$ or $\mathrm{TiO}_{2}$, but too rich for use in the cement industry. As such, hydrometallurgical routes recover the titanium from these slags with concentrated $\mathrm{H}_{2} \mathrm{SO}_{4}$ [13]. However, these methods co-dissolve the $\mathrm{CaO}, \mathrm{MgO}$, and $\mathrm{Al}_{2} \mathrm{O}_{3}$, and thus consume more acid. But with mild conditions, less co-dissolution occurs.

Much more titanium was recovered from water-quenched and naturally cooled slag. Valighazvini et al. leached titanium from BF slags with $\mathrm{H}_{2} \mathrm{SO}_{4}$ [14]. They noted that the $\mathrm{TiO}_{2}, \mathrm{Al}_{2} \mathrm{O}_{3}$, and $\mathrm{MgO}$ became soluble, whereas the $\mathrm{CaO}$ remained in the residue as $\mathrm{CaSO}_{4}$. Nearly all the titanium could be leached with $2-\mathrm{M} \mathrm{H}_{2} \mathrm{SO}_{4}$ in $2 \mathrm{~h}$ at $65{ }^{\circ} \mathrm{C}$ and a liquid-to-solid ratio of 30 . He et al. described recovering titanium by alkali roasting with $\mathrm{NaOH}$, followed by leaching with $\mathrm{H}_{2} \mathrm{SO}_{4}$ at $160{ }^{\circ} \mathrm{C}$ [15]. Under ideal conditions, $93 \%$ of the titanium was recovered. It is also possible to dissolve part of the matrix, which results in a residue with enough $\mathrm{TiO}_{2}$ for use as a secondary raw material. Mang et al. leached titanium-bearing BF slag with hydrochloric acid to dissolve the $\mathrm{Ca}, \mathrm{Mg}, \mathrm{Al}$, and $\mathrm{Fe}$, leaving behind $\mathrm{a} \mathrm{TiO}_{2}$-rich residue. They increased the $\mathrm{TiO}_{2}$ content after solid/liquid 
separation to $40 \%$, which is sufficient for titanium recovery in the titanium industry [16].

Others have investigated $\mathrm{BF}$ slag as a source of rare-earth elements (REEs) [17] by leaching with $\mathrm{H}_{2} \mathrm{SO}_{4}(1 \mathrm{M}, 5 \%$ pulp density, $1 \mathrm{~h}$, room temperature, and $95{ }^{\circ} \mathrm{C}$ ), followed by solvent extraction with Cyanex 923. The REEs were stripped from the loaded organic phase by oxalic acid. However, this is uneconomic at present, because of the low concentration of REEs, e.g., 17 ppm La, 16 ppm Ce, and 44 ppm Nd. The final product contained only 4-5\% REEs.

$\mathrm{BF}$ slag can be used for $\mathrm{CO}_{2}$ sequestration with the leaching-carbonation process [18-20]. Here, the calcium in the slags is solubilized, using acetic acid or ammonium salts, and the dissolved calcium is precipitated as pure $\mathrm{CaCO}_{3}$ by carbonation. This $\mathrm{CaCO}_{3}$ is known as precipitated calcium carbonate (PCC) and can be used as filler for rubber, plastics, and paper.

\section{Basic Oxygen Furnace (BOF) Slag}

It is important to differentiate (1) BOF or converter slag in primary steelmaking, (2) BOF secondary-metallurgy slag (BOF SM slag), and (3) desulfurization slag (de-S slag) [11].

Compared to BF slag, converter slag is difficult to recover. The problems are the presence of steel droplets (making metal recovery necessary) and the free (unhydrated) lime $(\mathrm{CaO})$ and periclase $(\mathrm{MgO})$ content, which varies from 2 to $12 \%$, with the former being more abundant. Both can hinder applications through expansion, a high fines content and a high $\mathrm{pH}$ in water. The high free-lime content is a problem in applications like aggregates, but can be used for fertilizers and cement.

BOF slags can be internally recycled to the sinter plant, the BF or the converter. External applications include fertilizers, soil conditioners, cement components, raw material for clinker or rock wool, filler for concrete, and absorbent for wastewater pollutants. As with BF slag, converter slag is used for $\mathrm{CO}_{2}$ sequestration, with the high lime content being an advantage. The phosphorus content of BOF slag limits its internal recycling to the sinter plant or the BF. Phosphorus reports to the hot metal and comes back in a loop to the converter, where it must be removed by consuming more lime and generating more slag, which is a costly process. In general, the heavy-metal content of converter slags is not problematic, but there is concern about the chromium content of slags used for clinker production. The average is $460 \mathrm{ppm}$, with a maximum of $2000 \mathrm{ppm}$. The chromium in slag is trivalent, but it can be oxidized in the clinker kiln and become the hazardous hexavalent chromium.

BOF secondary-metallurgy (SM) slag has a chemical composition different to that of converter slag and so these slags should be kept separate. BOF SM slags have a high
$\mathrm{Al}_{2} \mathrm{O}_{3}$ content and a low iron content, which is an advantage in some applications. However, a high $\mathrm{Al}_{2} \mathrm{O}_{3}$ content is undesirable for recycling in a sinter plant. This type of slag is used in construction, particularly for roads; however, about one-third is landfilled.

The main problem with desulfurization slag is the high content of sulfur, alkali, free lime, and sometimes fluorine. This makes it more difficult to valorize than converter slag. It also contains metal droplets, so that metal recovery is required. Some of these slags are recycled via the sinter plant or the EAF and some to road construction. More than $40 \%$ was landfilled in 2006 [11].

The vanadium content of vanadium-titanium-containing magnetite iron ores-called "vanadium slags" (vide supra)-reports to BOF slags in the primary steelmaking process. Vanadium co-occurs with iron, titanium, manganese, aluminum, and silicon. The main mineral phases in vanadium slag are fayalite $\left(\mathrm{Fe}_{2} \mathrm{SiO}_{4}\right)$, titanomagnetite $\left(\mathrm{Fe}_{2.5} \mathrm{Ti}_{0.5} \mathrm{O}_{4}\right)$, and spinel $\left(\mathrm{FeV}_{2} \mathrm{O}_{4}\right.$ or more generally $\left.(\mathrm{Mn}, \mathrm{Fe})(\mathrm{V}, \mathrm{Cr})_{2} \mathrm{O}_{4}\right)$. Chromium spinel phases can also be present. Vanadium slag is an important resource of vanadium. For instance, it accounts for $40 \%$ of production in China [21].

The molten $\mathrm{NaOH}$ roasting method can extract vanadium from vanadium slag. But this process uses a lot of energy and $\mathrm{NaOH}$, making it costly. The conventional approach to recovering vanadium is roasting with $\mathrm{NaCl}$, followed by water leaching, purification of the vanadium solution, and precipitation of the vanadium as ammonium polyvanadate $\left(\mathrm{NH}_{4} \mathrm{~V}_{3} \mathrm{O}_{8}\right)$. Finally, calcination yields vanadium pentoxide $\left(\mathrm{V}_{2} \mathrm{O}_{5}\right)$. Figure 1 shows a flow sheet of this process [22]. The purpose of roasting with $\mathrm{NaCl}$ (or other sodium salts) is to convert the spinel phase into soluble sodium vanadate $\left(\mathrm{NaVO}_{3}\right)$. However, roasting with $\mathrm{NaCl}$ is being abandoned due to the emissions of $\mathrm{HCl}$ and $\mathrm{Cl}_{2}$ and the loss of vanadium from volatile $\mathrm{VOCl}_{3}$ during chlorination roasting above $600{ }^{\circ} \mathrm{C}$. The low vanadium recovery $(<60 \%)$ and high energy use make this process uneconomic. Chromium spinel, which is commonly found in vanadium slag, can be partially oxidized to hexavalent chromium when roasting with sodium salts [23]. Chromium can be leached with vanadium in the water-leach process, resulting in toxic $\mathrm{CrO}_{4}{ }^{2-}$ in the water and the leaching residue. The removal of $\mathrm{CrO}_{4}{ }^{2-}$ from wastewater involves reducing with sulfur or $\mathrm{SO}_{2}$. This generates a lot of chromium sludge, and so new vanadium-extraction technologies have been developed.

By roasting with $\mathrm{CaO}$, the problem of sodium salts can be avoided [23, 24]. After calcification roasting, the fayalite phase $\mathrm{Fe}_{2} \mathrm{SiO}_{4}$ is decomposed and transformed to $\mathrm{CaSiO}_{3}$ and $\mathrm{Fe}_{2} \mathrm{O}_{3}$, and, subsequently, the spinel phase $\left(\mathrm{FeV}_{2} \mathrm{O}_{4}\right)$ is oxidized and transformed to $\mathrm{Ca}_{2} \mathrm{~V}_{2} \mathrm{O}_{7}$ and $\mathrm{Ca}\left(\mathrm{VO}_{3}\right)_{2}$ [25]. The leaching involves dilute $\mathrm{H}_{2} \mathrm{SO}_{4}$ [23]. However, there are operational difficulties and a low vanadium recovery. 


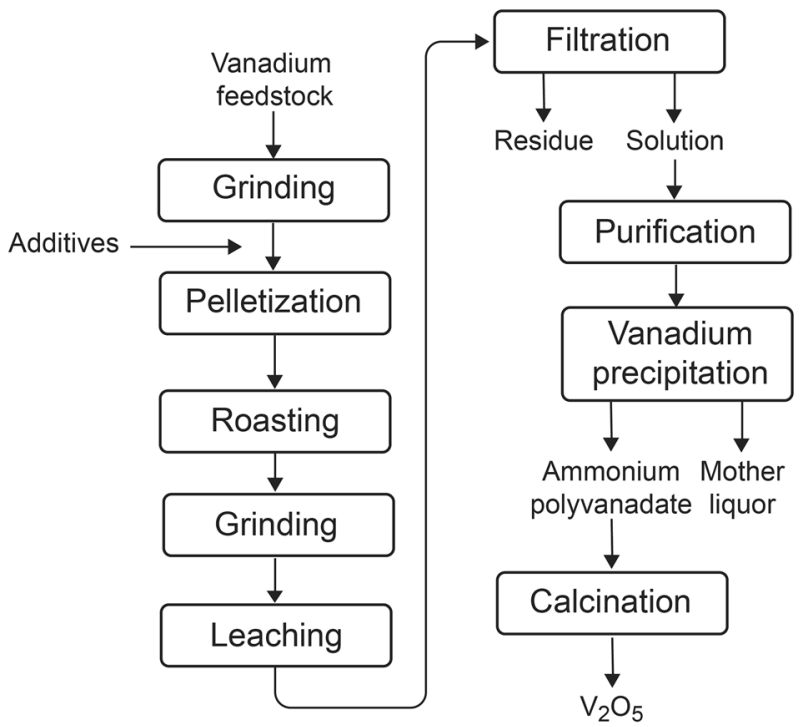

Fig. 1 Conventional flow sheet for vanadium extraction from vanadium slag. Adapted from [22]

Furthermore, during acid leaching, calcium sulfate accumulates in the residues, inhibiting further use as a raw material. Leaching is easier with ammonium carbonate, since it allows the selective leaching of the vanadium into the liquor from calcification-roasted vanadium slag, but maintains the phosphorus in the solid phase because of the differences in the reactivity of calcium vanadate and calcium phosphate with ammonium carbonate [25]. Vanadium was recovered from Ca-rich slags by direct oxidative roasting, without added salt, followed by leaching with a sodium carbonate solution [26]. During the oxidation roasting, the olivine phases and spinel phases decomposed at 500 and $800{ }^{\circ} \mathrm{C}$, respectively. Vanadium-rich phases were formed above $850{ }^{\circ} \mathrm{C}$. To recover the vanadium and titanium, the vanadium slag was roasted with ammonium sulfate at moderately high temperatures, followed by dilute $\mathrm{H}_{2} \mathrm{SO}_{4}$ leaching [27]. To enhance the extraction, an activation pre-treatment of the vanadium slag via high-temperature water quenching was employed. The activation accelerated the extraction, with the yields increasing by $16 \%$ and $12 \%$, respectively, compared with the untreated slag. Li et al. developed non-salt roasting, followed by leaching with ammonium carbonate [23, 28]. This can be recycled in the process and the leaching residue can be returned to the blast furnace (Fig. 2). The vanadium is recovered as ammonium vanadate $\left(\mathrm{NH}_{4} \mathrm{VO}_{3}\right)$. Instead of ammonium carbonate, ammonium oxalate was found to be an efficient lixiviant [29]. After roasting with $\mathrm{CaO}$, the vanadium could be extracted from $\mathrm{Cr}$-rich vanadium slag by leaching with a $\left(\mathrm{NH}_{4}\right)_{2} \mathrm{SO}_{4}-\mathrm{H}_{2} \mathrm{SO}_{4}$ mixture at $20{ }^{\circ} \mathrm{C}$ [30] and recovered from the leachate as a $\left(\mathrm{NH}_{4}\right)_{2} \mathrm{~V}_{6} \mathrm{O}_{16}$ precipitate after heating to $60{ }^{\circ} \mathrm{C}$ and adjusting the $\mathrm{pH}$ to 8.0. Roasting the $\left(\mathrm{NH}_{4}\right)_{2} \mathrm{~V}_{6} \mathrm{O}_{16}$ precipitate yielded $\mathrm{V}_{2} \mathrm{O}_{5}$.

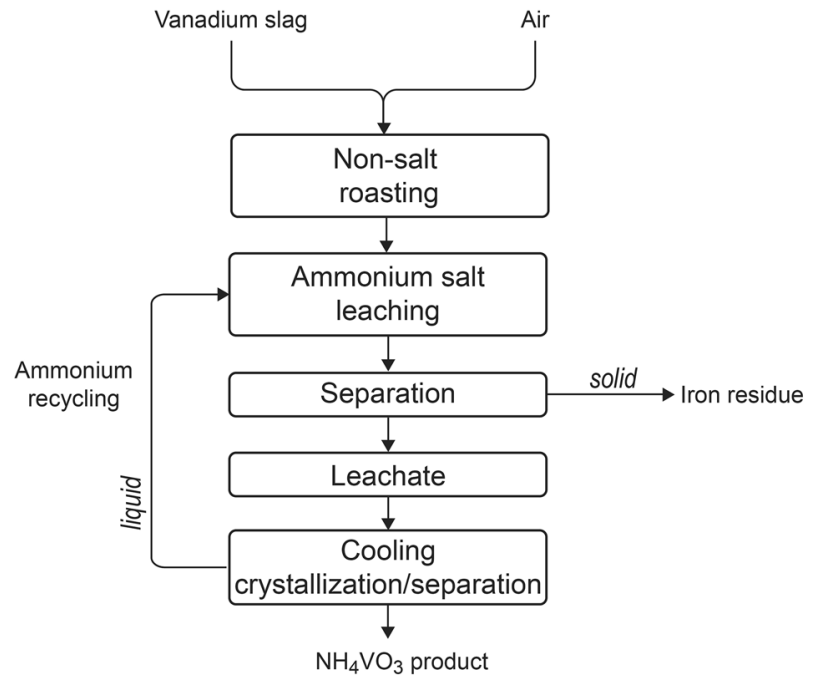

Fig. 2 Flow sheet for vanadium extraction from vanadium slag via non-salt roasting and ammonium salt leaching. Adapted from [23]

Direct vanadium leaching with acids, without prior roasting, is efficient and has no emission problems. Unfortunately, it consumes a lot of acid and has poor selectivity. Zhang et al. recovered the vanadium from slag using high-pressure oxidative acid leaching [21] where the fayalite and spinel phases are decomposed by $\mathrm{H}_{2} \mathrm{SO}_{4}$, releasing vanadium and iron in solution, while the unreacted silicon and titanium are enriched in the residues. With an initial $250 \mathrm{~g} \mathrm{~L}^{-1}$ concentration of $\mathrm{H}_{2} \mathrm{SO}_{4}$, leaching at $140{ }^{\circ} \mathrm{C}$, a time of $50 \mathrm{~min}$, a liquid-to-solid ratio of $10: 1 \mathrm{~mL} \mathrm{~g}^{-1}$, and an oxygen pressure at $0.2 \mathrm{MPa}$, vanadium recovery reached $97.7 \%$. To mitigate the acid consumption, waste acids have been proposed [31]. To mitigate the low selectivity, the leachate can be purified by solvent extraction. For instance, Zhang et al. purified a leachate with bis(2-ethylhexyl)phosphoric acid (D2EHPA) as the extractant, tri- $n$-butyl phosphate (TBP) as the modifier, and sulfonated kerosene as the diluent [32]. It is clear that the recovery of vanadium from vanadium slags is an active research field.

The US Bureau of Mines has developed a process to recover manganese from BOF slag by leaching with ammonium carbamate [33]. Figure 3 shows the flow sheet. The ammonium carbamate hydrates irreversibly to ammonium carbonate: $\mathrm{NH}_{2} \mathrm{CO}_{2} \mathrm{NH}_{4}+\mathrm{H}_{2} \mathrm{O} \rightarrow\left(\mathrm{NH}_{4}\right)_{2} \mathrm{CO}_{3}$. Therefore, leaching with mixtures of $\mathrm{NH}_{3}$ solution and ammonium carbamate is essentially ammonia-ammonium carbonate (AAC) leaching. The BOF slag was pre-treated at high temperatures in a reducing $\left(\mathrm{H}_{2}\right.$ or $\left.\mathrm{CO}\right)$ or oxidizing atmosphere (air), for $2 \mathrm{~h}$ at $700{ }^{\circ} \mathrm{C}$, prior to leaching. Only a treatment with $\mathrm{H}_{2}$ improved the leaching compared to the as-received slag: $71 \%$ Mn recovery versus $34 \%$ recovery for the asreceived slag. There was also a large co-dissolution of iron, 


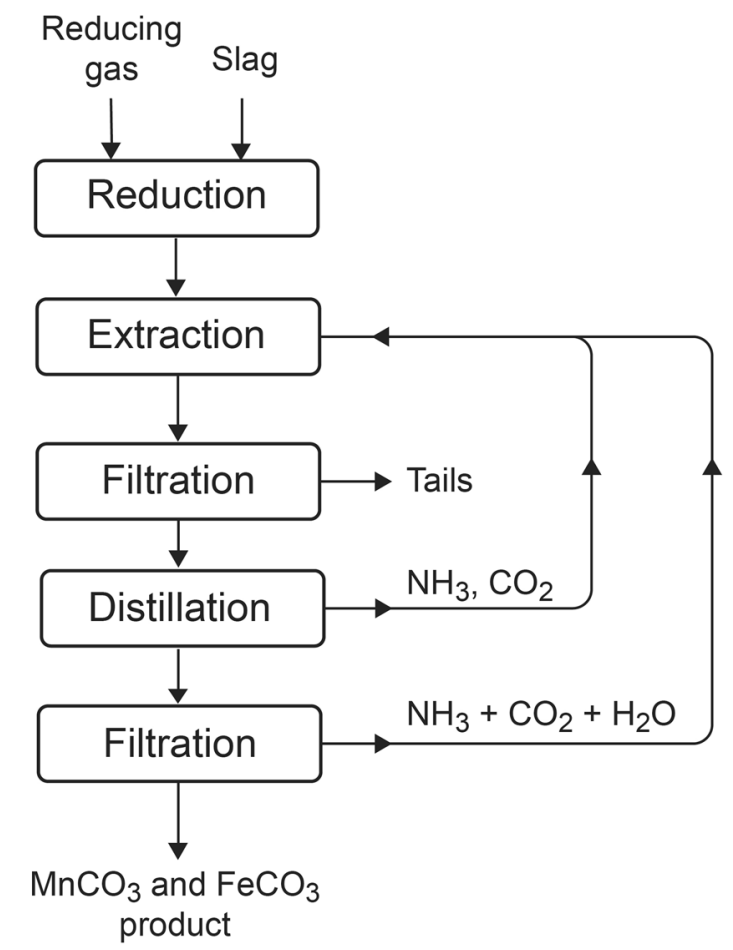

Fig. 3 Flow sheet for ammonium carbamate leaching of manganese and iron from BOF slag. Adapted from [33]

indicating that it is present as $\mathrm{Fe}(\mathrm{II})$. After leaching, $\mathrm{MnCO}_{3}$ and $\mathrm{FeCO}_{3}$ were recovered from the solution by heating, with the $\mathrm{NH}_{3}$ and $\mathrm{CO}_{2}$ driven off. Under optimum conditions, $80 \%$ of the manganese and $50 \%$ of the iron could be recovered. Manganese is a valuable, strategic metal, but the process was uneconomic because of the cost of roasting, the low manganese content, and ammonium carbamate cannot leach manganese from all types of BOF slags.

Krasheninin et al. recovered manganese from a residue after leaching vanadium with $\mathrm{Na}_{2} \mathrm{CO}_{3}$ from oxidatively roasted manganese-vanadium slag [34]. The manganese was present as $\mathrm{MnCO}_{3}$ and could be recovered from the leachates by adding $\left(\mathrm{NH}_{4}\right)_{2} \mathrm{CO}_{3}$ and then calcining to $\mathrm{Mn}_{2} \mathrm{O}_{3}$.

\section{Electric Arc Furnace (EAF) Slag}

There is a difference between EAF primary slag and EAF secondary-metallurgy slag [11]. The main use of EAF slags is in roads, waterways, railways, etc. The chemical composition of EAF slags varies, based on the type of feed. The main components are calcium, iron, magnesium, aluminum, and silicon oxides. Less than $1 \%$ of the calcium is present as free lime. EAF slags have high chromium and iron contents and low basicity $\left(=\mathrm{CaO} / \mathrm{SiO}_{2}\right.$ mass ratio). The metallic iron content is $0.8-11.4 \%$, with an average of $4 \%$. The chromium content can be problematic, i.e., $0.01-2.52 \%$, with

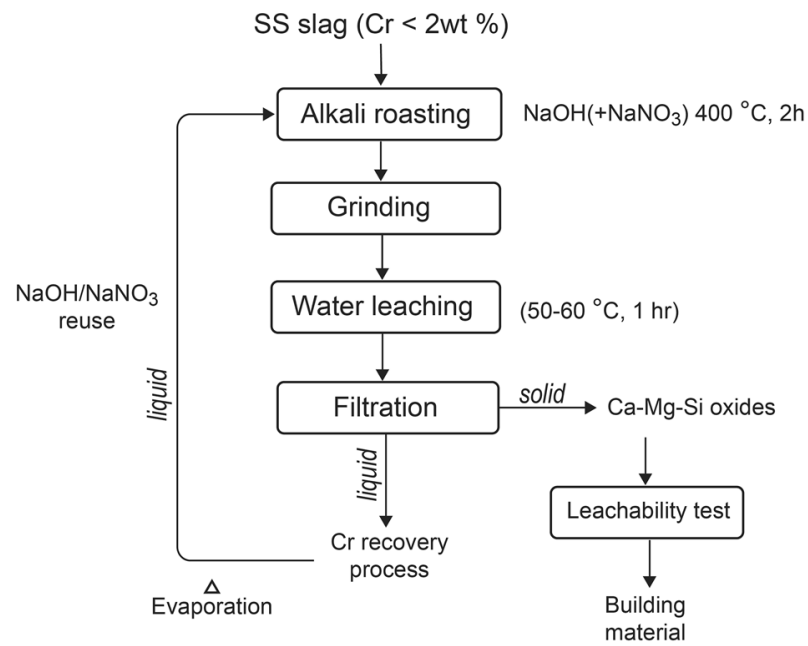

Fig. 4 Flow sheet for recovery of chromium from stainless-steel slag by alkali roasting, followed by water leaching. Adapted from [39]

an average of $1.03 \%$, because in clinker production it can be oxidized to the soluble and toxic hexavalent chromium. Standard tests on EAF slag have investigated the leachability of chromium and other metals [35], where it is related to the slag's basicity and particle size [36]. The cooling conditions also influence the leachability of chromium from EAF slags, e.g., a neutral or reducing atmosphere can prevent the formation of hexavalent chromium [37]. EAF slags are better for metal recovery than other slags due to their high iron and chromium contents [38]. Chromium is present in spinel phases and $\mathrm{FeCr}$ metallic droplets. Few studies have looked at metal recovery from EAF slags, and most of these concern manganese recovery from ferromanganese slags.

Researchers at the Flemish Institute for Technological Research (VITO) in Belgium studied the recovery of chromium from landfilled Cr-rich stainless-steel slags. They used alkali roasting with a low concentration of alkaline salt $\left(\mathrm{NaOH}\right.$ or $\left.\mathrm{NaOH}+\mathrm{NaNO}_{3}\right)$, followed by water leaching [39]. Figure 4 shows the flow sheet. The effects of the processing parameters and a pre-treatment on leaching behavior were checked. $\mathrm{NaNO}_{3}$ acts as an oxidizing agent and increases the chromium recovery, while the residue could be used in construction. In a follow-up, alkaline pressure leaching with a $\mathrm{NaOH}$ solution was investigated [40]. The design-of-experiment method was used to optimize the process parameters. The maximum chromium leaching was $46 \%$ with 1-M NaOH, $240{ }^{\circ} \mathrm{C}, 6 \mathrm{~h}$, mechanical activation $30 \mathrm{~min}$, while the matrix material was only partially dissolved (Al $2.88 \%$, Si $0.12 \%$, Ca $0.05 \%$ ). After chromium leaching, followed by alkali washing, a carbonation treatment stabilized the remaining chromium and the matrix was recycled for construction. Chromium can also be recovered under milder reactions conditions, with a temperature-controlled 
extraction using $\mathrm{NaOH}$ in the presence of $\mathrm{NaOCl}$, followed by water leaching [41]. The dissolved chromium can be precipitated as barium chromate $\left(\mathrm{BaCrO}_{4}\right)$. The dissolution of chromium was optimized by studying parameters like $\mathrm{NaOCl}$ concentration, $\mathrm{NaOH}$-to-slag ratio, leaching time and temperature, and particle size. The reuse of the residue via accelerated carbonation was also studied. Lab-scale batch and column leaching showed that the process can be used in the heap leaching of chromium from landfilled stainlesssteel slags, allowing in-situ chromium recovery [42].

Ferromanganese slag comprises waste from the production of ferromanganese metal in BFs and EAFs [43]. The manganese content of the slag (>30\%) makes it attractive for manganese recovery with hydrometallurgical methods and using the residue for cement. Mohanty et al. used dilute $\mathrm{H}_{2} \mathrm{SO}_{4}$ to leach ferromanganese slag at temperatures up to $80{ }^{\circ} \mathrm{C}$ at a liquid-to-solid ratio of 10:1 with almost $100 \%$ recovery of the manganese [44]. Step-wise leaching with dilute acid was proposed to reduce the dissolution of impurities, which can be precipitated from the leachate by increasing the $\mathrm{pH}$ from 2.5 to 5.65 . The purified $\mathrm{MnSO}_{4}$ can be used as an electrolyte for the recovery of manganese metal, with the residue containing only aluminum and calcium. Naganoor et al. used $\mathrm{FeCl}_{3}$ to leach ferromanganese slag [45]. Roasting with $\mathrm{CaO}$ or $\mathrm{CaCO}_{3}$ prior to leaching ensured the manganese was in soluble form. A manganese recovery of $82 \%$ was achieved with a $0.154-\mathrm{M} \mathrm{FeCl}_{3}$ solution in $2 \mathrm{~h}$ at $80{ }^{\circ} \mathrm{C}$ and a pulp density of $5-10 \%$. The sucrose in the $\mathrm{FeCl}_{3}$ solution meant $86 \%$ of the manganese was recovered from the slag in $1 \mathrm{~h}$. The pregnant leach solution was then treated to produce electrolytic $\mathrm{MnO}_{2}$ and manganese metal. Ferromanganese slags contain silicate phases, so leaching silicate minerals with dilute acids can be difficult due to silica-gel formation, which hinders solid-liquid separation. Silica-gel formation can be avoided by dry digestion with concentrated acid. This creates water-starved conditions where the condensation of orthosilicic acid to silica gel is impossible [46]. Kazadi et al. digested ferromanganese slags with concentrated $\mathrm{H}_{2} \mathrm{SO}_{4}$ and the residue was leached with water [47]. Up to $90 \%$ manganese recovery was achieved, depending on the number of leachings. The leachate could then be processed to manganese metal by electrolysis, as well as $\mathrm{MnO}_{2}$ or other salts. The residue obtained after solid-liquid separation, containing amorphous silica and calcium sulfate, was tested as an additive for Portland cement. In a follow-up, Baumgartner and Groot purified a $\mathrm{MnSO}_{4}$ leach solution [43], with the pregnant leach solution having 25-35 g/L of Mn. Impurities were removed by hydroxide precipitation using $\mathrm{NH}_{3}$ or $\mathrm{NaOH}$. The $\mathrm{NH}_{3}$ was the most effective, reducing $\mathrm{Fe}, \mathrm{Si}$, and $\mathrm{Al}$ to less than $1 \mathrm{ppm} . \mathrm{MnCO}_{3}$ precipitated at $\mathrm{pH}>8$ by adding $\mathrm{Na}_{2} \mathrm{CO}_{3}$ or $\left(\mathrm{NH}_{4}\right)_{2} \mathrm{CO}_{3}$. However, phases such as $\left(\mathrm{NH}_{4}\right)_{2} \mathrm{Mg}\left(\mathrm{SO}_{4}\right)_{2} \cdot 6 \mathrm{H}_{2} \mathrm{O}$ and $\mathrm{Na}_{2} \mathrm{SO}_{4}$ co-precipitated and contaminated the product, rendering it unsuitable as a furnace feed. Therefore, the product was washed with distilled water to produce a viable furnace feed. Pure $\mathrm{MnCO}_{3}$ (>92\%) was produced; however, although technically viable, the large amounts of base reagent required to enhance the $\mathrm{pH}$ made the process uneconomic. An optimization to determine the ideal amount of acid for the water-starved digestion stage was conducted, which reduced acid and base consumption while optimizing the quality of the pregnant leach solution, and producing a leach residue that contained less than $1 \%$ $\mathrm{Mn}$. The outcome was an economically viable process.

Hocheng et al. bioleached metals from EAF slag that was washed with water before bioleaching [48]. This reduced the slag's pH from 11.2 to 8.3. Culture supernatants of Acidithiobacillus thiooxidans (At.thiooxidans), Acidithiobacillus ferrooxidans (At. ferrooxidans), and Aspergillus niger (A. niger) were used for metal solubilization. The At. thiooxidans culture supernatant containing $0.016-\mathrm{M} \mathrm{H}_{2} \mathrm{SO}_{4}$ was the most effective for bioleaching metals from EAF slag. The maximum metal extraction was obtained for $\mathrm{Mg}(28 \%)$, while the lowest was obtained for Mo $(0.1 \%)$ in 6 days. Repeated bioleaching increased the metal recovery from 28 to $75 \%$, from 14 to $60 \%$ and from 11 to $27 \%$, for $\mathrm{Mg}, \mathrm{Zn}$, and $\mathrm{Cu}$, respectively.

\section{Dusts and Sludges}

\section{BF Dust and Sludge}

\section{Chemistry and Mineralogy}

Dust leaves a BF via the top gas, which carries the particles through the gas cleaner, creating a coarse fraction called $B F$ dust (or primary dust) and a wet-scrubbed, fine fraction, called BF sludge (or secondary dust) [49]. Less BF dust and sludge are produced now, due to improvements in the coke and sinter properties and better control of blast furnaces. The average production in 2006 was $11.4 \mathrm{~kg} / \mathrm{ton}$ of hot metal for primary dusts and $8.9 \mathrm{~kg} / \mathrm{ton}$ of hot metal for secondary sludges [11]. It is not clear if the value for secondary sludge is for wet or dry material.

The difference between primary and secondary materials is the zinc and lead contents, with more of these elements in the finer BF sludge. On average, there is $0.2 \mathrm{wt} \%$ of $\mathrm{Zn}$ in $\mathrm{BF}$ dusts and $1.5 \mathrm{wt} \%$ in BF sludges [11]. Maximum values are $1.2 \mathrm{wt} \%$ for the $\mathrm{BF}$ dusts and $2.7 \mathrm{wt} \%$ for the $\mathrm{BF}$ sludges. Zinc, with its boiling point of $907{ }^{\circ} \mathrm{C}$, travels with the ascending gas in the $\mathrm{BF}$, condensing in its upper parts. The dust-forming mechanism for zinc is therefore chemical, not mechanical [49]. Consequently, the zinc, unable to form larger particles, will be found in the finest particles. Furthermore, zinc will condense more on finer particles due to their large surface area. The $\mathrm{Pb}$ content in $\mathrm{BF}$ sludges is 
$0.1-0.9 \mathrm{wt} \%$. The zinc (and lead) in BF off-gas, BF dusts and sludges, originates from the reuse of $\mathrm{BOF}$ dust in the sinter plant. The zinc (and lead) in the BOF dust comes mainly from the scrap (vide infra). These elements negatively affect the BF because they can destroy the refractory lining. The total iron content is $20-70 \%$, while the carbon content is $10-50 \%$.

The main mineral phase in BF sludge is hematite $\left(\mathrm{Fe}_{2} \mathrm{O}_{3}\right)$, together with calcite, periclase, graphite, and amorphous coke. Magnetite and quartz have also been reported [50]. Kretschmar stated that identifying zinc phases in BF sludges is demanding, because of the low zinc content, the large amounts of amorphous phase, and the isomorphism of zinccontaining phases with non-zinc phases [51]. For instance, franklinite is isostructural with magnetite, and smithsonite is isostructural with calcite. In general, zinc is associated with all the phases in BF sludge [49, 52]. Since the zinc reactions are in the gas phase, $\mathrm{ZnO}$ condenses on solid particles and can react with the particles' matrix. For instance, if $\mathrm{ZnO}$ condenses on a $\mathrm{Fe}_{3} \mathrm{O}_{4}$ particle, it can react with it to form $\mathrm{ZnFe}_{2} \mathrm{O}_{4}$. This means solid particles with an $\mathrm{Fe}_{3} \mathrm{O}_{4}$ core, a layer of $\mathrm{ZnFe}_{2} \mathrm{O}_{4}$, and an outer layer of $\mathrm{ZnO}$ can be found.

There are also reports that the zinc in BF sludge is in the form of zinc sulfide ( $\mathrm{ZnS}$, sphalerite) [53]. The sulfur is introduced in the BF via coke or coal. The highest sulfur contents occur when pulverized coal injection (PCI) is used [54], with the coal containing more sulfur than the coke. Although most of the sulfur reports to the slag, about 2-3\% is found in the dusts and off-gases, where it can react with zinc or $\mathrm{ZnO}$ to form $\mathrm{ZnS}$ [55, 56]. Furthermore, the weathering of BF sludges in landfills changes the zinc speciation. For instance, zinc phyllosilicates and hydrozincite are found in weathered samples, but not in fresh ones [51].

Some sludges contain high levels of mercury. The levels in 14 samples of landfilled BF sludge were $3.91-20.8 \mathrm{mg} / \mathrm{kg}$ [57]. Another study of $65 \mathrm{BF}$ sludges gave values of 0.006 to $20.8 \mathrm{mg} / \mathrm{kg}$ (mean $3.08 \mathrm{mg} / \mathrm{kg}$ ) [58]. However, these amounts do not pose an environmental risk.

Close to $100 \%$ of the primary dust is recovered in steel plants, with the favored internal route being the sinter plant. This suggests that there are no significant barriers to recovery [11]. Although more than $80 \%$ of the secondary dust and sludges are being recouped, some BF sludges are not recycled because of their high water content, fineness, and zinc/lead content. Using hydrocyclones and dry cyclones is an effective way to separate high-Zn BF dust into $\mathrm{Zn}$-rich smaller particles and Zn-lean larger particles [59].

The recycling of all the dusts and sludges back to the BF means the zinc would accumulate, i.e., a formidable challenge recognized by the steel industry [49]. To recycle the BF sludges to the BF, a "zinc bleed" must be introduced. By de-zincing the BF sludge, a Zn-depleted fraction can be recycled, so reducing the amount of landfill. When
Zn-containing residues are fed to the sinter plant, some of the zinc is evaporated. Therefore, when operating the BF on pellets, recycling the BF dust via cold-bonded agglomerates and injection, the requirements for zinc removal from BF sludges are tougher than when operating on the sinter. Hence, the aim of de-zincing is to introduce a bleed of zinc from the $\mathrm{BF}$, regardless of the zinc starting content, rather than having a general zinc content of the de-zinced fraction to be recycled. Most research has focused on the removal of zinc from BF sludges, rather than the removal of lead.

\section{Sulfuric Acid Leaching}

Sulfuric acid $\left(\mathrm{H}_{2} \mathrm{SO}_{4}\right)$ leaching is the most popular way to recover zinc from $\mathrm{BF}$ sludges, because of its availability and price. A process was developed to leach $\mathrm{BF}$ sludge with this acid at room temperature [60]. For 1.0- $\mathrm{M} \mathrm{H}_{2} \mathrm{SO}_{4}$, liquid-to-solid ratio $=10$, leaching time $=10 \mathrm{~min}, 82 \%$ of the zinc was recovered, with a $5 \%$ co-dissolution of iron. Shorter times reduced the co-dissolution of iron, but only at room temperature. The dissolved iron was precipitated from the leachate as jarosite, and the solution was purified by solvent extraction using LIX622 and LIX984. Finally, zinc metal was obtained by electrowinning from the sulfate solution. Havlik et al. leached BF sludges with 1-M and 2-M $\mathrm{H}_{2} \mathrm{SO}_{4}$, at 20,50, and $80^{\circ} \mathrm{C}$ [61]. The zinc was dissolved in $\mathrm{H}_{2} \mathrm{SO}_{4}$ concentrations of $1 \mathrm{M}$ or higher within a few minutes. Although the amount of iron leached at $20^{\circ} \mathrm{C}$ was relatively low, it increased with temperature. For 2- $\mathrm{M} \mathrm{H}_{2} \mathrm{SO}_{4}$ and $80^{\circ} \mathrm{C}$, a lot of iron went into solution. Banerjee leached BF flue dust and sludge with a low zinc content $(0.007 \%$ for the dust and $0.45 \%$ for the sludge) in $\mathrm{H}_{2} \mathrm{SO}_{4}$ solutions between 0.1 and $1.0 \mathrm{M}$ and reported less selectivity with higher concentrations: for 1.0- $\mathrm{M} \mathrm{H}_{2} \mathrm{SO}_{4}$ a significant amount of iron was dissolved [62]. Steer and Griffiths reported very efficient zinc leaching: > 98\% dissolved, but $47 \%$ of the iron went into solution [52]. This is probably due to the longer leaching time $(24 \mathrm{~h})$ and high acid concentration $(1 \mathrm{~mol} / \mathrm{L})$.

Andersson et al. found that leaching with $\mathrm{H}_{2} \mathrm{SO}_{4}$ is better than with $\mathrm{HCl}$ or $\mathrm{HNO}_{3}$ [49]. Hot leaching $\left(80{ }^{\circ} \mathrm{C}\right)$ with $\mathrm{H}_{2} \mathrm{SO}_{4}$ at $\mathrm{pH} 1$ dissolved $95 \%$ of the zinc, leaving just $0.025 \%$ in the residue, which also had $91 \%$ of the iron. The leaching took $10 \mathrm{~min}$. Longer times increased the heat losses, acid consumption, and iron leaching. Therefore, shorter times mean more iron in the residue, which contained $86 \%$ of the original solid, $91 \%$ of the iron, and $100 \%$ of the carbon. When using $\mathrm{pH} 3$, iron recovery increased to $96 \%$, with $93 \%$ of the original solid remaining. Although the leachate was not purified, cementation was suggested as a way to remove the lead and recover the zinc as $\mathrm{ZnCO}_{3}$ by adding $\mathrm{Na}_{2} \mathrm{CO}_{3}$. $\mathrm{ZnCO}_{3}$ can then be calcined to $\mathrm{ZnO}$. This suggests it is easy to de-zinc BF sludge, making it suitable for in-plant recycling. Nevertheless, although the process 
works, the liquid-to-solid ratio is high $(\mathrm{L} / \mathrm{S}=10)$. By leaching $\mathrm{BF}$ sludge with $0.1-\mathrm{M} \mathrm{H}_{2} \mathrm{SO}_{4}$ in a strongly oxidizing ozone gas, the co-dissolution of iron could be suppressed, while $85 \%$ of the zinc could be leached [63].

The microwave-assisted leaching of BF sludge with $\mathrm{H}_{2} \mathrm{SO}_{4}$ solutions recovered only slightly more zinc (4\%), although the authors claim that the process was faster [64]. Mikhailov et al. reported the ultrasound-assisted leaching of $\mathrm{BF}$ sludge with $\mathrm{H}_{2} \mathrm{SO}_{4}-\mathrm{H}_{2} \mathrm{O}_{2}$ solutions [65]. For 0.4-M $\mathrm{H}_{2} \mathrm{SO}_{4}+0.1-\mathrm{M} \mathrm{H}_{2} \mathrm{O}_{2}$ and a liquid-to-solid ratio of $10,84 \%$ of the zinc and $1.3 \%$ of the iron were removed, with hydrogen peroxide oxidizing the sulfides of sphalerite to sulfate ions. A conceptual flow sheet for an industrial process is shown in Fig. 5. The mechanism is not entirely clear and probably has errors (for instance, that $\mathrm{Fe}_{2} \mathrm{O}_{3}$ would dissolve by bringing $\mathrm{Fe}^{2+}$ into solution).

Pure $\mathrm{ZnSO}_{4} \cdot 7 \mathrm{H}_{2} \mathrm{O}$ was leached from zinc-containing $\mathrm{BF}$ sludge with $\mathrm{H}_{2} \mathrm{SO}_{4}$ [50]. $\mathrm{Fe}$ (II) was oxidized to iron(III) by $\mathrm{H}_{2} \mathrm{O}_{2}$ and precipitated as $\mathrm{Fe}(\mathrm{OH})_{3}$ with the addition of $\mathrm{CaCO}_{3}$. Calcium was removed from the filtrate by adding $\mathrm{ZnF}_{2}$ to form insoluble $\mathrm{CaF}_{2}$. High-purity (99.57\%) hydrated zinc sulfate, $\mathrm{ZnSO}_{4} \cdot 7 \mathrm{H}_{2} \mathrm{O}$, was crystallized from the filtrate by evaporating the water.

\section{Hydrochloric Acid Leaching}

SIDMAR (now ArcelorMittal Gent, Belgium) and the Department of Chemical Engineering of KU Leuven (Belgium) have developed a hydrometallurgical process based on oxidative leaching in $\mathrm{HCl}$ to treat BF sludges in SIDMAR's tailings pond [53]. A flow sheet is shown in Fig. 6. Oxidative leaching was chosen because part of the zinc was in the form of $\mathrm{ZnS}$ (sphalerite), which only dissolves in very acidic conditions $(\mathrm{pH}<0.25)$ because of the low solubility product. When oxidizing conditions are used, $\mathrm{ZnS}$ dissolves more

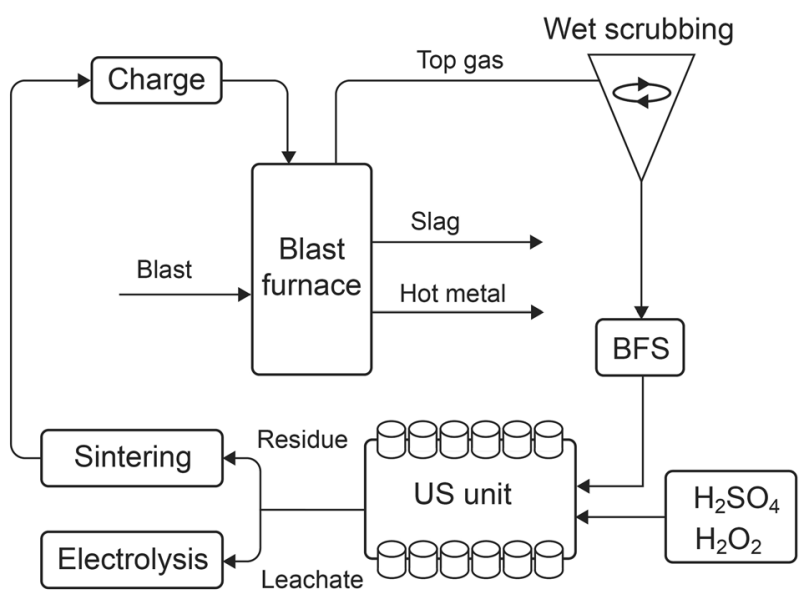

Fig. 5 Conceptual flow sheet for the ultrasound-assisted leaching of BF sludge with a $\mathrm{H}_{2} \mathrm{SO}_{4}-\mathrm{H}_{2} \mathrm{O}_{2}$ solution. Adapted from [65]

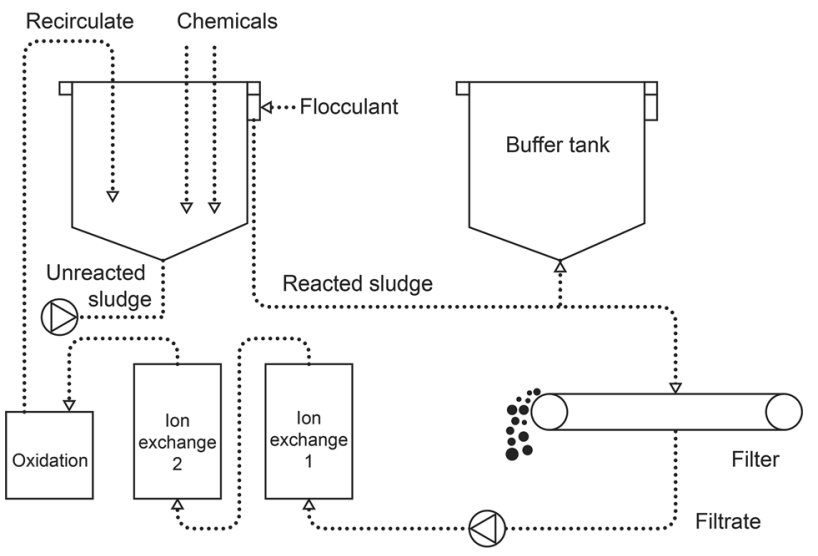

Fig. 6 Flow sheet of the SIDMAR process for the treatment of BF sludge. Adapted from [53]

easily, and at higher $\mathrm{pH}$ values because the sulfide ions are oxidized. In a $\mathrm{BF}$ dust sample, $17 \%$ of the zinc was present as $\mathrm{ZnS}$, and only 3-4\% as $\mathrm{ZnFe}_{2} \mathrm{O}_{4}$. Leaching involved $\mathrm{HCl}$ and $\mathrm{NaOCl}$, and/or $\mathrm{FeCl}_{3}$ as an oxidizing agent. The $\mathrm{HCl}$ and $\mathrm{NaOCl}$ were added directly to the reactor to keep the $\mathrm{pH}$ below 1.5 and the redox potential above $650 \mathrm{mV}$. The slurry could leach zinc and lead, while iron and calcium dissolved. The sludge was added to the bottom of the reactor, with the reagents and the recirculate. The turbulent reaction mixed the sludge and the chemicals. A flocculant was added to the overflow of the reactor, with the solid/liquid separation carried out by a filter band.

The leaching efficiencies were $95 \%$ for zinc and $92 \%$ for lead, while that for iron was 32-49\%. Zinc and lead chlorocomplexes were removed using two anion exchangers, which did not retain the iron, calcium, and aluminum. That part of the iron was extracted was not a problem, as it is not retained on the anion exchanger. It is returned to the reactor to precipitate once more as goethite and remain with the residue as the concentration increases. Recirculating the solution limits the consumption of water and chemicals. The average consumption of reagent was $0.5 \mathrm{~L}$ of $12-\mathrm{M} \mathrm{HCl}$ per $\mathrm{kg}$ of incoming dry solids and $0.4 \mathrm{~L}$ of $\mathrm{NaOCl}$ (min. $120 \mathrm{~g}$ of active chlorine per $\mathrm{L}$ ) per $\mathrm{kg}$ of incoming dry solids. The overall costs for the process (including investment, personnel, reagents, energy, and maintenance) were estimated in 2000 to be $\$ 125$ per ton of dry solids. Belgian patent BE1011619A3, assigned to SIDMAR, is the same process, but with $\mathrm{Cl}_{2}$ replacing $\mathrm{NaOCl}$ [66]. The same claim is covered by patent WO 99/31285 [67].

Belgian patent BE1001781A6 discloses the use of an oxidized, spent pickling liquor used for steel plate. The liquor is oxidized with $\mathrm{Cl}_{2}$ solution to obtain one rich in $\mathrm{FeCl}_{3}$. This $\mathrm{FeCl}_{3}$-enriched $\mathrm{HCl}$ solution is then used to leach $\mathrm{BF}$ sludge, which is washed and sent to a sintering plant [68]. Canadian patent CA2985027A1, assigned to ArcelorMittal, 
discloses the leaching of $\mathrm{BF}$ sludge with a mixture of $\mathrm{HCl}$ and sodium chlorate $\left(\mathrm{NaClO}_{3}\right)$ oxidizing agent [69]. To keep the lead soluble, the leaching is at $\mathrm{pH} 0.8-1.2$ and $50-60{ }^{\circ} \mathrm{C}$. If the $\mathrm{pH}$ is too low, too much iron dissolves. The iron is precipitated as goethite by increasing the $\mathrm{pH}$ to $>1.5$ with lime. The method was used for BF sludges with $4.5-12 \%$ zinc, i.e., well above normal levels.

In patent WO 2018/219464, ThyssenKrupp discloses how to treat $\mathrm{BF}$ sludge with a $\mathrm{HCl}$ solution and dissolve most of the iron, leaving behind a C-rich residue [70]. The $\mathrm{HCl}$ solution has a concentration of 5-20\%, a time of 5-15 min, at temperature of $60-80^{\circ} \mathrm{C}$. Ultrasound can help to homogenize the solution and shorten reaction times. The $\mathrm{C}$-rich phase is filter-pressed and washed with water to remove any chloride impurities. After drying, this C-rich phase can be returned to the $\mathrm{BF}$. After solid/liquid separation, the $\mathrm{Fe}$ rich solution is treated to recover the iron as $\mathrm{Fe}_{2} \mathrm{O}_{3}$. The $\mathrm{Fe}$-rich solution can be reduced by hydroxylammonium chloride to $\mathrm{Fe}^{2+}$, and the lead and zinc are removed with an ion exchanger. Next, the $\mathrm{Fe}^{2+}$ is oxidized to $\mathrm{Fe}^{3+}$ by $\mathrm{H}_{2} \mathrm{O}_{2}$ and the $\mathrm{Fe}^{3+}$ is trapped on a second ion exchanger. After eluting the $\mathrm{Fe}^{3+}$ with $\mathrm{HCl}$, the $\mathrm{FeCl}_{3}$ solution is treated by pyrohydrolysis. The $\mathrm{HCl}$ is recovered and the residue is $99 \%$ $\mathrm{Fe}_{2} \mathrm{O}_{3}$. Alternatively, after solid/liquid separation the Fe-rich solution can be treated with $\mathrm{H}_{2} \mathrm{O}_{2}$ to oxidize the $\mathrm{Fe}^{2+}$ to $\mathrm{Fe}^{3+}$, and the $\mathrm{Fe}^{3+}$ is precipitated as $\mathrm{Fe}(\mathrm{OH})_{3}$ by adding lime. $\mathrm{Fe}(\mathrm{OH})_{3}$ is separated by a filter press and $\mathrm{Fe}(\mathrm{OH})_{3}$ is transformed into $\mathrm{Fe}_{2} \mathrm{O}_{3}$ in a roast furnace. The $\mathrm{HCl}$ is regenerated for reuse in the process by treating the solution in a spray roast furnace (pyrohydrolysis). The residue contains $90 \%$ $\mathrm{CaO}$ as well as other alkali, alkaline earth, and transitionmetal oxides. It can be reused for making lime suspension.

\section{Leaching with Organic Acids}

Steer and Griffith tested some carboxylic acids for zinc and iron extraction with a concentration of $1 \mathrm{~mol} / \mathrm{L}$ : acetic, citric, oxalic, benzoic, malonic, and acrylic acid (prop-2enoic acid) [52]. The BF sludge was from a tailing pond with $2.25 \%$ zinc content. The results are shown in Fig. 7 . Although $\mathrm{H}_{2} \mathrm{SO}_{4}$ gave the highest zinc yield, large amounts of iron were also co-dissolved. The authors then selected acrylic acid (prop-2-enoic acid). This gave a better extraction efficiency for zinc (83.1\%), with the co-dissolution of small amounts of iron (8.5\%). However, the use of acrylic acid is not appropriate from the safety and environmental points of view. It is very hazardous for skin (permeator) and eye contact (irritant, corrosive). Although the authors considered acetic and benzoic acid to be inferior to acrylic acid, because of the lower zinc extraction, the acetic and especially the benzoic acid (with just $0.1 \%$ ) led to less codissolution of iron. An interesting feature of this paper is the effect of non-aqueous solvents on the extraction of zinc

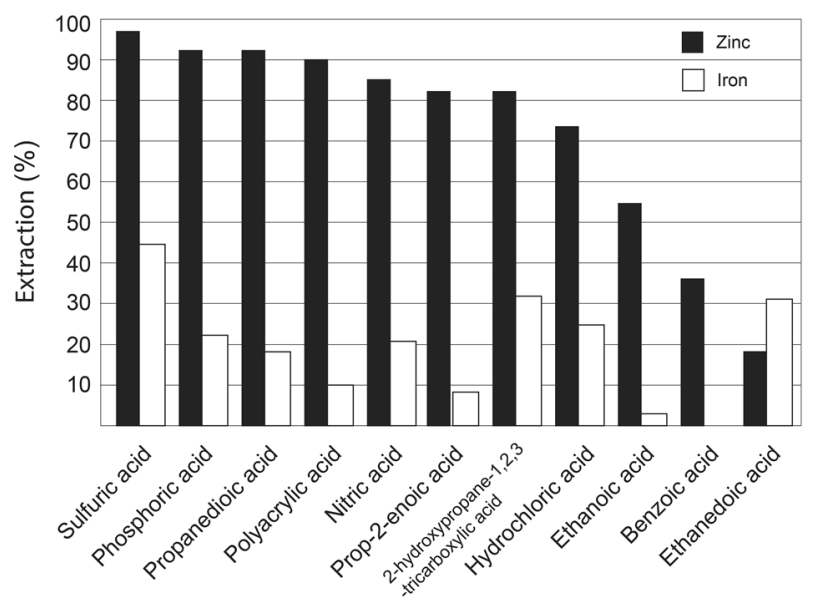

Fig. 7 Zinc and iron extractions from BF sludge for a range of acids at $1 \mathrm{~mol} / \mathrm{L}$. Adapted from [52]

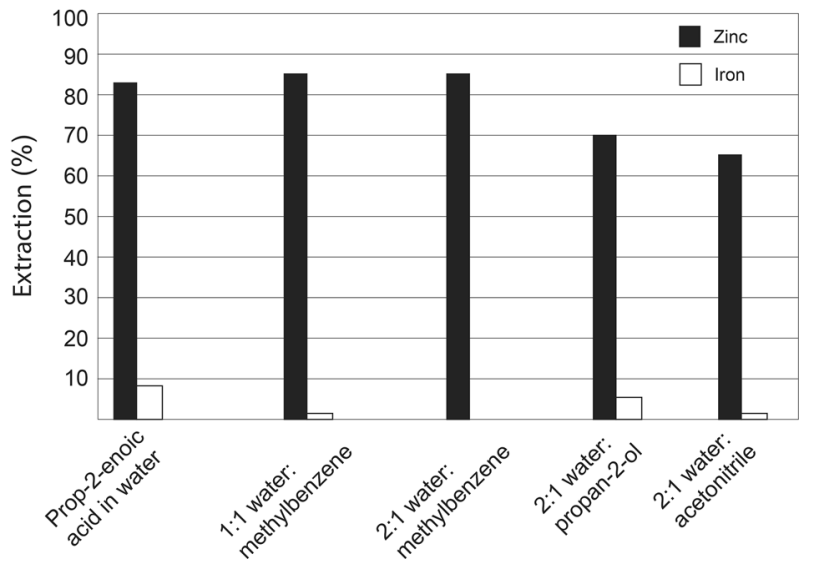

Fig. 8 Extraction of zinc and iron from BF sludge using $1 \mathrm{~mol} / \mathrm{L}$ prop-2-enoic acid in different non-aqueous solvents. Adapted from [52]

and iron with acrylic acid (Fig. 8). Mixtures of water and methylbenzene (toluene) extracted around $85 \%$ of the zinc. More importantly, the co-dissolution of iron was just $0.1 \%$ for 2:1 water:toluene mixtures. This is probably because the iron was re-precipitated after dissolution due to a high $\mathrm{pH}$. There have been no follow-up studies.

Citric acid is often used to remove zinc from contaminated soils [71-74]. Therefore, we could anticipate that citric acid, and related chelating organic acids, have the potential to remove zinc from landfilled BF sludges. Something that has not been investigated yet. Furthermore, there is little on recycling the lixiviant in soil-remediation studies with citric acid. All the lead (but not zinc) could be removed from BF sludges with an EDTA solution [75]. 


\section{Leaching with Ammonia + Ammonium Salts}

Tata Steel discloses in EP 3333272 A1 a process for leaching $\mathrm{BF}$ (and BOF) residues with a leaching solution of $\mathrm{NH}_{3}$ and an ammonium salt, $\left(\mathrm{NH}_{4}\right)_{2} \mathrm{SO}_{4}, \mathrm{NH}_{4} \mathrm{Cl}$, or $\left(\mathrm{NH}_{4}\right)_{2} \mathrm{CO}_{3}$, at $\mathrm{pH}$ 8-12 [76]. When leaching with an $\mathrm{NH}_{3}+$ ammonium sulfate solution, dried and untreated BF sludge yielded $40 \%$ zinc with only $1 \%$ of co-dissolved iron. With roasting in air, the zinc recovery was $60 \%$. Roasting with $\mathrm{Na}_{2} \mathrm{CO}_{3}$, followed by leaching with $\mathrm{NH}_{3}+\left(\mathrm{NH}_{4}\right)_{2} \mathrm{SO}_{4}$, gave $70 \%$. These increases are due to the decomposition of $\mathrm{ZnFe}_{2} \mathrm{O}_{4}$.

\section{Bioleaching}

Cheikh et al. suggested a clean-up for BF sludges that combined an initial leaching with Na-EDTA (pH 6) to remove the lead, followed by a second bioleaching with A. ferrooxidans to remove the zinc [75]. For the bioleaching, $1 \mathrm{~g}$ of sludge was used in $50 \mathrm{~mL}$ of solution.

\section{BOF Dust and Sludge}

\section{Chemistry and Mineralogy}

According to a 2006 survey, the average amount of BOF dust and sludge is about $22 \mathrm{~kg} / \mathrm{ton}$ of crude steel (range $10-40 \mathrm{~kg} / \mathrm{ton}$ ) [11]. Most BOF dusts and sludges are collected in the secondary/fine systems. Improvements in gas cleaning systems mean more material is being collected, rather than emitted into the atmosphere. This has led to slightly increased amounts of BOF dusts and sludges over the years. There are also increases in BOF dusts and sludges due to altered process conditions, e.g., blowing rates, slag practices, bath additions, and bath agitations.

Tables 1 and 2 show the chemical composition of primary (coarse) and secondary (fine) BOF dusts and sludges. These are mainly iron particles ejected from the BOF, which partially oxidize within the gas cleaning system [11]. The extent of the oxidation depends on the extraction system. Due to the high temperatures involved and the mechanism of formation, the carbon levels associated with BOF dusts and sludges are low compared to BF dusts and sludges. A study of BOF

Table 1 Chemical composition of primary BOF dust and sludge (wt\%) [11]

\begin{tabular}{lclc}
\hline Element & Minimum & Maximum & Average \\
\hline Iron (total) & 47.6 & 92 & 73.7 \\
Iron (metallic) & 1.9 & 79.4 & 44.1 \\
Carbon & 0.1 & 2.2 & 0.9 \\
Zinc & 0.01 & 1.7 & 0.3 \\
Lead & 0.0016 & 0.1 & 0.06 \\
\hline
\end{tabular}

sludge by ArcelorMittal Monlevade, Brazil, showed that the fine fraction is much richer in zinc and lead than the coarse fraction. Whereas the coarse fraction contained $0.51 \% \mathrm{Zn}$ and $<0.010 \% \mathrm{~Pb}$, the fine fraction contained $4.37 \% \mathrm{Zn}$ and $0.068 \% \mathrm{~Pb}$ [77]. A study of the distribution of zinc in BOF off-gases in two ArcelorMittal steelmaking plants showed that the dusts collected close to the BOF vessels contain much less zinc than the dust collected downstream in the off-gas cleaning system. The primary dust contains such a low zinc content and is so Fe-rich that it can be considered as a secondary iron resource, comparable to high-quality iron ores [78]. BOF sludge contains much less sulfur than BF sludge [79].

A mineralogical study of BOF sludge from ArcelorMittal Monlevade found the following mineralogical phases were present in both the coarse and fine fractions: wüstite $(\mathrm{FeO})$, magnetite $\left(\mathrm{Fe}_{3} \mathrm{O}_{4}\right)$, metallic iron $(\alpha-\mathrm{Fe})$, lepidocrocite $(\gamma-\mathrm{FeOOH})$, calcite $\left(\mathrm{CaCO}_{3}\right)$, and portlandite $\left(\mathrm{Ca}(\mathrm{OH})_{2}\right)$ [77]. Zincite $(\mathrm{ZnO})$ was not identified, and franklinite $\left(\mathrm{ZnFe}_{2} \mathrm{O}_{4}\right)$ could not be identified due to an overlap with the peaks of magnetite in the X-ray diffractogram. Graphite (C) was only found in the fine fraction and fluorite $\left(\mathrm{CaF}_{2}\right)$ only in the coarse fraction. Sammut et al. made a zinc speciation in $\mathrm{BOF}$ dust and found $43 \% \mathrm{ZnFe}_{2} \mathrm{O}_{4}, 23 \% \mathrm{ZnCO}_{3}$, and $16 \% \mathrm{ZnO}$ [80]. The $\mathrm{ZnCO}_{3}$ was attributed to the presence of limestone in the process. Veres et al. reported the following mineralogical phases in a 9.37\%-Zn BF dust: magnetite, hematite, wüstite, franklinite, zincite, and amorphous phases [81]. Wang et al. investigated the zinc distribution and zinc speciation in $\mathrm{Zn}$-rich (3.4\% $\mathrm{ZnO}$ ) BOF sludge by micro-XRD and micro-XANES. The main zinc phases were franklinite $\left(\mathrm{ZnFe}_{2} \mathrm{O}_{4}\right)$ and smithsonite $\left(\mathrm{ZnCO}_{3}\right)[82,83]$.

Since BOF dusts and sludges have a lot of iron, their recycling should be a high priority. Internal recycling via the sinter plant/BF route is limited by the concentrations of zinc and lead. In such cases, steel plants can blend materials and produce briquettes/pellets that are then charged back to the BOF [11]. Another option is stockpiling, and a significant fraction is used by the cement industry. Environmental concerns are reducing the amount of landfilling, while the high moisture content of BOF sludge is an obstacle to recycling [84].

Table 2 Chemical composition of secondary/fine BOF dust and sludge (wt\%) [11]

\begin{tabular}{lclc}
\hline Element & Minimum & Maximum & Average \\
\hline Iron (total) & 39.9 & 82 & 60.5 \\
Iron (metallic) & 2.1 & 25 & 12.9 \\
Carbon & 0.1 & 5.9 & 1.9 \\
Zinc & 0.05 & 8 & 1.6 \\
Lead & 0.01 & 0.3 & 0.1 \\
\hline
\end{tabular}




\section{Leaching with Mineral Acids}

There are very few studies on leaching BOF dust and sludge with mineral acids. Kelebek et al. studied the leaching of BOF sludge with $\mathrm{H}_{2} \mathrm{SO}_{4}$ [85]. Leaching with a solution at $\mathrm{pH} 2$ for 20 min reduced the zinc in the coarse fraction from 1.6 to $0.4 \%$ and in the fine fraction from 1.9 to $1.6 \%$. In the coarse fraction, the zinc removal rate was $80-85 \%$, with an $18 \%$ iron loss. However, in the fine fraction the zinc removal was only $29 \%$, with a $1.85 \%$ iron loss. The differences were due to mineralogy (with more $\mathrm{ZnFe}_{2} \mathrm{O}_{4}$ in the fine fraction). The flow sheet (Fig. 9) has an upfront size separator to split the sludge stream into fine and coarse fractions (with a hydrocyclone). The fine stream is directed to a dewatering circuit (e.g., thickener) and then to a disposal site (with no treatment). The coarse fraction is sent to a leaching system, preferably arranged as a counter-current circuit. The solid particles leaving this system are relatively coarse and low in zinc, and can be recycled to the sinter plant.

Trung et al. studied the leaching of BOF sludge with $\mathrm{H}_{2} \mathrm{SO}_{4}[86,87]$. The BOF sludge was a very heterogeneous material, so that it was hard to select a $\mathrm{H}_{2} \mathrm{SO}_{4}$ solution with the right concentration for leaching. After $15 \mathrm{~min}$ at $80^{\circ} \mathrm{C}$, $70 \%$ of the zinc was removed with a 1-M solution. Veres et al. used the microwave-assisted leaching of BOF sludge with a 1- $\mathrm{M} \mathrm{H}_{2} \mathrm{SO}_{4}$ solution at a liquid-to-solid ratio of 20 [88]. The microwaves increased the zinc leaching, but also the iron leaching, resulting in poor selectivity. US patent $3,375,069$ discloses how to remove zinc from BOF sludge by leaching with spent pickling liquor ( $\mathrm{HCl}$ [ [89]. BOF dust samples with $0.80 \%$ and $0.78 \%$ zinc were investigated. With the $\mathrm{pH}$ at $4-5$, iron dissolution could be avoided.

\section{Leaching with Organic Acids}

Wang et al. recovered zinc from BOF sludge with different organic acids [90]: oxalic, citric, acetic, propionic, butyric, and valeric acid. These organic acids are biodegradable, so that secondary waste can be avoided. The leaching tests

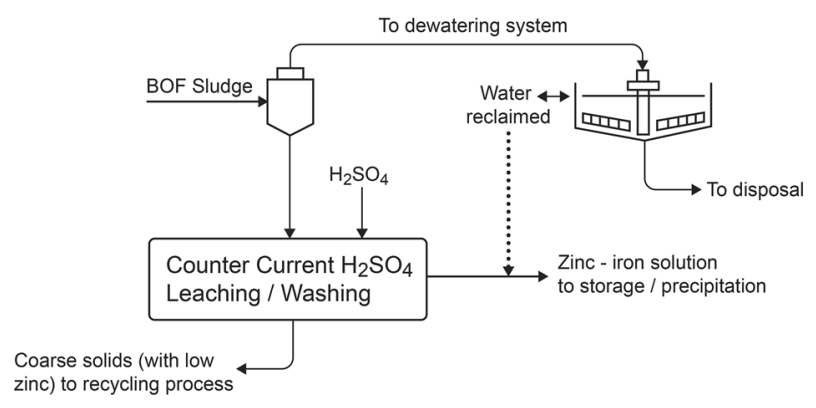

Fig. 9 Flow sheet for the mild treatment of BOF sludge at $\mathrm{pH} 2$ with $\mathrm{a}_{2} \mathrm{SO}_{4}$ solution. Adapted from [85] aimed to maximize zinc recovery and minimize iron dissolution. The filter cake was dried overnight at $105{ }^{\circ} \mathrm{C}$, screened, and the 300-500- $\mu \mathrm{m}$ fraction was used. The sample had $6.5 \% \mathrm{Zn}$. The main mineralogical phases were wüstite, metallic iron, and magnetite. About half of the zinc in the filter cake was $\mathrm{ZnO}$ and franklinite, whereas the other half was present in solid solutions of $\mathrm{ZnO}$ and $\mathrm{FeO}$ (zincite-wüstite) and $\mathrm{ZnFe}_{2} \mathrm{O}_{4}$ and $\mathrm{Fe}_{3} \mathrm{O}_{4}$ (franklinite-magnetite). For the leaching, $150 \mathrm{~mL}$ of a $1-\mathrm{M}$ acid solution was used with a filter cake corresponding to $70 \%$ of the ratio of the actual amount of acid to that theoretically consumed if all the iron and zinc were present as $\mathrm{FeO}$ and $\mathrm{ZnO}$. The leaching was at room temperature for $10 \mathrm{~h}$. Figure 10 shows the efficiency for zinc and iron with different acids as a function of time. Butyric acid was the most efficient lixiviant, with $49.7 \%$ $\mathrm{Zn}$ removal and $2.5 \% \mathrm{Fe}$ leached. After $20 \mathrm{~min}, 23.2 \%$ of the zinc was extracted, with $41.0 \%$ after $3 \mathrm{~h}$ and $49.7 \%$ after $10 \mathrm{~h}$. Although acetic and propionic acids extracted more zinc, they also led to more iron dissolving. Oxalic acid was not efficient for leaching. Citric acid dissolved the most zinc, but also the most iron, i.e., poor selectivity. The efficiency of the zinc leaching was acetic $>$ propionic $>$ butyric $>$ valeric acid. The order for iron leaching was acetic $>$ propionic $>$ butyric $<$ valeric acid, i.e., a minimum for butyric acid.

Based on the most promising results for butyric acid, the authors then investigated the leaching behavior of BOF sludge with butyric acid in a follow-up study. The optimum leaching conditions were determined. In the best case, $51 \%$ of zinc was leached, with less than $1 \%$ of iron co-dissolution [91]. The results showed that zinc extraction increased with a higher acid-to-filter-cake ratio. Acid concentration had no effect on zinc, but iron dissolution decreased with a stronger acid. The authors suggested leaching in counter-current mode (Fig. 11). A key finding was butyric acid cannot dissolve $\mathrm{ZnFe}_{2} \mathrm{O}_{4}$ (franklinite). To assess the butyric route, three BOF filter cakes with $2.42 \%, 6.52 \%$, and $13.8 \%$ $\mathrm{Zn}$, as well as weathered samples, were tested [92]. After optimum leaching, 2-3\% Zn remained. The effects of adding other organic or mineral acids to butyric acid on leaching zinc and iron from BOF filter cake were investigated to find the maximum-allowed impurity levels in butyric acid [93]. While the presence of acetic and propionic acids in butyric acid has little effect on zinc leaching, the addition of $\mathrm{H}_{2} \mathrm{SO}_{4}$ or $\mathrm{HCl}$ reduced the selectivity, unless the acids were added such that the $\mathrm{pH}$ did not fall below that of pure butyric acid.

\section{Alkali Leaching}

Leaching BOF sludge with 5-M sodium hydroxide $(\mathrm{NaOH})$ solution was very selective for zinc over iron [77]. However, as no $\mathrm{ZnFe}_{2} \mathrm{O}_{4}$ was dissolved, the total zinc recovery rate was only $40-60 \%$. The $\mathrm{ZnFe}_{2} \mathrm{O}_{4}$ could be decomposed 

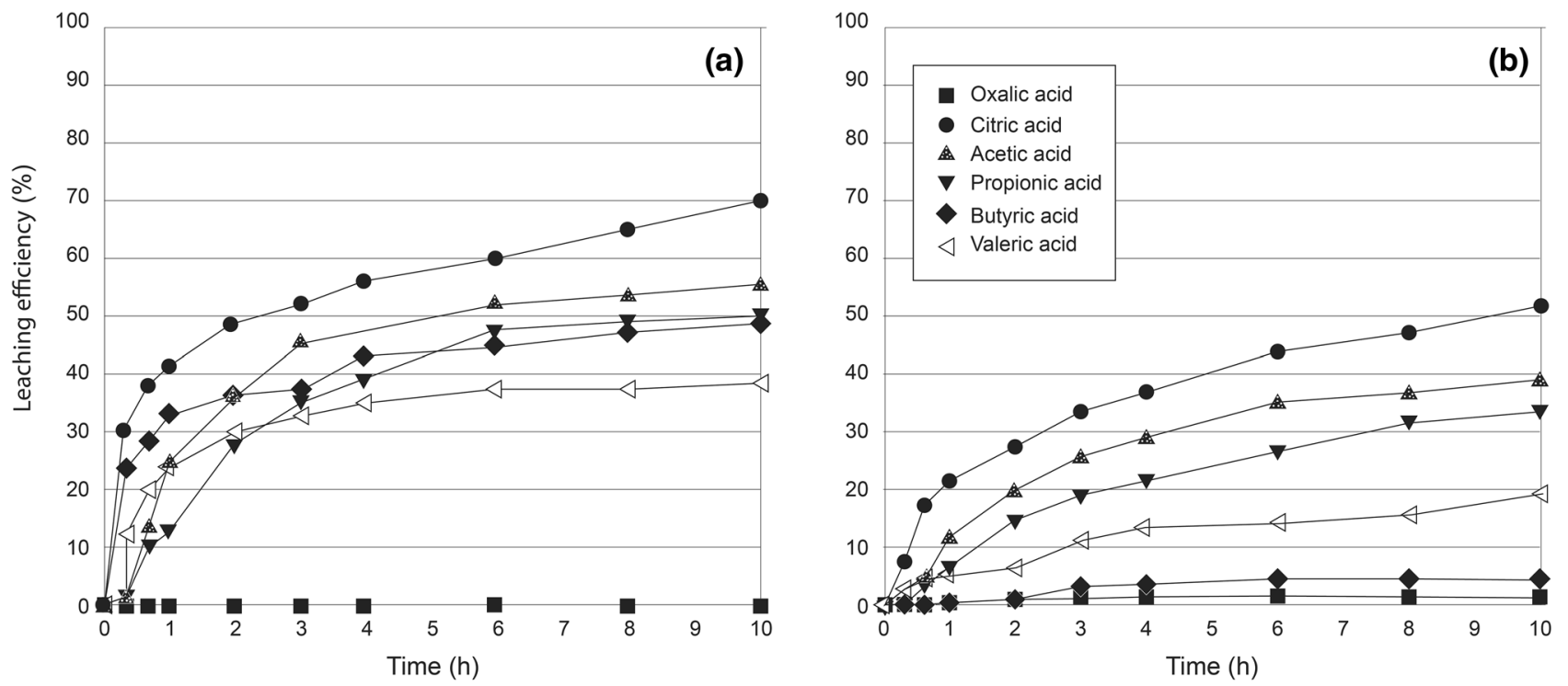

Fig. 10 Leaching efficiency for $\mathbf{a}$ zinc and $\mathbf{b}$ iron for different acids as a function of time. Adapted from [90]

Fig. 11 Conceptual flow sheet of a counter-current process for leaching BOF sludge with butyric acid. Adapted from [91]

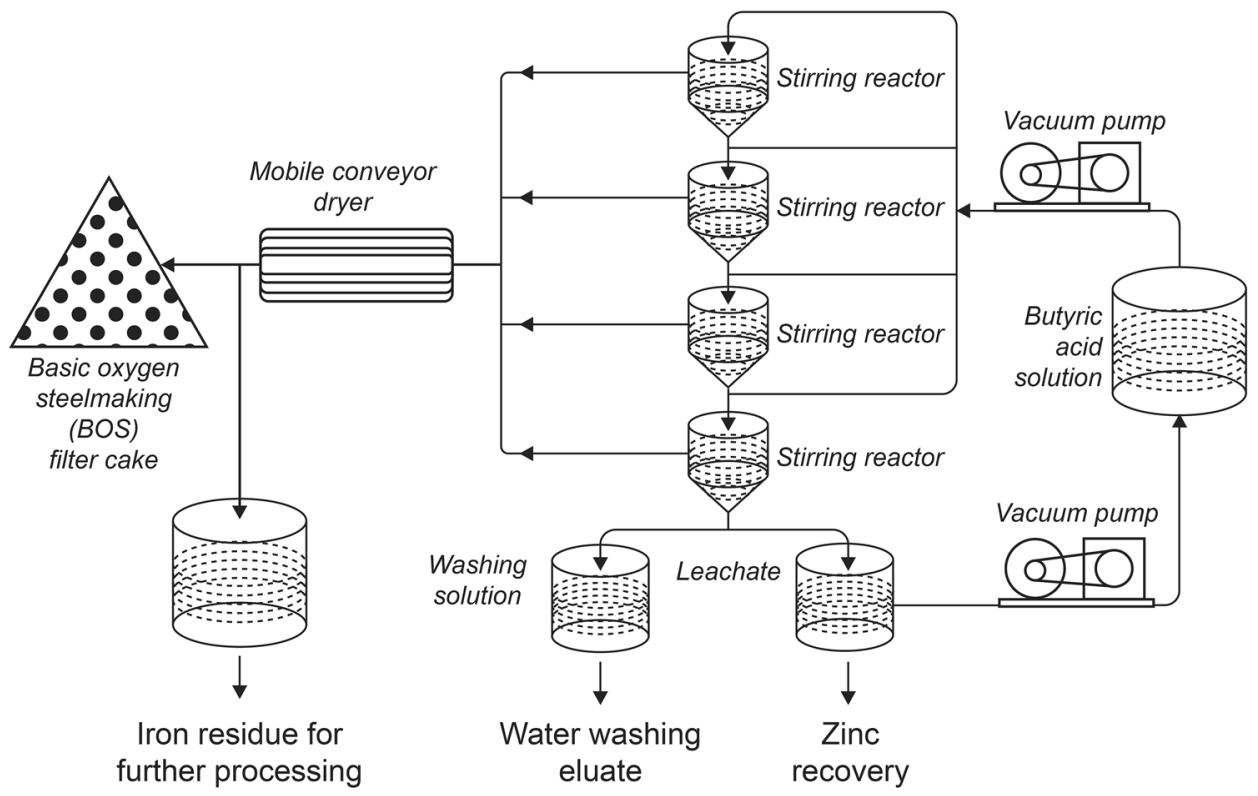

by heating with $\mathrm{NaOH}\left(\mathrm{T}=450{ }^{\circ} \mathrm{C}, \mathrm{t}=1-5 \mathrm{~h}, \mathrm{NaOH} /\right.$ sludge ratio $=0.75)$. Leaching this $\mathrm{BOF}$ sludge sample with $5-\mathrm{M} \mathrm{NaOH}$ resulted in $94 \%$ of zinc recovered. The main disadvantage of leaching with $\mathrm{NaOH}$ is that concentrated solutions are required and a lot of reagent is consumed (see section on "EAF Dust"). Gargul et al. reduced the zinc content of a BOF sludge from $2.82 \% \mathrm{Zn}$ to $1 \% \mathrm{Zn}$ after leaching for $100 \mathrm{~h}$ with 5-M NaOH [94]. Leaching with a 1-M (or less) $\mathrm{NaOH}$ solution selectively recovered molybdenum and tungsten from steelmaking dust, with no significant co-dissolution of zinc [95].

\section{Leaching with Ammonium Salts}

Gargul and Boryczko compared the leaching of a BOF sludge containing $2.82 \% \mathrm{Zn}$ with an $\mathrm{NH}_{3}$ solution and the ammonium salts $\mathrm{NH}_{4} \mathrm{Cl}$ and $\left(\mathrm{NH}_{4}\right)_{2} \mathrm{CO}_{3}$ [96]. The best results came with $\mathrm{NH}_{4} \mathrm{Cl}$, where the zinc was reduced to $<1 \%$. Although the authors claimed minimal loss of iron, 
there were no data for its co-dissolution. In European patent EP 3333272 A1, Tata Steel discloses the leaching of BF and BOF residues with a solution of $\mathrm{NH}_{3}$ and an ammonium salt, $\left(\mathrm{NH}_{4}\right)_{2} \mathrm{SO}_{4}, \mathrm{NH}_{4} \mathrm{Cl}$ or $\left.\left(\mathrm{NH}_{4}\right)_{2} \mathrm{CO}_{3}\right)$, at $\mathrm{pH}$ 8-12 [76]. In an example, $\mathrm{BOF}$ and $\mathrm{BF}$ flue dusts were roasted at $750-900{ }^{\circ} \mathrm{C}$ for $1 \mathrm{~h}$ with $\mathrm{Na}_{2} \mathrm{CO}_{3}$ to decompose the $\mathrm{ZnFe}_{2} \mathrm{O}_{4}$. After leaching with $\mathrm{NH}_{3}+$ ammonium sulfate solution, $>80 \%$ of the zinc was recovered.

\section{EAF Dust and Sludge}

\section{Chemistry and Mineralogy}

EAF dust and sludge amount to $14.2 \mathrm{~kg} /$ ton of crude steel (range 3.4-25 kg/ton) [11]. The first stage of the gas cleaning (typically a baghouse) is the main generator of dust: $12.7 \mathrm{~kg} /$ ton of crude steel on average. The other dusts and sludges collected from the process represent a small fraction, and most studies focus on the primary dust. The chemical composition of EAF dust is shown in Table 3 [11]. Iron and zinc are the dominant components, while there is a relatively low carbon content ( $1.8 \%$ on average), similar to the carbon content of BOF dusts and sludges, suggesting it is driven off during steelmaking. The zinc content of EAF dust varies with the steel plant because of the different zinc contents of the input scrap and the grades being produced. EAF dust can also contain various amounts of lead and cadmium.

The physical properties of EAF dust depend on the steel type and the melting process. The particle size is $0.1 \mu \mathrm{m}$ to $>200 \mu \mathrm{m}$. Therefore, EAF can be airborne, which makes it difficult to handle or separate using physical methods [97]. Due to the presence of salts $(\mathrm{NaCl}$ and $\mathrm{KCl})$, the soluble fraction can be up to $10 \mathrm{wt} \%$. Zinc accumulates in the fine fraction of the dust, whereas iron tends to report to the larger particles, being present as $\mathrm{ZnO}$ (zincite) or $\mathrm{ZnFe}_{2} \mathrm{O}_{4}$ (franklinite). The zincite in EAF dust is due to the high zinc content [98]. However, there is usually less zincite than franklinite.

\section{Pyrometallurgical Versus Hydrometallurgical Processes}

The high zinc content of EAF dusts means they cannot be used in steelmaking. They must either be landfilled or

Table 3 Chemical composition of EAF dust (wt\%) [11]

\begin{tabular}{lllc}
\hline Element & Minimum & Maximum & Average \\
\hline Iron (total) & 16 & 60.8 & 35.1 \\
Iron (metallic) & 0.19 & 9.2 & 3.5 \\
Carbon & 0.94 & 4.1 & 1.8 \\
Zinc & 0.03 & 37 & 14.6 \\
Lead & 0.05 & 21.5 & 3.1 \\
\hline
\end{tabular}

processed for zinc recovery. However, the content is low compared to conventional zinc-industry raw materials, and a proportion is present as $\mathrm{ZnFe}_{2} \mathrm{O}_{4}$, a refractory phase. The levels of toxic heavy metals, particularly lead, are far too high to permit disposal in sanitary landfills. Hence, there has been a trend to send less EAF dust to landfills and recover more using external methods. The most common of these is the (pyrometallurgical) Waelz-kiln process [5, 99], accounting for around $80 \%$. A Waelz kiln is expensive, but it is attractive for EAF dusts with 15-20\% zinc and plant capacities of at least 50,000 tons/year [100]. In contrast, hydrometallurgical treatment methods are better suited to a smaller scale. Their advantages are low energy consumption, high zinc solubility in different lixiviants, and the possibility to recycle residues to the EAF or BF. Although these hydrometallurgical methods have lower CAPEX and OPEX, the purification process is more complex. The EAF dust recycling produces a residue with a huge moisture content, which must be dried before it can enter the steelmaking process. Hydrometallurgical processes can recover metals other than zinc, such as lead, cadmium, and copper, generating iron oxide with less metal contamination. As well as pyrometallurgical and hydrometallurgical methods, EAF dust can be used in construction or as a filler in acoustic or thermal insulators [97].

It is difficult to compare studies on zinc leaching from EAF dust, because the compositions can vary widely, not only from steel plant to steel plant, but also over time, because of feed fluctuations. Therefore, we have different concentrations of zinc, but also variations in $\mathrm{ZnO} / \mathrm{ZnFe}_{2} \mathrm{O}_{4}$ ratio, with $\mathrm{ZnO}$ (zincite) easy to dissolve, whereas $\mathrm{ZnFe}_{2} \mathrm{O}_{4}$ (franklinite) is not. Because of the fluctuating chemical and mineralogical compositions of EAF dust, the optimum process parameters also vary.

\section{Removal of Chlorides}

EAF dust contains chloride salts. This is a problem when leaching EAF dust with $\mathrm{H}_{2} \mathrm{SO}_{4}$, because the chloride will end up in the leachate and, hence, in the electrolyte for the electrowinning of zinc. Chloride impurities in $\mathrm{ZnSO}_{4}$ electrolytes are problematic because they corrode the electrodes, incorporate lead dissolved from the anode in the zinc, and make it hard to remove the electrodeposited zinc from the aluminum cathode. Therefore, the chloride salts must be removed from the EAF dust prior to leaching or from the pregnant leachate.

A convenient way to remove the chloride salts from EAF dust is washing with water, because the chlorides are mostly water soluble $(\mathrm{NaCl}$ and $\mathrm{KCl})$. Bruckard et al. removed $99 \%$ by washing with tap water at room temperature for $60 \mathrm{~min}$ at the natural $\mathrm{pH}$ of EAF dust (pH 12). The residue had only 200 ppm chloride [101]; the liquid-to-solid ratio was 3:1; no 
adjustment of the $\mathrm{pH}$ was necessary; and water at ambient temperature was as effective as hot water. The kinetic experiments showed that about $1 \mathrm{~h}$ was sufficient to eliminate the water-soluble salts from the EAF dust. The washing step removed all the potassium and sulfate in the sample, about $50 \%$ of the sodium and less than about $10 \%$ of the calcium. Only trace amounts of zinc and manganese were leached. Environmentally significant amounts of lead, chromium, and cadmium reported to the wash solution, so this solution must be treated for heavy-metal removal. This involved $\mathrm{Na}_{2} \mathrm{~S}$ solution to precipitate the heavy metals and then adding a little $\mathrm{Fe}$ (II) sulfate to remove the excess of sulfide ions. $\mathrm{H}_{2} \mathrm{SO}_{4}$ was used to lower the $\mathrm{pH}$ from 12 to 8-10.

However, some of the chloride in EAF dust is in the form of water-insoluble lead hydroxyl chloride $(\mathrm{PbOHCl})$ and lead chloride carbonate $\left(\mathrm{Pb}_{2} \mathrm{Cl}_{2} \mathrm{CO}_{3}\right)$ [102]. Washing with water cannot remove the chloride from these compounds. They require roasting of the EAF dust at $<600{ }^{\circ} \mathrm{C}$ before washing with water. Sulfation roasting is more efficient than carbonation or air roasting. The metal chlorides in the roasted $\mathrm{EAF}$ dust are $\mathrm{NaCl}$ and $\mathrm{KCl}$, which can be easily removed with water. The roasting must be below $600{ }^{\circ} \mathrm{C}$ to avoid the evaporation of zinc and lead. Carbonation roasting requires a $\mathrm{CO}_{2}$ gas stream, whereas sulfation roasting requires $\mathrm{SO}_{2}$, and air roasting requires air. The washing step should be applied to freshly collected EAF dust, because it absorbs $\mathrm{CO}_{2}$ from the atmosphere and this can lock up part of the chloride in water-insoluble zinc hydroxyl-chloride, $\mathrm{ZnCl}_{2} \cdot 4 \mathrm{Zn}(\mathrm{OH})_{2} \cdot \mathrm{H}_{2} \mathrm{O}$.

After leaching with $\mathrm{H}_{2} \mathrm{SO}_{4}$, chloride impurities can be removed by electrodialysis with a mono/bipolar ionexchange membrane [103]. Monopolar membranes are either cation-exchange or anion-exchange membranes. A bipolar membrane contains an anion-exchange and a cation-exchange layer. These membranes split water into $\mathrm{H}^{+}$ and $\mathrm{OH}^{-}$ions in an electric field. A one-step electrodialysis process produces a $\mathrm{ZnSO}_{4}$ solution with a low-enough chloride concentration for an electrolytic zinc production process from leaching solutions of $\mathrm{Zn}$-bearing raw materials with up to $1 \%$ chloride.

\section{Sulfuric Acid Leaching}

Solutions of sulfuric acid $\left(\mathrm{H}_{2} \mathrm{SO}_{4}\right)$ are the most popular lixiviants for a hydrometallurgical treatment of EAF dust. $\mathrm{H}_{2} \mathrm{SO}_{4}$ is cheap and it is possible to use the $\mathrm{ZnSO}_{4}$ leachate for the electrowinning of zinc metal [104]. Zinc oxide (zincite) dissolves very rapidly in $\mathrm{H}_{2} \mathrm{SO}_{4}$ solutions, irrespective of the concentration and the temperature [105]. The diffusion-controlled reaction can take as little as $1 \mathrm{~min}$. The dissolution of $\mathrm{ZnFe}_{2} \mathrm{O}_{4}$ (franklinite) is much slower and depends on the temperature [106]. The rate-limiting step is the rate of the chemical reaction. For the highest selectivity of zinc over iron, it is better to use $0.5-\mathrm{M}$ (or lower) $\mathrm{H}_{2} \mathrm{SO}_{4}$ solutions and to stop leaching after about $15 \mathrm{~min}$. The codissolution of iron is suppressed by working at lower concentrations $[107,108]$. The reason why only a little iron is dissolved at lower $\mathrm{H}_{2} \mathrm{SO}_{4}$ concentrations is that the other elements are dissolved first and there is not enough free acid to dissolve all of the iron. The final $\mathrm{pH}$ after leaching with a dilute $\mathrm{H}_{2} \mathrm{SO}_{4}$ solution will be so elevated that codissolved Fe(III) will precipitate on the residue. Lead is not solubilized by leaching with $\mathrm{H}_{2} \mathrm{SO}_{4}$, because poorly soluble $\mathrm{PbSO}_{4}$ (anglesite) is formed. A problem often encountered when leaching with $\mathrm{H}_{2} \mathrm{SO}_{4}$ is the poor settling and filtration behavior of the residues.

Leaching for longer times with higher $\mathrm{H}_{2} \mathrm{SO}_{4}$ concentrations at high temperatures will always bring significant iron into solution $[61,109]$. For instance, $100 \%$ of zinc and $90 \%$ of iron were dissolved in 3- $\mathrm{M} \mathrm{H}_{2} \mathrm{SO}_{4}$ at $80{ }^{\circ} \mathrm{C}$ and a liquidto-solid ratio of 5:1 for $6 \mathrm{~h}$ [109]. A small residual fraction rich in lead was obtained. The iron could be precipitated after sufficient dilution as goethite $(\alpha-\mathrm{FeOOH})$, which has the advantage that it can precipitate iron from an $\mathrm{Fe}(\mathrm{III})$ sulfate solution without the need for high temperatures and pressure. The main disadvantage is that a lot of alkali is required for neutralization, although it is more efficient if the solution is neutralized by fresh EAF dust. A study of autoclave leaching of EAF dust with $\mathrm{H}_{2} \mathrm{SO}_{4}$ confirmed that calcium dissolves up to $150{ }^{\circ} \mathrm{C}$, but later precipitates as calcium sulfate [110]. Above $150^{\circ} \mathrm{C}$, calcium remains permanently in solution, even after cooling to room temperature after the leaching process. High concentrations of calcium in the EAF dust have a negative influence on the cost of leaching, because the dissolution of $\mathrm{CaO}$ consumes $\mathrm{H}_{2} \mathrm{SO}_{4}$ and leads to the precipitation of $\mathrm{CaSO}_{4}$ [111].

When leaching EAF dust with $\mathrm{H}_{2} \mathrm{SO}_{4}$, iron co-dissolution can be avoided by using moderate concentrations so that the final $\mathrm{pH}$ is $4-5$ [112] and the dissolved iron will precipitate as Fe(III) hydroxide.

AMAX Inc. developed a two-stage leaching process to recover zinc from steel-plant dusts, with the complete rejection of iron as hematite [113]. The conceptual flow sheet is shown in Fig. 12. The first stage is leaching at atmospheric pressure and a temperature below the boiling point. In the second stage, leaching is at high pressures in an autoclave, at $225-300{ }^{\circ} \mathrm{C}$. The two stages are connected in countercurrent fashion, with two liquid/solid separation steps. Under autoclave conditions, most of the iron in the feed slurry was converted to hematite $\left(\mathrm{Fe}_{2} \mathrm{O}_{3}\right)$, which is more dense and separates more easily from the solution than goethite, jarosite, or Fe(III) hydroxide. Due to its high iron content and virtually zero sulfur content, hematite is the preferred form of iron precipitate for recycling in steelmaking furnaces. The solids were washed to recover $\mathrm{ZnSO}_{4}$. If lead is still present in the residue, it can be leached with brine. 


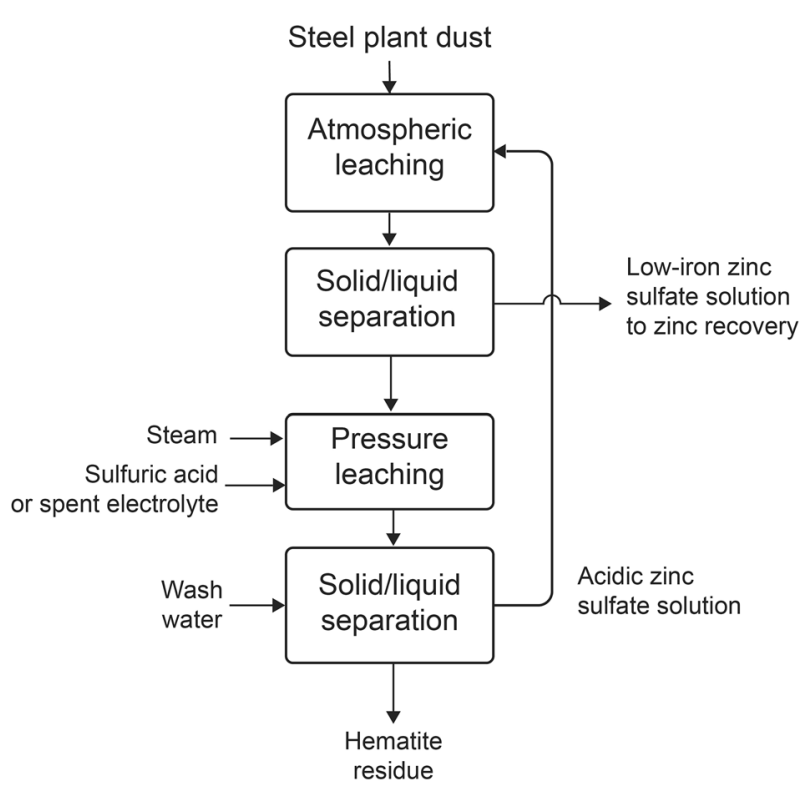

Fig. 12 Conceptual flow sheet for two-stage leaching of EAF dust with $\mathrm{H}_{2} \mathrm{SO}_{4}$, developed by AMAX Inc. Adapted from [113]

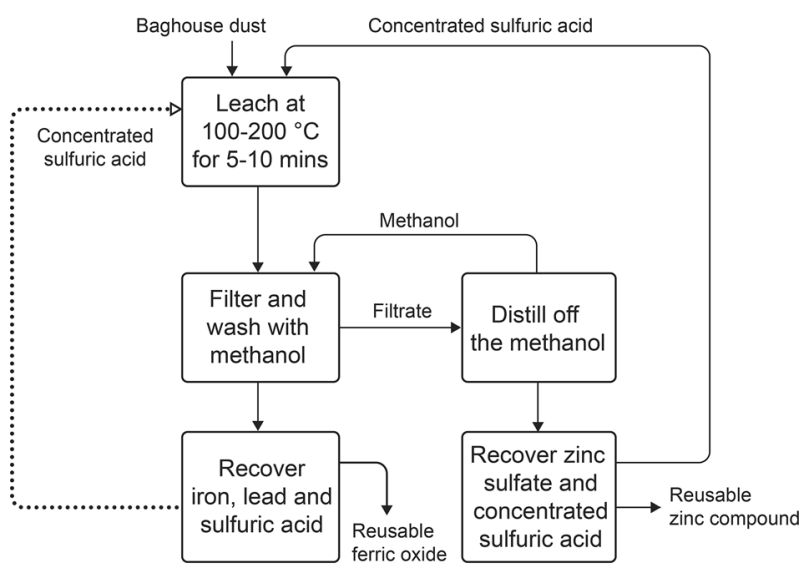

Fig. 13 Flow sheet of a process based on leaching of EAF dust with hot concentrated $\mathrm{H}_{2} \mathrm{SO}_{4}$ and washing the residue with methanol. Adapted from [114]

US patent 5,286,465 discloses the leaching EAF dust with hot concentrated $\mathrm{H}_{2} \mathrm{SO}_{4}$ at $100-200{ }^{\circ} \mathrm{C}$ for $5-10 \mathrm{~min}$ (Fig. 13) [114]. Under these conditions, zinc is dissolved as $\mathrm{ZnSO}_{4}$ and iron precipitates as ferric sulfate, $\mathrm{Fe}_{2}\left(\mathrm{SO}_{4}\right)_{3}$. The precipitate can be separated by filtration and washing with methanol, which can be recovered by distillation. The zinc can be recovered from the $\mathrm{H}_{2} \mathrm{SO}_{4}$ solution by adding water to precipitate hydrated $\mathrm{ZnSO}_{4}$ at $10{ }^{\circ} \mathrm{C}$, separating it by filtration and evaporating the water to regenerate the $\mathrm{H}_{2} \mathrm{SO}_{4}$. Iron can be recovered by roasting the $\mathrm{Fe}_{2}\left(\mathrm{SO}_{4}\right)_{3}$, yielding ferric oxide and sulfur trioxide, which can be reconverted to $\mathrm{H}_{2} \mathrm{SO}_{4}$ by rehydration. Alternatively, the $\mathrm{Fe}_{2}\left(\mathrm{SO}_{4}\right)_{3}$ can be reacted with an $\mathrm{NH}_{3}$ solution. The resulting ammonium sulfate can be thermally decomposed into $\mathrm{NH}_{3}$ and $\mathrm{H}_{2} \mathrm{SO}_{4}$, both of which can be recycled.

The Modified Zincex Process involves the following steps to recover the zinc from zincite in EAF dust: (1) atmospheric leaching with $0.5 \mathrm{~N} \mathrm{H}_{2} \mathrm{SO}_{4}$ at $40{ }^{\circ} \mathrm{C}, 1 \mathrm{~h}, \mathrm{pH} 2$ to dissolve $\mathrm{ZnO}$; (2) purifying the leachate by precipitating the iron with lime; (3) extracting the zinc with bis(2-ethylhexyl) phosphoric acid (D2EHPA), (4) stripping the zinc from the loaded organic phase, and (5) electrowinning of the zinc metal [115].

A design of experiment for leaching EAF dust with dilute $\mathrm{H}_{2} \mathrm{SO}_{4}$ indicated that the optimum leaching conditions were $3 \mathrm{~N} \mathrm{H}_{2} \mathrm{SO}_{4}, 60{ }^{\circ} \mathrm{C}$ and a liquid-to-solid ratio of 10:1 [116], where $80 \%$ of the zinc was extracted, while $45 \%$ of iron was co-dissolved. The main phases in the residue were basanite $\left(\mathrm{CaSO}_{4} \cdot 1 / 2 \mathrm{H}_{2} \mathrm{O}\right)$, anhydrite $\left(\mathrm{CaSO}_{4}\right)$, and anglesite $\left(\mathrm{PbSO}_{4}\right)$. The leachate was further purified [117]. The proposed flow sheet had four unit operations: (1) removal of iron as jarosite, by precipitation at $95{ }^{\circ} \mathrm{C}$ and $\mathrm{pH} 3.5$; (2) solvent extraction of zinc by the extractant Cyanex 272 at pH 3.5, $40{ }^{\circ} \mathrm{C}, 25 \mathrm{vol} \%$ extractant, diluted in kerosene $+5 \mathrm{vol}$. TBP, organic-to-aqueous phase volume ratio $(\mathrm{O} / \mathrm{A})=2$ (3) stripping of the loaded organic phase by spent zinc electrolyte $\left(62.5 \mathrm{~g} / \mathrm{L} \mathrm{Zn}^{2+}\right)$ at $40{ }^{\circ} \mathrm{C}$, diluted with $\mathrm{H}_{2} \mathrm{SO}_{4}(3 \mathrm{M})$; (4) zinc electrowinning from $\mathrm{ZnSO}_{4}$ solutions at $38^{\circ} \mathrm{C}$, using an aluminum cathode and a lead anode. The acidity of the electrolyte was $180 \mathrm{~g} / \mathrm{L} \mathrm{H}_{2} \mathrm{SO}_{4}$, with a zinc concentration of $80.4 \mathrm{~g} / \mathrm{L}$, and a current density of $500 \mathrm{~A} / \mathrm{m}^{2}$. Gotfryd et al. leached EAF dust with $\mathrm{H}_{2} \mathrm{SO}_{4}$ and purified the leachate by solvent extraction with D2EHPA $[118,119]$. The tests were performed on a pilot scale.

Montenegro et al. described an efficient process to recover zinc from EAF dust [100]. The process has three leaching stages: (1) $60 \%$ of zinc and $80 \%$ of cadmium can be leached at ambient temperature with $2 \mathrm{~N}_{2} \mathrm{SO}_{4}$ and $20 \%$ pulp density, for $20 \mathrm{~min}$. (2) A second leaching stage on the first-stage leach residue with dilute $\mathrm{H}_{2} \mathrm{SO}_{4}(0.5 \mathrm{~N})$ and $20 \%$ pulp density at ambient temperature for $20 \mathrm{~min}$ led to total dissolution of the zinc content contained in the EAF dust. Zinc recovery in this stage is $75 \%$ and cadmium recovery is $90 \%$. (3) A third step of autoclave leaching using $2 \mathrm{~N} \mathrm{H}_{2} \mathrm{SO}_{4}$ and $20 \%$ pulp density, at $200{ }^{\circ} \mathrm{C}$ for $60 \mathrm{~min}$, led to total zinc recovery from the second-stage leach residue, mainly as $\mathrm{ZnFe}_{2} \mathrm{O}_{4}$. After three stages, the metal content in the final residue was $0.16 \% \mathrm{Zn}, 5.67 \% \mathrm{~Pb}, 11.96 \% \mathrm{Fe}$, and $0.003 \%$ $\mathrm{Cd}$. The total zinc recovery was $99 \%$ and the total cadmium recovery was $94 \%$. The process reduced the initial residue mass by $30 \%$. EAF dust has a high calcium content, due to lime being added during the steelmaking process. The dissolution of $\mathrm{ZnO}$ in the first stage takes $20 \mathrm{~min}$. Lead is dissolved in the first stage, but precipitates as $\mathrm{PbSO}_{4}$ in the 
solid residue. $\mathrm{CaO}$ reacts with $\mathrm{H}_{2} \mathrm{SO}_{4}$ forming $\mathrm{CaSO}_{4} \cdot 2 \mathrm{H}_{2} \mathrm{O}$ (gypsum) and crystallizes in the residue. The reaction of $\mathrm{CaO}$ with $\mathrm{H}_{2} \mathrm{SO}_{4}$ consumes more acid. In the first stage, the acid concentration was kept at $2 \mathrm{~N} \mathrm{H}_{2} \mathrm{SO}_{4}$ to minimize iron dissolution, but this led to lower $\mathrm{ZnO}$ dissolution. The leach residue after the first stage still contained zinc because of the high concentration of zinc ions in solution, and the consumption of acid, due to the reaction with $\mathrm{CaO}$, reduced the dissolution of free $\mathrm{ZnO}$. Therefore, a second stage at room temperature was used to dissolve any zinc from the $\mathrm{ZnO}$ and increase the metal recovery. No iron was dissolved during the second stage. Iron was, however, dissolved during the first stage, and re-precipitated as $\alpha-\mathrm{FeOOH}$ during the leaching when more acid was consumed and the $\mathrm{pH}$ rose to $4-5$. The leachate from both stages could be combined and directed to zinc and cadmium recovery by cementation or solvent extraction, followed by zinc electrowinning. Pressure leaching was applied to dissolve the remaining zinc, which is present in the form of $\mathrm{ZnFe}_{2} \mathrm{O}_{4}$. The leachate after pressure leaching was contaminated by iron, which was removed by precipitation as jarosite at atmospheric pressure at $\mathrm{pH} 3.5$ and $95{ }^{\circ} \mathrm{C}$.

Montenegro et al. further improved their flow sheet for $\mathrm{H}_{2} \mathrm{SO}_{4}$ leaching of EAF dust with water washing, at ambient temperature and equilibrium $\mathrm{pH} 10$, before the leaching [120]. More than $50 \%$ of the calcium, present as free $\mathrm{CaO}$, dissolved without the co-dissolution of any other metals. Removing the $\mathrm{CaO}$ prior to leaching reduced the consumption of $\mathrm{H}_{2} \mathrm{SO}_{4}$. The washing also removed the water-soluble chloride salts. Next, the washed EAF dust was leached with dilute $\mathrm{H}_{2} \mathrm{SO}_{4}(2 \mathrm{~N})$ at ambient temperature and $\mathrm{pH} 4$. Almost complete dissolution of the free $\mathrm{ZnO}$ took $10 \mathrm{~min}$. The recovery of zinc was $70 \%$ and that of cadmium was $90 \%$. This leaching was very selective regarding iron and lead. The pregnant leach solution could be directly treated for zinc and cadmium recovery by solvent extraction and electrolysis. The leaching residue from the previous step was treated with $\mathrm{H}_{2} \mathrm{SO}_{4}(3 \mathrm{~N})$ at $95{ }^{\circ} \mathrm{C}$, in two stages. Under these conditions, almost all the $\mathrm{ZnFe}_{2} \mathrm{O}_{4}$ was dissolved in $120 \mathrm{~min}$. The total zinc recovery was $97 \%$, with cadmium removal also 97\%. The final leach residue consisted of $\mathrm{CaSO}_{4}, \mathrm{PbSO}_{4}$, and $\mathrm{Fe}_{3} \mathrm{O}_{4}$. Its dry mass was about $27 \%$ of the initial dry mass of the dust. It was proposed to remove the iron from the pregnant leachate of the hot leaching step as jarosite or goethite, with subsequent recovery of zinc and cadmium by solvent extraction and electrolysis. Lead could be extracted by leaching with a $\mathrm{NaCl}$ solution at $95{ }^{\circ} \mathrm{C}$ and precipitation of the lead from $\mathrm{PbS}$ by adding $\mathrm{Na}_{2} \mathrm{~S}$ at ambient temperature. The residue after $\mathrm{NaCl}$ leaching contained $1.3 \% \mathrm{Zn}, 6.6 \%$ $\mathrm{Fe}, 0.5 \% \mathrm{~Pb}$, and $19.5 \% \mathrm{Ca}$. Its dry mass was about $20 \%$ of the dry mass of the original dust. The final residue could be used in the cement industry. Instead of electrowinning, the zinc in the pregnant leachates can be precipitated [121].
By adding $\mathrm{Na}_{2} \mathrm{CO}_{3}$ in $110 \%$ of the stoichiometric quantity, $95 \%$ of the zinc could be recovered at $\mathrm{pH}$ 6.5-7.5, after the addition of $\mathrm{ZnCO}_{3}$ seed crystals. The main mineralogical phases were hydrozincite $\left(\mathrm{Zn}_{5}(\mathrm{OH})_{6}\left(\mathrm{CO}_{3}\right)_{2}\right)$ and a hydrated basic zinc carbonate $\left(\mathrm{Zn}_{4}\left(\mathrm{CO}_{3}\right)(\mathrm{OH})_{6} \cdot \mathrm{H}_{2} \mathrm{O}\right)$.

Ultrasound was found to enhance the dissolution of $\mathrm{ZnFe}_{2} \mathrm{O}_{4}$ at low $\mathrm{H}_{2} \mathrm{SO}_{4}$ concentrations, and resulted in more zinc recovery under all conditions [122]. For instance, after 30 min of leaching in $0.5-\mathrm{M} \mathrm{H}_{2} \mathrm{SO}_{4}$ at $80{ }^{\circ} \mathrm{C}$, the zinc recovery was $38 \%$ for conventional leaching and $59 \%$ for ultrasound-assisted leaching, i.e., an increase of 55\%. As ultrasound brings more calcium into solution, it is assumed that it destroys the $\mathrm{CaSO}_{4}$ layer that forms on top of the $\mathrm{CaO}$ in the EAF dust. The $\mathrm{CaO}$ reacts with $\mathrm{H}_{2} \mathrm{SO}_{4}$ to $\mathrm{CaSO}_{4}$, which enhances the $\mathrm{pH}$.

\section{Hydrochloric Acid Leaching}

Hydrochloric acid $(\mathrm{HCl})$ has an extraordinary dissolving power for many oxides, hydroxides, and carbonates [123]. In contrast to $\mathrm{H}_{2} \mathrm{SO}_{4}, \mathrm{HCl}$ solutions are volatile and corrosive, but problems can be mitigated by selecting suitable materials. Steel manufacturers have experience with chloride hydrometallurgy because of steel pickling [124].

Compared to $\mathrm{H}_{2} \mathrm{SO}_{4}$, which dissolves metallic iron, and thus "blows" the iron oxide layer with $\mathrm{H}_{2}$ gas, $\mathrm{HCl}$ dissolves the oxides and forms Fe(III) ions, which prevent the hydrogen forming. Since steel makers want to remove iron oxides and not iron metal, $\mathrm{HCl}$ pickling is preferred. Furthermore, $\mathrm{HCl}$ pickling offers better surface quality and higher pickling rates. But the technology has to wait for a process by which the $\mathrm{HCl}$ is regenerated through the thermal decomposition of $\mathrm{Fe}$ (II) chloride in a spray roaster or fluid bed. Solid/liquid separation of iron precipitated from chloride solutions is easier to filter than iron precipitated in sulfate solutions. The chlorides present in the EAF dust must not be removed before $\mathrm{HCl}$ leaching [125], because the chlorides aid the leaching process. Lead and cadmium can be removed from the dust as soluble chlorides if a high concentration of chlorides is present in the lixiviant.

AMAX Inc. developed a $\mathrm{HCl}$ leaching process for EAF dust [126]. The flow sheet is shown in Fig. 14. In the first step, EAF dust is leached with $\mathrm{HCl}$. After liquid/solid separation, the solution is oxidized by chlorine gas and simultaneously neutralized by adding lime to precipitate the iron. The Fe-rich residue is free of sulfur and can be recycled to the steel furnace. Alternatively, the leach residue can be treated to recover the lead prior to being fed back to the steel plant. The Fe-free solution, following solid/liquid separation from the residue, can be further purified by solvent extraction with D2EHPA or Cyanex 272. The purified $\mathrm{ZnCl}_{2}$ electrolyte is electrolyzed and zinc metal is produced at the cathode. The chlorine gas released during electrowinning is 


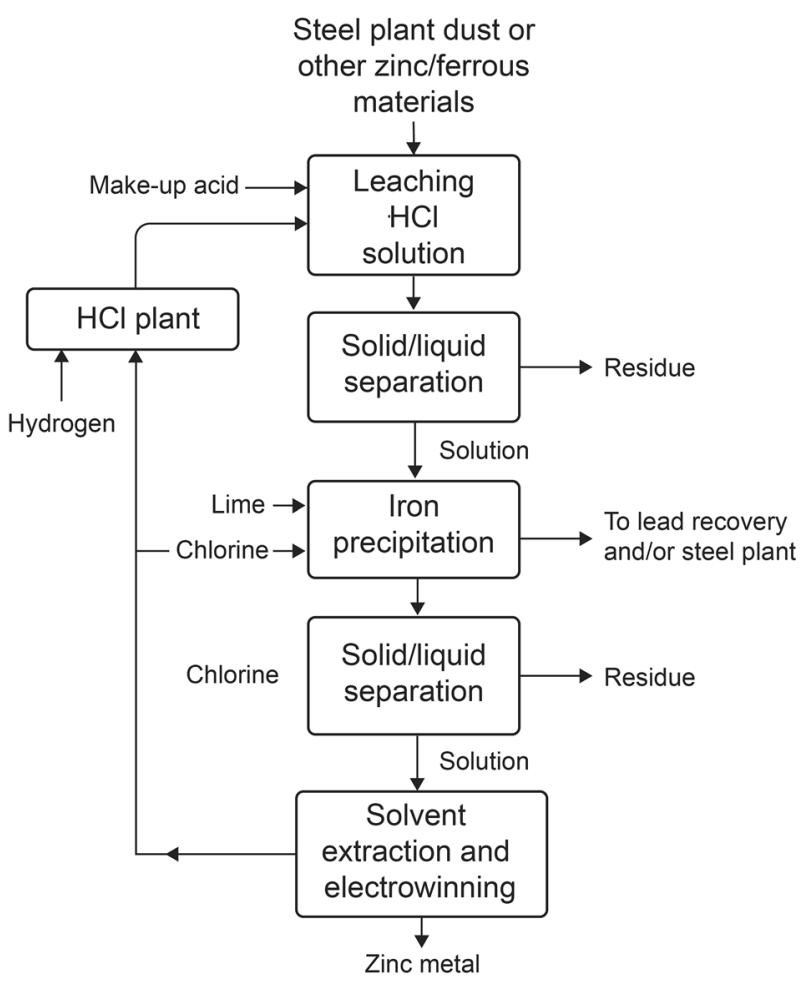

Fig. 14 Flow sheet of the AMAX $\mathrm{HCl}$ leaching process. Adapted from [126]

recycled to the system, partly as chlorine gas to oxidize the iron, and partly as $\mathrm{HCl}$ to dissolve more zinc. The process can treat many Zn-containing feed materials, not only EAF dust, and a wide range of concentrations. When a $\mathrm{HCl}$ concentration of $75 \mathrm{~g} / \mathrm{L}$ was used for leaching, $88 \%$ of the zinc and $48 \%$ of the iron were dissolved. Higher $\mathrm{HCl}$ concentrations dissolved significantly more iron; at a $\mathrm{HCl}$ concentration of $200 \mathrm{~g} / \mathrm{L}, 100 \%$ of the zinc dissolved, but also $93 \%$ of the iron. The leaching was at $90{ }^{\circ} \mathrm{C}$, because higher temperatures increased zinc recovery and the slurry was easier to filter. Leaching can also be in counter-current mode. The first stage will receive all the $\mathrm{HCl}$ and discharge the leach residue. This stage can be maintained at $\mathrm{pH} 0.5$ or lower. The last stage will receive the EAF dust and discharge the leach liquor. This stage can be operated at $\mathrm{pH} 2.5$ to 3 . A pulp density of $5-40 \%$ is recommended. Although countercurrent leaching makes best use of reagents, it is more costly (inter-stage thickeners and pumps).

Another AMAX Inc. patent describes the leaching of EAF dust with a mixture of $\mathrm{HCl}$ and $\mathrm{H}_{2} \mathrm{SO}_{4}$ [127]. The inventors claim that $\mathrm{H}_{2} \mathrm{SO}_{4}$ leaching is undesirable because the residue is hard to separate from the liquid. Likewise, direct $\mathrm{HCl}$ leaching must be avoided as it solubilizes nearly all of the iron and most of the lead, leading to a separation problem. A mixed lixiviant, on the other hand, will provide sulfate ions for the formation of $\mathrm{Pb}$ (II) sulfate, while

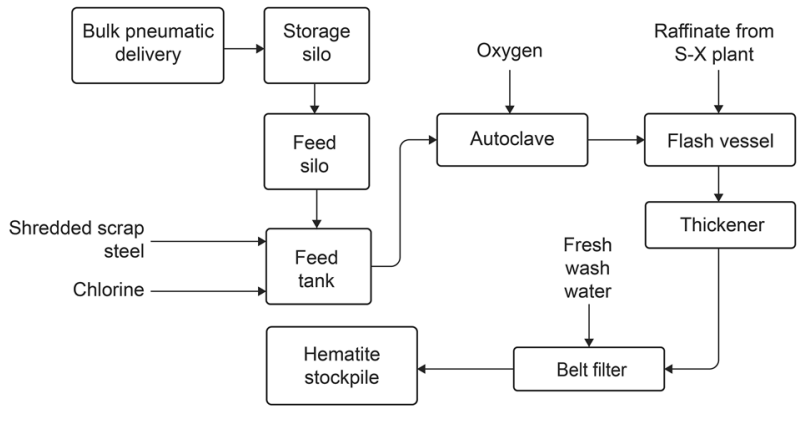

Fig. 15 Simplified flow sheet of the leaching part of the Terra Gaia process. Adapted from [129]

solubilizing zinc and aluminum. Partial dissolution of aluminum is advantageous, because it provides aluminum ions for the precipitation of fluoride ions. The mixed lixiviant allows the use of chlorine as the oxidant in the iron oxidation/precipitation stage. It is remarkable that in this patent the formation of insoluble $\mathrm{Pb}$ (II) sulfate (anglesite) is seen as an advantage, whereas it is seen as a disadvantage when leaching EAF dust with $\mathrm{H}_{2} \mathrm{SO}_{4}$.

Terra Gaia Environmental Group Inc. developed a process for leaching EAF dust with $\mathrm{FeCl}_{3}$ solution [128, 129]. Figure 15 shows a flow sheet of the leaching process. The first step is leaching the EAF dust with a $\mathrm{FeCl}_{3}$ solution at atmospheric pressure. The EAF dust is delivered to a tank, where it is mixed with a $\mathrm{FeCl}_{3}$ solution. Hydrolyzing the $\mathrm{FeCl}_{3}$ solution produces $\mathrm{HCl}$, which dissolves $\mathrm{ZnO}$ and $\mathrm{PbO}$. The concentration of $\mathrm{FeCl}_{3}$ in the solution should be sufficient to provide the stoichiometric amount of $\mathrm{Fe}^{3+}$ required to dissolve all the $\mathrm{ZnO}$ and $\mathrm{PbO}$, as well as to leave a surplus of $\mathrm{Fe}^{3+}\left(5 \mathrm{~g} / \mathrm{L}\right.$ iron as $\left.\mathrm{FeCl}_{3}\right)$ to maintain acidity. The leach solution should also contain at least $140 \mathrm{~g} / \mathrm{L}$ of chloride for the zinc solvent-extraction step. In the second step, the hydrous iron oxide slurry produced by the atmospheric leach settles sluggishly and is difficult to filter. In the conditioning step, the slurry is treated in an autoclave to convert the hydrous iron oxide slurry into a crystalline residue that can settle and be filtered. The slurry is heated in an autoclave to more than $140{ }^{\circ} \mathrm{C}$ and is held for at least $30 \mathrm{~min}$. For higher temperatures, the times are shorter. The conditioning involves the conversion of the goethite $(\alpha-\mathrm{FeOOH})$ that is stable at low temperatures, or hydrous iron oxide, to crystalline hematite $\left(\mathrm{Fe}_{2} \mathrm{O}_{3}\right)$ at temperatures above $110{ }^{\circ} \mathrm{C}$ in an acidic chloride solution: $2 \alpha-\mathrm{FeOOH} \rightarrow \mathrm{Fe}_{2} \mathrm{O}_{3}+\mathrm{H}_{2} \mathrm{O}$. The next step in the process is a liquid/solid separation, which involves hot filtration of the conditioned slurry, with brine washing, to produce the hematite residue for recycling. The hot brine washing removes the lead from the residue. The filtration and the washing require more than $80^{\circ} \mathrm{C}$ to keep the $\mathrm{Pb}$ (II) chloride in solution, but which can be recovered 
by precipitation upon cooling. Lead can be reclaimed by reacting the solid $\mathrm{Pb}(\mathrm{II})$ chloride with iron scrap in a cementation reaction: $\mathrm{Fe}^{0}+\mathrm{PbCl}_{2} \rightarrow \mathrm{Pb}^{0}+\mathrm{FeCl}_{2}$. Zinc is recovered from the filtrate by solvent extraction, followed by stripping and electrowinning. The chlorine gas evolved at the anode is used to oxidize the $\mathrm{FeCl}_{2}$ of the lead cementation step: $2 \mathrm{FeCl}_{2}+\mathrm{Cl}_{2} \rightarrow 2 \mathrm{FeCl}_{3}$. The excess chlorine gas is reacted with scrap iron to form $\mathrm{FeCl}_{3}$ : $3 \mathrm{Cl}_{2}+2 \mathrm{Fe}^{0} \rightarrow 2 \mathrm{FeCl}_{3}$. Cadmium can be removed from the circulation circuit via a bleed stream and precipitated as $\mathrm{CdS}$ by adding $\mathrm{Na}_{2} \mathrm{~S}$. Except for the washing of the leach residue, the system is closed for chloride. Any shortfall can be overcome by adding $\mathrm{NaCl}$ or spent $\mathrm{HCl}$ picking liquor.

US patent 5,709,730 discloses the leaching of EAF dust with a mixed solution of $\mathrm{CaCl}_{2}$ and $\mathrm{HCl}$, with subsequent regeneration of the $\mathrm{HCl}$ with $\mathrm{H}_{2} \mathrm{SO}_{4}$ to produce gypsum as a building material [130]. The process makes use of the low solubility of iron oxides in moderately acidic chloride solutions. Leaching is executed at $\mathrm{pH} 2.6$ at $15-30 \%$ pulp density. $\mathrm{Fe}(\mathrm{II})$ is oxidized to $\mathrm{Fe}(\mathrm{III})$ and hematite is formed by heating the slurry in an oxygen atmosphere at $90-120{ }^{\circ} \mathrm{C}$. The combination $\mathrm{CaCl}_{2} / \mathrm{HCl}$ puts more lead in solution compared to leaching with only $\mathrm{HCl}$. $\mathrm{CaCl}_{2}$ alone will not dissolve metal oxides, whereas $\mathrm{HCl}$ by itself will dissolve only a minor fraction of the lead present in the EAF dust. Lead, cadmium, and copper can be recovered by cementation with zinc powder. Adding lime to the $\mathrm{Zn}$-rich solution will precipitate the zinc as zinc hydroxide and generate a $\mathrm{CaCl}_{2}$ solution. The lixiviant can be recovered by adding $\mathrm{H}_{2} \mathrm{SO}_{4}$ to the $\mathrm{CaCl}_{2}$ solution, and clean gypsum will precipitate.

A two-stage leaching process with $\mathrm{HCl}$ was developed to extract the zinc from EAF dust $[125,131]$. The first low-acid leaching dissolves the $\mathrm{ZnO}$ from the dust, while the second step reacts $\mathrm{HCl}$ at $90{ }^{\circ} \mathrm{C}$ with the $\mathrm{ZnFe}_{2} \mathrm{O}_{4}$ residue from the first leach. $\mathrm{H}_{2} \mathrm{O}_{2}$ was found to be efficient for oxidizing $\mathrm{Fe}(\mathrm{II})$ to $\mathrm{Fe}$ (III). This oxidation could also be with aeration. The iron residue from the hot-acid leach was hematite and goethite. Fresh EAF dust was added to the filtrate after the hot-acid leach to raise the $\mathrm{pH}$ and precipitate iron. The $\mathrm{ZnCl}_{2}$ solution was purified by activated carbon to eliminate the organics and by cementation with metallic zinc powder to remove the lead, cadmium, and copper. The purified $\mathrm{ZnCl}_{2}$ solution was electrolyzed in electrowinning cells with a cation-exchange membrane to high-purity zinc metal and regenerated the $\mathrm{HCl}$. The spent electrolyte contained 1-2-M $\mathrm{HCl}$ and was used for the residue in the hot-acid leach. The zinc recovery exceeded $90 \%$. A drawback of the process is the need for the costly membrane in the cell.

Barrera-Godinez et al. investigated ultrasound leaching for the selectivity of zinc from double-kiln-treated EAF calcined with $\mathrm{CaCl}_{2}$ and $\mathrm{HCl}$ [132]. Recovery was enhanced in this way, possibly due to a combination of lixiviant pore penetration, boundary, and product layer breakdown. Iron recovery was inhibited by the ultrasound, attributed to the precipitation of any dissolved iron. The material investigated consisted largely of zincite, with a very small amount of refractory $\mathrm{ZnFe}_{2} \mathrm{O}_{4}$ phase.

\section{Nitric Acid Leaching}

Nitric acid $\left(\mathrm{HNO}_{3}\right)$ is less common for leaching EAF dust than $\mathrm{H}_{2} \mathrm{SO}_{4}$ or $\mathrm{HCl}$. However, $\mathrm{HNO}_{3}$ can give a near-zerowaste valorization of EAF dust, with iron recovered as hematite. There are no insoluble metal nitrates, so $\mathrm{HNO}_{3}$ can be regenerated by precipitating gypsum in a mixed nitrate/sulfate system. Lead is solubilized by $\mathrm{HNO}_{3}$. $\mathrm{HNO}_{3}$ processes were considered to be expensive, environmentally unfriendly, and unsafe, but this is changing. $\mathrm{HNO}_{3}$ can be recycled [133-136], and $\mathrm{HNO}_{3}$ leaching is becoming more popular in hydrometallurgy, for instance, for nickel laterites [137], where the advantage of $\mathrm{HNO}_{3}$ is not in digesting the ore, but in the way the acid can be recycled, eliminating a major cost of $\mathrm{H}_{2} \mathrm{SO}_{4}$ high-pressure leaching plants, i.e., neutralization after leaching. A hydrometallurgical $\mathrm{HNO}_{3}$ process plant can be built with modular stainless-steel equipment, i.e., no titanium-lined autoclaves are required.

Hematite produced from sulfate solutions often contains zinc and sulfate impurities, while that formed by the thermal decomposition of $\mathrm{Fe}(\mathrm{III})$ nitrate is purer [138]. The hydrolysis of $\mathrm{Fe}\left(\mathrm{NO}_{3}\right)_{3}$ requires more than $100{ }^{\circ} \mathrm{C}$ in an autoclave. However, the advantage over conventional neutralization is that the hydrolyzed product contains fewer impurities and the lixiviant can be regenerated without introducing foreign ions. Another advantage is that the precipitate has a larger particle size and is easier to filter. Fe(III) hydroxides produced at room temperature can be gelatinous and it is hard to remove any entrained mother liquor. Below $140{ }^{\circ} \mathrm{C}$, a mixture of hematite and goethite is formed, whereas above $160{ }^{\circ} \mathrm{C}$, only hematite [138]. The high-temperature precipitate was free of nitrate ions. The precipitate formed at $180{ }^{\circ} \mathrm{C}$ was dense $\left(\rho \approx 2450 \mathrm{~kg} / \mathrm{m}^{3}\right)$, while those obtained from more concentrated $\mathrm{Fe}(\mathrm{III})$ solutions were easier to filter than in the case of more dilute $\mathrm{Fe}(\mathrm{III})$ solutions.

US patent 5,912,402 discloses a $\mathrm{HNO}_{3}$-based process for the zero-waste valorization of EAF dust [139]. The dust is washed with water to remove soluble chlorides. Next, it is reacted with $\mathrm{HNO}_{3}(53 \%)$ to dissolve zinc, cadmium, copper, magnesium, calcium, manganese, and lead. The residue can be recycled to the EAF. Dissolution in $\mathrm{HNO}_{3}$ results in $\mathrm{NO}_{x}$ gases that must be recovered for reconversion to $\mathrm{HNO}_{3}$. Iron is precipitated from the filtrate by increasing the $\mathrm{pH}$ of the solution with basic $\mathrm{ZnCO}_{3}$. The dissolved lead, copper, and cadmium can be recovered by electrolysis or sulfide precipitation. The filtrate is evaporated and decomposed to obtain 
a solid residue of metal oxides and $\mathrm{Ca}\left(\mathrm{NO}_{3}\right)_{2}$. The solid residue is leached with water to solubilize the $\mathrm{Ca}\left(\mathrm{NO}_{3}\right)_{2}$, which can be crystallized from the leachate. The zinc can be separated from the manganese and magnesium by leaching with an AAC solution. After solid-liquid separation, the residue is treated with $\mathrm{H}_{2} \mathrm{SO}_{4}$ to solubilize the magnesium as $\mathrm{MgSO}_{4}$. The residue consists largely of $\mathrm{MnO}_{2}$. The filtrate of the AAC leaching step is heated to drive off the $\mathrm{CO}_{2}$ and to precipitate $\mathrm{ZnCO}_{3}$. The advantages include the recycling of the iron to the EAF and selling the other by-products. In addition, the process can be carried out at atmospheric pressure, without an autoclave, and the $\mathrm{HNO}_{3}$ can be recycled.

US patent 7,399,454 describes a process for leaching EAF dust with $\mathrm{HNO}_{3}$ at elevated temperatures and pressures, with the iron recovered as hematite [140]. The process is built on the principle that, at a certain pressure and temperature, the iron forms hematite in a $\mathrm{HNO}_{3} /$ nitrate solution. Since many of the other metal contaminants are solubilized in $\mathrm{HNO}_{3}$ when the $\mathrm{Fe}_{2} \mathrm{O}_{3}$ precipitates, the $\mathrm{Fe}_{2} \mathrm{O}_{3}$ can be separated. Before the pressure leach, an atmospheric leach in conditions at which $\mathrm{ZnO}$ dissolves, but the $\mathrm{ZnFe}_{2} \mathrm{O}_{4}$ and other iron compounds do not. Pressure leaching involves $180-220^{\circ} \mathrm{C}$ for 180 min at $15-20 \%$ pulp density with varying concentrations of $\mathrm{HNO}_{3}$. Recovering zinc from the leachate is not described here.

\section{Acetic Acid Leaching}

Acetic acid $\left(\mathrm{CH}_{3} \mathrm{COOH}\right.$, sometimes $\left.\mathrm{AcOH}\right)$ is weak compared with $\mathrm{H}_{2} \mathrm{SO}_{4}, \mathrm{HCl}$, or $\mathrm{HNO}_{3}$. Since $\mathrm{CH}_{3} \mathrm{COOH}$ is an organic acid consisting only of carbon, hydrogen, and oxygen, it does not contaminate the leaching residue with elements that are incompatible with BF, BOF, or EAF installations. $\mathrm{CH}_{3} \mathrm{COOH}$ will dissolve oxides and carbonates of calcium, zinc, and lead, but not of iron, and so can be used for selective leaching. Unfortunately, $\mathrm{CH}_{3} \mathrm{COOH}$ cannot dissolve $\mathrm{ZnFe}_{2} \mathrm{O}_{4}$.

The UBC-Chaparral Process treats EAF dust so as (1) to recover zinc, cadmium, and lead; (2) to render the EAF dust non-toxic (1990s legislation), and (3) to process it at minimum cost [141]. The process decontaminates EAF dust for sanitary landfill, rather than recovering an iron product for the steel industry. This complex process combines $\mathrm{CH}_{3} \mathrm{COOH}$ leaching for calcium removal with
Fig. 16 Generalized flow sheet for the UBC-Chaparral process. Adapted from [141]

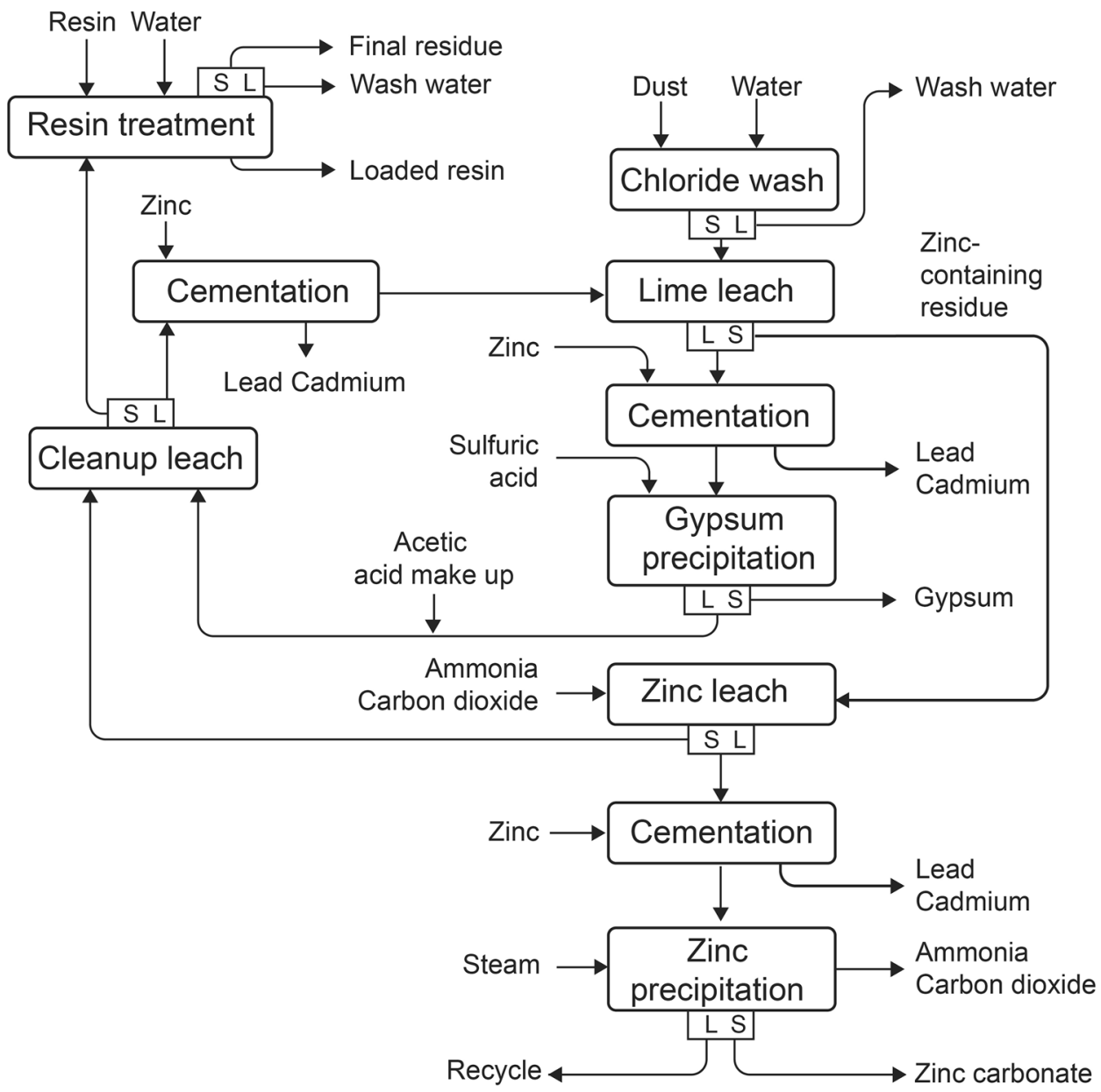




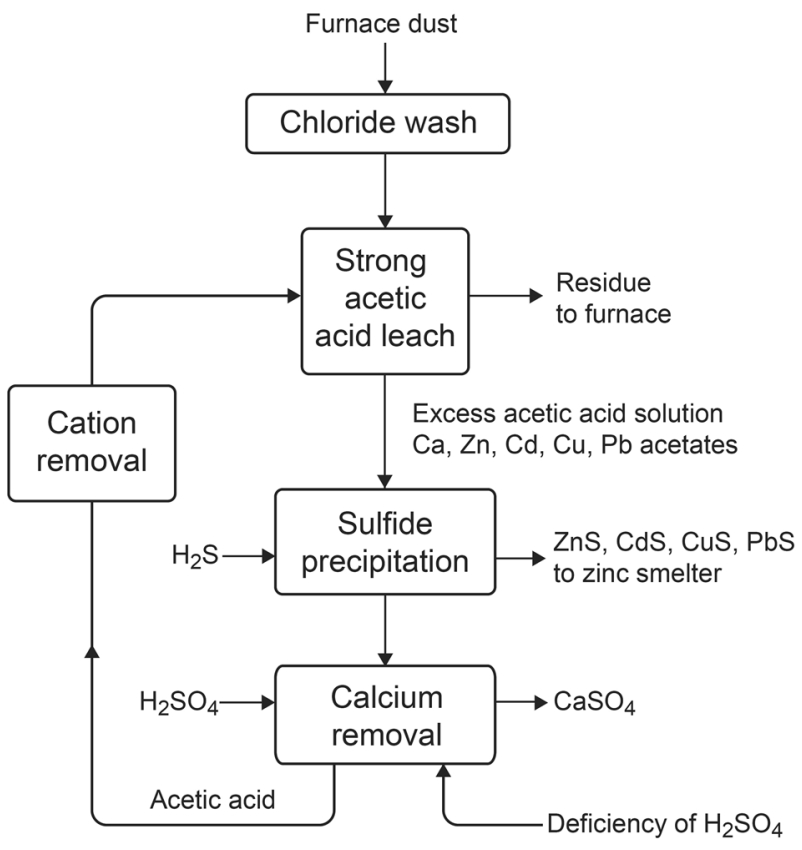

Fig. 17 Generalized flow sheet of the Hatch Acetic Acid Leach Process. Adapted from [143]

AAC leaching for zinc removal (Fig. 16). The free $\mathrm{CaO}$ is removed before the zinc leach with $\mathrm{AAC}$, so that the $\mathrm{CaO}$ does not react with $\mathrm{CO}_{2}$ to form $\mathrm{CaCO}_{3}$ (i.e., high $\mathrm{CO}_{2}$ consumption). The $\mathrm{CaO}$ and $\mathrm{CaCO}_{3}$ in the EAF dust will react with $\mathrm{CH}_{3} \mathrm{COOH}$ to form calcium acetate. The zinc acetate formed by the reaction between $\mathrm{ZnO}$ and $\mathrm{CH}_{3} \mathrm{COOH}$ will further react with the $\mathrm{CaO}$ as follows: $\mathrm{CaO}+\mathrm{Zn}(\mathrm{OAc})_{2}$ $+\mathrm{H}_{2} \mathrm{O} \rightarrow \mathrm{Ca}(\mathrm{OAc})_{2}+\mathrm{Zn}(\mathrm{OH})_{2}$. Leaching involves adding EAF dust to a 3-M $\mathrm{CH}_{3} \mathrm{COOH}$ solution close to the boiling point. Lead and calcium can be removed from the leachate by cementation with zinc powder. Calcium can be removed by the addition of $\mathrm{H}_{2} \mathrm{SO}_{4}$, precipitating gypsum and regenerating the $\mathrm{CH}_{3} \mathrm{COOH}$. The $\mathrm{Zn}$-rich residue is then leached with AAC, after which the zinc is precipitated as basic $\mathrm{ZnCO}_{2}$ by steam stripping. The final residue is resin-in-pulp treated with a very acidic cation exchanger in $\mathrm{H}^{+}$form to dissolve the lead. A preliminary economic analysis was conducted.

The Hatch Acetic Acid Leach Process is a simplified form of the UBC-Chaparral Process, developed to recover an Fe-rich residue for recycling to the steel plant rather than landfilling $[142,143]$. Figure 17 shows a flow sheet. First water removes the soluble chloride salts. Next, a 3-M $\mathrm{CH}_{3} \mathrm{COOH}$ leach at room temperature separates the easily removable elements. The pulp density is $150 \mathrm{~g} / \mathrm{L}$. The leach residue is separated by filtration, washed, pelletized, and recycled to the EAF to recover the iron. $\mathrm{CH}_{3} \mathrm{COOH}$ leaching removes zinc and lead from EAF dust to bleed them from

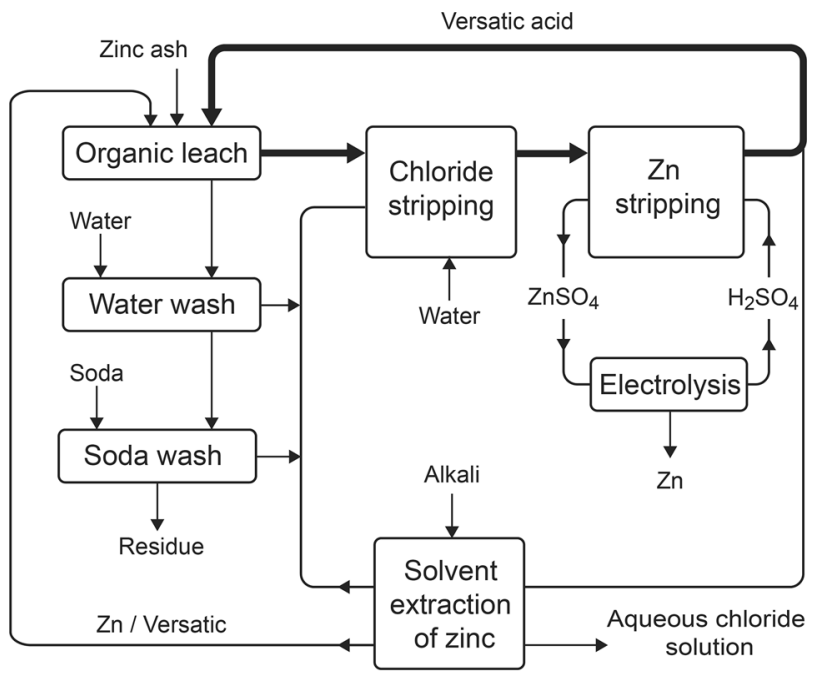

Fig. 18 Flow sheet of the Versatic acid leaching process. Adapted from [148]

the recycling process. The zinc, cadmium, lead, and copper are precipitated as a sulfide product using a stream of $\mathrm{H}_{2} \mathrm{~S}$ gas. The sulfide precipitation simplifies the process, because the metals are recovered as useful sulfides, while regenerating the $\mathrm{CH}_{3} \mathrm{COOH}$. The filtrate is then treated with $\mathrm{H}_{2} \mathrm{SO}_{4}$ to precipitate the calcium as a clean gypsum, which can be sold, and reform the $\mathrm{CH}_{3} \mathrm{COOH}$. Adding the correct amount of $\mathrm{H}_{2} \mathrm{SO}_{4}$ avoids any excess of sulfate ions. The remaining solution is treated with a strong acetic cation exchanger to remove the $\mathrm{Mg}^{2+}$ and other cations, and a weakly basic anion exchanger in $\mathrm{OH}^{-}$form to remove the chloride and sulfate anions. The cation exchanger can be regenerated by $\mathrm{H}_{2} \mathrm{SO}_{4}$, the anion exchanger by $\mathrm{NaOH}$. The $\mathrm{CH}_{3} \mathrm{COOH}$ after the ionexchange step is too dilute to recycle to the leach step, and so must be concentrated. The process minimizes the quantity of liquid effluents that require treatment before discharge. All the products are solid and either commercially valuable or recyclable in a steel-plant furnace. The Hatch Acetic Acid Leaching Process is attractive if no $\mathrm{ZnFe}_{2} \mathrm{O}_{4}$ has to be recovered. That it has not been developed further is probably due to the price of $\mathrm{CH}_{3} \mathrm{COOH}$.

Siebenhofer et al. investigated leaching EAF dust with $\mathrm{CH}_{3} \mathrm{COOH}$ in concentrations of $25 \%$ to $100 \%$ [144]. For $80 \% \mathrm{CH}_{3} \mathrm{COOH}, 90-93 \%$ of zinc and $5-7 \%$ of iron were extracted. For $100 \%$ glacial acetic acid, the zinc $(35 \%)$ and iron $(0.6 \%)$ extractions were much lower with water present. This leaching process can be considered as a pure "solvometallurgical" process. Lead was recovered as $\mathrm{PbSO}_{4}$ by adding $\mathrm{H}_{2} \mathrm{SO}_{4}$, while zinc required electrowinning. The solubility of the zinc from EAF dust in aqueous $\mathrm{CH}_{3} \mathrm{COOH}$ was nearly twice that of analytical-grade zinc acetate [145]. The solubility of zinc acetate is also highly temperature dependent. The $\mathrm{CH}_{3} \mathrm{COOH}$ leaching of EAF dust is negatively 
affected by an acid excess, while zinc can be electrowon from a zinc acetate solution [146].

\section{Versatic Acid Leaching}

A solvometallurgical process has been developed to recover zinc from chloride-containing solid residues, e.g., EAF dust and the crude $\mathrm{ZnO}$ of the Waelz process [147-149]. It is based on reacting fine-grained $\mathrm{ZnO}$ with acidic extractants, particularly carboxylic acids, like naphthenic and Versatic (a mixture of branched carboxylic acids with 10 carbon atoms). A flow sheet is shown in Fig. 18.

The carboxylic acids are used as a $30 \%$ solution in an aliphatic diluent. The co-dissolved chlorides can be scrubbed from the organic phase with water. After this, the organic phase is chloride-free and contains only the dissolved zinc carboxylate salt. Zinc can be stripped from the loaded organic phase by $\mathrm{H}_{2} \mathrm{SO}_{4}$, resulting in a $\mathrm{ZnSO}_{4}$ solution, from which the zinc metal can be electrolyzed. Alternatively, the $\mathrm{ZnSO}_{4}$ can be crystallized $\left(\mathrm{ZnSO}_{4} \cdot 7 \mathrm{H}_{2} \mathrm{O}\right)$ by stripping the organic phase with an excess of $\mathrm{H}_{2} \mathrm{SO}_{4}$. After stripping the zinc with $\mathrm{H}_{2} \mathrm{SO}_{4}$, the carboxylic acid is regenerated to leach a new batch. After leaching, the solid residue is decontaminated with hot water and $\mathrm{Na}_{2} \mathrm{CO}_{3}$ solution. The residue from the zinc ash was mainly metallic zinc particles, while the residue from the flue dust was $\mathrm{Pb}$-rich.

To separate the zinc from the iron, the Versatic acid leaching step can be combined with solvent extraction. $\mathrm{ZnO}$ is leached with a $30 \%$ solution of Versatic acid in an aliphatic diluent. After subsequent contact between the zinc-containing organic phase and an iron-containing $\mathrm{ZnSO}_{4}$ solution, an exchange between the zinc and iron takes place. The iron is transferred to the organic phase, where it is present as an $\mathrm{Fe}(\mathrm{III})$ versatate complex. In this exchange, an equivalent amount of zinc passes from the organic phase to the $\mathrm{ZnSO}_{4}$ solution. This completely removes the iron from the $\mathrm{ZnSO}_{4}$

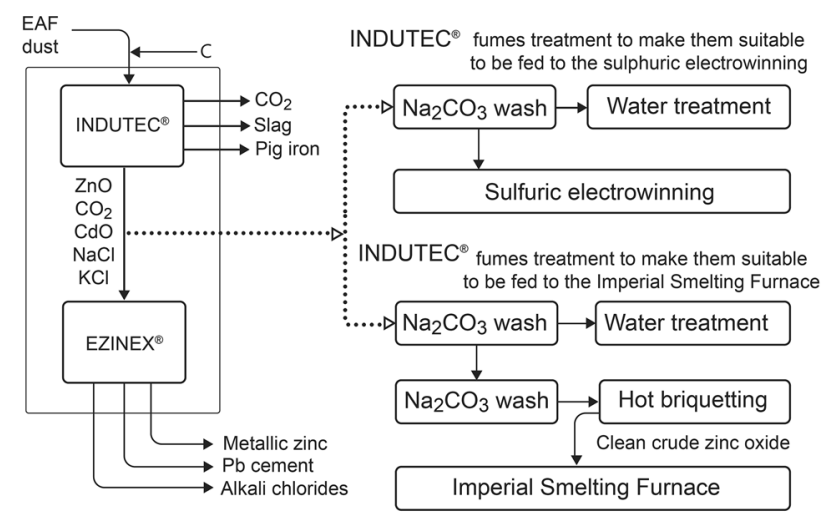

Fig. 19 Conceptual flow sheet of the combined INDUTEC/EZINEX Process. Adapted from [154] solution through the contact between two immiscible phases. This involves one or more stages, depending on the technical procedure. Iron can be stripped from the organic phase by bringing it into contact with $\mathrm{H}_{2} \mathrm{SO}_{4}$ or another mineral acid in one or more stages. In this way, the Versatic acid can be regenerated and is ready to be loaded with zinc when reacted with solid $\mathrm{ZnO}$. Instead of Versatic acid, extractants such as D2EHPA can be used. With this approach, it is also possible to separate zinc from copper.

\section{Ammonium Chloride Leaching}

The advantage of ammonium chloride $\left(\mathrm{NH}_{4} \mathrm{Cl}\right)$ leaching is that the solution $\mathrm{pH}$ remains almost neutral (pH 6-7) [150], contains few dissolved impurities, and is totally iron-free.

The INDUTEC/EZINEX process is the only hydrometallurgical treatment that operates on an industrial scale [151-154]. In the 1990s, the Italian company Engitec developed the EZINEX ("Engitec zinc extraction") process and a pilot plant to treat $\mathrm{Zn}$-bearing EAF dust. In the following year, a plant producing 2000 tons/year of cathode zinc was introduced. A thermal pilot plant for converting Zn-bearing materials to crude $\mathrm{ZnO}$ (C.Z.O.) was also built. This thermal fuming process, called INDUTEC, is based on an induction furnace. The first industrial scale EZINEX plant produced zinc directly from EAF dust. Several tests using a C.Z.O. feed were run in this plant, and the results were promising. C.Z.O. simplified the problem of the EZINEX process: the recovery of zinc from $\mathrm{ZnFe}_{2} \mathrm{O}_{4}$. EZINEX leaching involves a hot concentrated $\mathrm{NH}_{4} \mathrm{Cl}+\mathrm{NaCl}$ solution. The $\mathrm{ZnO}$ is almost $100 \%$ leached, but the $\mathrm{ZnFe}_{2} \mathrm{O}_{4}$ is unleached. When there are solubility problems, the leaching is at 70 to $80{ }^{\circ} \mathrm{C}$, making it a very quick operation. The leaching residue with all the iron and $\mathrm{ZnFe}_{2} \mathrm{O}_{4}$ is then recycled to the thermal system that generated the C.Z.O. The lead, cadmium, and copper are removed by cementation with zinc powder. The chloride solution is electrowon with titanium cathode blanks and graphite anodes at $65{ }^{\circ} \mathrm{C}$ to avoid solubility problems. The electro-active complex should be $\left[\mathrm{Zn}\left(\mathrm{NH}_{3}\right)_{2}\right] \mathrm{Cl}_{2}(5 \mathrm{~g} / \mathrm{L})$. Chlorine gas reacts with $\mathrm{NH}_{3}$ at the anode to form $\mathrm{N}_{2}$ and $\mathrm{HCl}$ without any hydrogen gas, which means a high current efficiency. However, a major drawback of zinc electrowinning from chloride solutions is the evolution of chlorine gas at the anode, instead of oxygen. This problem can be overcome by a cationic perm-selective membrane using $\mathrm{H}_{2} \mathrm{SO}_{4}$ in the anodic compartment to evolve oxygen at the anode. However, this is not devoid of technical issues. Calcium and magnesium are removed from the spent electrolyte by adding $\mathrm{Na}_{2} \mathrm{CO}_{3}$ or $\mathrm{NaHCO}_{3}$ to precipitate $\mathrm{CaCO}_{3}$ and $\mathrm{MgCO}_{3}$. The presence of $\mathrm{Ca}^{2+}$ ions keeps the number of fluoride ions very low due to $\mathrm{CaF}_{2}$ precipitation. $\mathrm{HCl}$ and $\mathrm{NaCl}$ are removed from the filtrate of the carbonation step by evaporation and 
crystallization. Figure 19 shows a flow sheet of the combined INDUTEC/EZINEX process.

Pedrosa et al. compared the leaching of EAF dust with $\mathrm{H}_{2} \mathrm{SO}_{4}, \mathrm{HCl}$, and $\mathrm{NH}_{4} \mathrm{Cl}$ [155]. $\mathrm{NH}_{4} \mathrm{Cl}$ was more selective, but less effective for zinc recovery, whereas the acids were more effective, but less selective. $\mathrm{NH}_{4} \mathrm{Cl}$ is very good for iron rejection. Rao et al. reported leaching in an $\mathrm{NH}_{3} / \mathrm{NH}_{4} \mathrm{Cl}$ solution containing nitrilotriacetic acid (NTA) as a complexing agent for leaching of low-grade $\mathrm{ZnO}$ [156]. The complex formation between NTA and zinc ions enhanced the zinc dissolution.

\section{Ammonia-Ammonium Carbonate (AAC) Leaching}

Leaching with ammonium-ammonium carbonate (AAC) solutions has advantages [157]. The lixiviant can be prepared by reacting $\mathrm{NH}_{3}$ and $\mathrm{CO}_{2}$, which are among the cheapest chemicals. Furthermore, they can be recycled in a process with minimal environmental impact. $\mathrm{NH}_{3}-\left(\mathrm{NH}_{4}\right)_{2} \mathrm{CO}_{3}$ can dissolve $\mathrm{ZnO}$, but not $\mathrm{ZnFe}_{2} \mathrm{O}_{4}$. The processes are as follows: (1) leaching with $\mathrm{NH}_{3}-\left(\mathrm{NH}_{4}\right)_{2} \mathrm{CO}_{3}$; (2) purification by cementation with zinc powder; (3) air oxidation to precipitate iron as $\mathrm{Fe}(\mathrm{OH})_{3}$; (4) process to recover $\mathrm{NH}_{3}$; and (5) precipitation of zinc as basic $\mathrm{ZnCO}_{2}$ by steam heating. During the steam heating, $\left(\mathrm{NH}_{4}\right)_{2} \mathrm{CO}_{3}$ is decomposed into $\mathrm{NH}_{3}$ and $\mathrm{CO}_{2}$; (6) recovery of $\mathrm{NH}_{3}$ and $\mathrm{CO}_{2}$, and recycling of the leachant to the depleted solution; and (7) calcination of the basic $\mathrm{ZnCO}_{2}$ to $\mathrm{ZnO}$.

US patents 4,071,357 [158] and 5,538,532 [159] disclose the AAC leaching process for EAF dust, Waelz oxide, and C.Z.O [160]. Leaching must be below $60{ }^{\circ} \mathrm{C}$ or under pressure. While heating is preferred, excessive heating results in the undesirable evolution of $\mathrm{NH}_{3}$ and $\mathrm{CO}_{2}$, limiting the capacity to dissolve zinc and risking the premature precipitation of zinc. A stoichiometric excess of $\mathrm{NH}_{3}$ is required to keep the zinc in solution as the ammine complex. In general, the excess $\mathrm{NH}_{3}$ is such that the ratio $\mathrm{NH}_{3}$ to $\mathrm{CO}_{2}$ is 3:1. Steam stripping can remove the $\mathrm{NH}_{3}$ in the steam vapor. The $\mathrm{NH}_{3}$ and $\mathrm{CO}_{2}$ stripped during the precipitation of basic $\mathrm{ZnCO}_{2}$ can be recovered in a condenser-absorber to regenerate the lixiviant, so only steam is required as a process input. When cool, the residual solution can be recycled to the condenser-absorber to reconstitute the lixiviant or discarded to get rid of the chloride salts. The calcination requires a suitable calcining vessel to decompose the basic $\mathrm{ZnCO}_{2}$ at $250-600{ }^{\circ} \mathrm{C}$. Aeration after leaching can oxidize the iron present as $\mathrm{Fe}$ (II) and precipitate $\mathrm{Fe}$ (III) hydroxides.

The leaching capacity is affected by the $\mathrm{NH}_{3}$ and carbonate in solution [158]. These substances are regulated by adding $\mathrm{NH}_{3}$ and $\mathrm{CO}_{2}$, respectively. More free $\mathrm{NH}_{3}$ increases the total leaching capacity with respect to zinc, by a tendency to form metal ammine complexes. On the other hand, an increase in $\mathrm{CO}_{2}$ acts in the opposite direction, with an

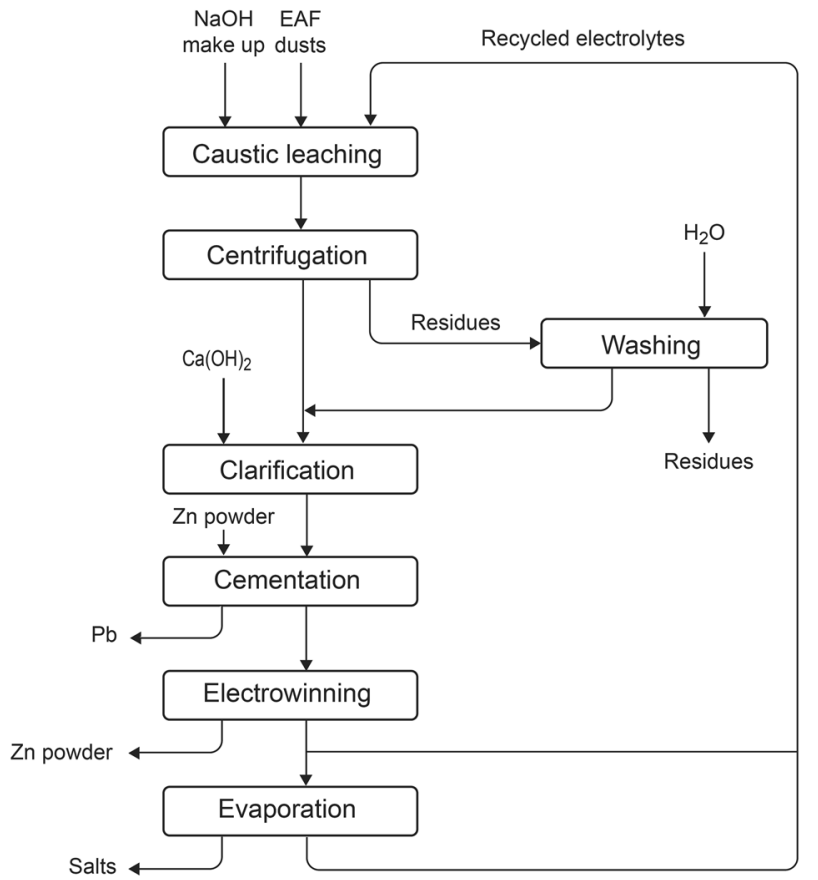

Fig. 20 Flow sheet of the Cebedeau Process for EAF dust. Adapted from [165]

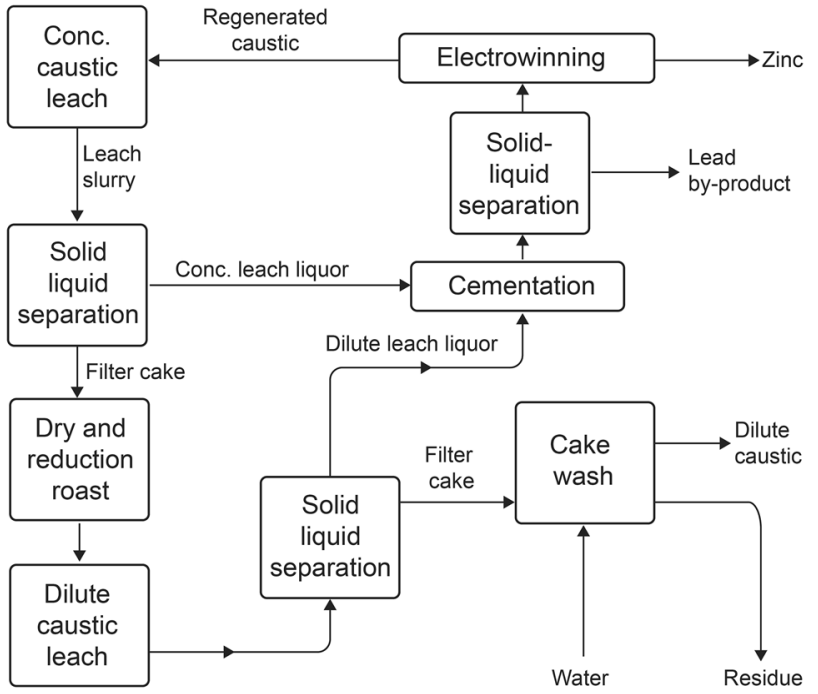

Fig. 21 Flow sheet of the Cardiff Process for EAF dust. Adapted from [165]

increased tendency to form soluble carbonates. The addition of $\mathrm{NH}_{3}$ should be enough for the sum of $\mathrm{NH}_{3}$ and ammonium to be 3-7 mol/L. The addition of $\mathrm{CO}_{2}$ should be enough for the sum of the carbonate and hydrogen carbonate ions to be $1-3 \mathrm{~mol} / \mathrm{L}$.

After the AAC leaching of $\mathrm{ZnO}$, iron can be removed by oxidation [161]. Varga and Torok describe the AAC 
leaching of EAF dust [162], where $\mathrm{ZnCO}_{2}$ is precipitated by bubbling of $\mathrm{CO}_{2}$ gas, followed by steam distillation. Ruiz et al. reported that the ammonium carbonate concentration (60-200 g/L) had hardly any influence on the leaching of zinc [163]. The average zinc recovery was $45 \%$. The solution needs $80-90{ }^{\circ} \mathrm{C}$ to drive out the $\mathrm{NH}_{3}$ and $\mathrm{CO}_{2}$, with the gases used to reform the lixiviant. Wylock et al. developed a model to predict the time evolution of $\mathrm{pH}$ during the injection of $\mathrm{CO}_{2}$ in aqueous solutions of $\mathrm{NH}_{3}$ and ammonium carbonate during the leaching of Waelz oxides [164].

\section{Alkaline Leaching}

The motivation for the leaching of EAF dust with $\mathrm{NaOH}$ solutions is the high rejection rate for iron and the compatibility with the alkaline electrowinning of zinc. The approach is based on the amphoteric character of $\mathrm{ZnO}$, cadmium oxide, and $\mathrm{Pb}$ (II) oxide, which dissolve in an alkaline solution, unlike Fe(III) oxide. This is similar to the dissolution of aluminum oxide from bauxite in the Bayer process, where $\mathrm{Fe}$ (III) oxide is not dissolved. However, the conditions used for alkaline leaching of EAF dust are milder than those of the Bayer process. The concentration of the $\mathrm{NaOH}$ solution is $5 \mathrm{M}$ or higher, which means high reagent consumption. Moreover, it is difficult to remove the sodium after leaching, which is a problem for reuse of the iron residue in the BF. Also, alkaline leaching (also called caustic leaching) is much slower than with acids, $\mathrm{ZnFe}_{2} \mathrm{O}_{4}$ cannot be dissolved, and $\mathrm{NaOH}$ is more expensive than $\mathrm{H}_{2} \mathrm{SO}_{4}$.

In the Cebedeau Process, EAF dust is leached in hot $\left(95^{\circ} \mathrm{C}\right)$ concentrated $\mathrm{NaOH}(6-12 \mathrm{M})$ for $1-2 \mathrm{~h}$ to dissolve the zinc, lead, and cadmium [165]. The flow sheet is shown in Fig. 20. It was developed commercially in France in 1986. However, the plant closed due to problems with filtration. The recovery of zinc is dependent on the amount of zinc that is present in $\mathrm{ZnFe}_{2} \mathrm{O}_{4}$, since this phase is not solubilized. For the tested EAF dust, $65-85 \%$ of the zinc and $70-85 \%$ of the lead were recovered. Centrifuging separated the leachate from the solid residue, which is precipitated in a thickener with starch $(1 \mathrm{~kg} / \mathrm{ton})$ as a flocculant. After washing with water, the residue was ready for disposal. The filtrate was clarified by adding a calcium hydroxide solution. Lead and cadmium were removed by cementation with zinc powder. The $\mathrm{Pb}$-free purified solution was electrolyzed to produce high-quality zinc metal.

In the early 1980s, there was a pilot facility for treating EAF dust at Cardiff University (Wales, UK) (Fig. 21) [165]. The Cardiff Process is similar to the Cebedeau process, but used centrifugal filtration for solid-liquid separation and a magnetic separator. The solids settling was very slow, the centrifugal separation disappointing, and the flocculants and filters were unsuccessful. Another difference was the Cardiff Process had reduction roasting to break down the $\mathrm{ZnFe}_{2} \mathrm{O}_{4}$, present in the leach residue. The Cardiff process was able to recover $85-90 \%$ of the zinc.

Mordogan et al. investigated leaching in solutions with a low concentration of $\mathrm{NaOH}(3.75 \mathrm{M})$, but the zinc yield was only about $21 \%$ [166]. Dutra et al. achieved $76 \%$ at a $\mathrm{NaOH}$ concentration of $6 \mathrm{M}$ and $90{ }^{\circ} \mathrm{C}$ [167]. Orhan used even more drastic conditions $\left(10-\mathrm{M} \mathrm{NaOH}, 95^{\circ} \mathrm{C}\right)$ and achieved 95\% recovery [168]. Palimaka et al. investigated zinc extraction from EAF dust and found $88 \%$ for $8-\mathrm{M} \mathrm{NaOH}$ at $80{ }^{\circ} \mathrm{C}$ and a liquid-to-solid ratio of 40 [169]. However, these yields are hard to compare because the different types of EAF dust. It is important to note that $\mathrm{ZnFe}_{2} \mathrm{O}_{4}$ is, once more, not dissolved under these conditions.

Although $\mathrm{ZnFe}_{2} \mathrm{O}_{4}$ cannot be dissolved in a $\mathrm{NaOH}$ solution, it can be decomposed by roasting with $\mathrm{NaOH}$ at $350-450{ }^{\circ} \mathrm{C}$ [170]. Although the authors called it "caustic roasting," "caustic fusion," or "alkali fusion," there are more appropriate terms because the $\mathrm{NaOH}$ is above its melting point of $318{ }^{\circ} \mathrm{C}$. This treatment transfers the $\mathrm{ZnFe}_{2} \mathrm{O}_{4}$ in soluble sodium zincate $\left(\mathrm{Na}_{2} \mathrm{ZnO}_{2}\right)$ and insoluble hematite $\left(\mathrm{Fe}_{2} \mathrm{O}_{3}\right)$. After the caustic roasting process, the EAF dust can be leached with a dilute $\mathrm{NaOH}$ solution, with zinc recoveries in excess of $95 \%$. The zinc can be reclaimed as zinc metal with alkaline electrolysis. The main disadvantage of this process is the large quantities of $\mathrm{NaOH}$ : depending on the zinc content of the EAF dust, $100-500 \mathrm{~kg}$ of $\mathrm{NaOH}$ per ton of EAF dust is required. It was reported that zinc recovery from synthetic $\mathrm{ZnFe}_{2} \mathrm{O}_{4}$ by alkali fusion could be increased by hydrolyzing with water or dilute $\mathrm{NaOH}$ prior to the fusion step [171, 172], although the mechanism for this pre-treatment is not clear. Lenz and Martins applied this method to EAF dust and recovered the dissolved lead as $\mathrm{PbS}$ by adding $\mathrm{Na}_{2} \mathrm{~S}$, with the zinc recovered as $\mathrm{ZnS}$ by adding $\mathrm{Na}_{2} \mathrm{~S}$ to the solution [173].

$\mathrm{ZnFe}_{2} \mathrm{O}_{4}$ has been decomposed by roasting with lime $(\mathrm{CaO})$. Xie et al. heated $\mathrm{ZnFe}_{2} \mathrm{O}_{4}$ with lime at $1000{ }^{\circ} \mathrm{C}$ for $4 \mathrm{~h}$ ("calcified roasting") [174]. This treatment transforms the $\mathrm{ZnFe}_{2} \mathrm{O}_{4}$ into $\mathrm{ZnO}$ and $\mathrm{Ca}_{2} \mathrm{Fe}_{2} \mathrm{O}_{5}$ in the reaction: $\mathrm{ZnFe}_{2} \mathrm{O}_{4}+2 \mathrm{CaO} \rightarrow \mathrm{ZnO}+\mathrm{Ca}_{2} \mathrm{Fe}_{2} \mathrm{O}_{5}$. After roasting the solid was leached with $\mathrm{NH}_{3}$ and $\mathrm{NH}_{4} \mathrm{Cl}$ to dissolve the $\mathrm{ZnO}$. Zinc recoveries were close to $90 \%$. Yakornov et al. roasted EAF dust with lime at $1400{ }^{\circ} \mathrm{C}$ to decompose the $\mathrm{ZnFe}_{2} \mathrm{O}_{4}$. The $\mathrm{ZnO}$ formed could be dissolved in 4-M NaOH [175]. Chairaksa-Fujimoto et al. used $\mathrm{ZnO}$ dissolution in 2-M $\mathrm{NaOH}$ for a liquid-to-solid ratio of 300 [176].

Zhang et al. ball-milled $\mathrm{ZnFe}_{2} \mathrm{O}_{4}$ with metallic iron (2:1 molar ratio $\mathrm{Fe}: \mathrm{ZnFe}_{2} \mathrm{O}_{4}$ ), prior to leaching with $6 \mathrm{M}$ $\mathrm{NaOH}$ at $90{ }^{\circ} \mathrm{C}$ [177]. The metallic iron reduced Fe(III) in the $\mathrm{ZnFe}_{2} \mathrm{O}_{4}$ lattice to $\mathrm{Fe}(\mathrm{II})$, making it more susceptible to leaching. Some $70 \%$ of zinc could be extracted from the mechanochemically reduced $\mathrm{ZnFe}_{2} \mathrm{O}_{4}$, compared to less than 
$2 \%$ from untreated $\mathrm{ZnFe}_{2} \mathrm{O}_{4}$. However, the process would be difficult to upscale.

Microwave-assisted alkali leaching of EAF dust resulted in the rapid dissolution of $\mathrm{ZnO}$ [178]. Leaching took minutes, whereas several hours were required for conventional leaching to achieve the same recovery. With microwave heating, the zinc recoveries were 10-15\% higher than with conventional heating, which indicates that some $\mathrm{ZnFe}_{2} \mathrm{O}_{4}$ dissolved. The optimum $\mathrm{NaOH}$ concentration was $8 \mathrm{M}$.

\section{Leaching with Deep-Eutectic Solvents}

Deep-eutectic solvents (DESs) are an alternative to volatile organic solvents [179-181]. Most DESs are mixtures of choline chloride and a hydrogen-bond donor (urea, ethylene glycol, malonic acid, lactic acid, citric acid) or mixtures of choline chloride with a hydrated metal salt. DESs have much lower melting points than their individual components. Popular DESs are obtained by mixing chloride and urea in a 1:2 molar ratio, or choline chloride and ethylene glycol in a 1:2 molar ratio. These solvents are liquid at room temperature. DESs are relatively cheap, but more expensive than conventional lixiviants. They often have a significant water content, but their properties are different from those of aqueous solutions. It is claimed that DESs can be easily recycled, but their long-term stability is questionable. Moreover, DESs can be very corrosive due to their high chloride content. Another disadvantage is their high viscosity, especially with a low water content, making solid/liquid separations difficult.

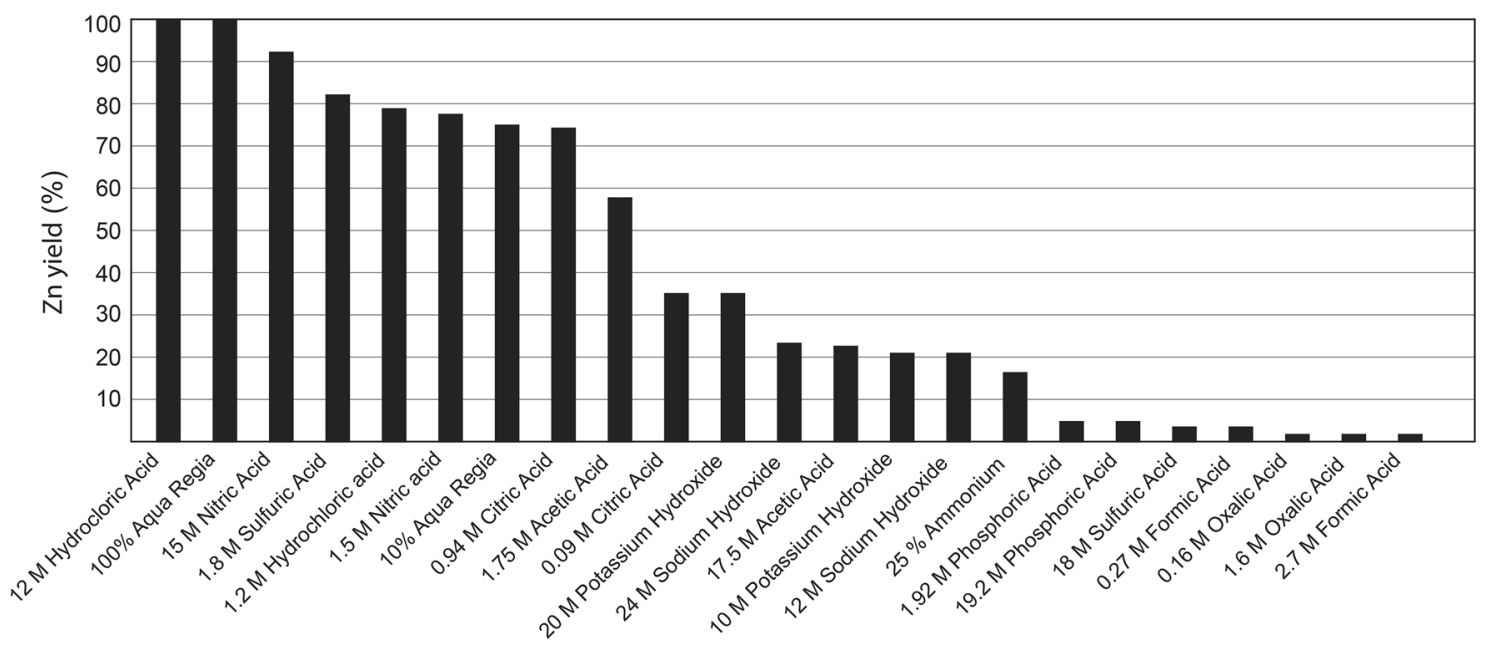

Fig. 22 Yield of zinc leaching from EAF dust in 27 different leaching media, in order of descending metal dissolution. Adapted from [186]

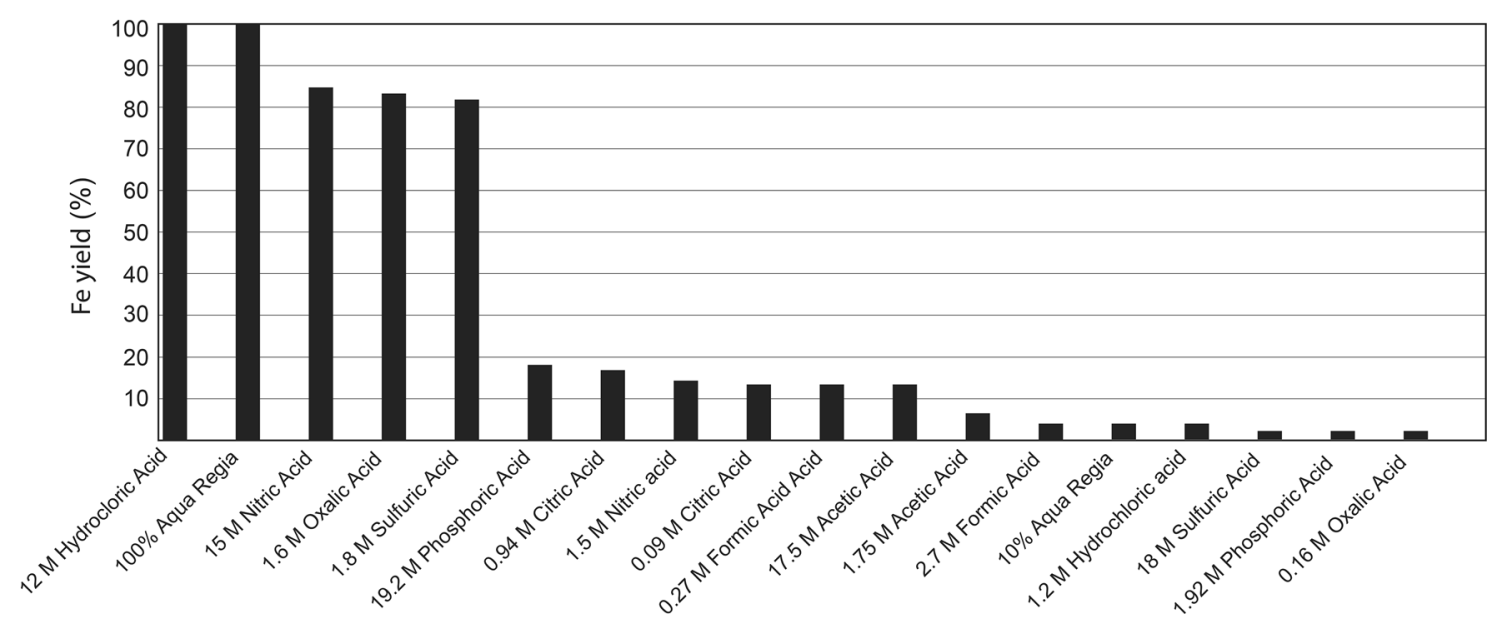

Fig. 23 Yield of iron leaching from EAF dust in 27 different leaching media, in order of descending metal dissolution. Adapted from [186] 
Abbott et al. developed a DES process to extract the lead and zinc from EAF dust. The DES choline chloride:urea (1:2) selectively dissolves $\mathrm{ZnO}$ and lead oxide, but has negligible solubility for iron oxides [182]. DESs based on urea can dissolve large amounts of $\mathrm{ZnO}$ and have high selectivity of zinc over iron, in contrast to DESs based on carboxylic acids. After the dissolution, lead and zinc can be recovered by electrodeposition. However, the high viscosity of the DES (about $800 \mathrm{cP}$ at $25^{\circ} \mathrm{C}$ ) resulted in impeded pumping and a more difficult separation of the DES from the undissolved solids by filtration. A leaching time of $48 \mathrm{~h}$ at $60{ }^{\circ} \mathrm{C}$ was used. The viscosity could be reduced by adding ethylene glycol to the choline chloride:urea DES [183]. A DES with the composition choline chloride:ethylene glycol:urea in the molar ratios 1:1.5:0.5 had a viscosity of $56 \mathrm{cP}$ at room temperature. A pulp density of up to $7 \mathrm{wt} \%$ was used, with a digestion time of at least $24 \mathrm{~h}$. The fine-particulate EAF dust powder decreased the viscosity of the DES. Hardly any iron was co-dissolved $(<1 \mathrm{ppm})$. The DES can dissolve part of the $\mathrm{ZnFe}_{2} \mathrm{O}_{4}$, but only very slowly, i.e., the extraction of zinc was incomplete after $72 \mathrm{~h}$. Lead was recovered by cementation with zinc dust, and zinc chloride could be precipitated by adding aqueous $\mathrm{NH}_{3}$. The electrowinning of zinc showed that the process was very slow and that the current efficiency was poor. A pilot plant was built to process $5 \mathrm{~kg}$ EAF dust batches. It consisted of a $125 \mathrm{~L}$ extraction tank, two $25 \mathrm{~L}$ cementation tanks, and a $12 \mathrm{~L}$ electrolysis cell. Difficulties were experienced with solid/liquid separation. The cementation of lead was efficient, with levels below $12 \mathrm{ppm}$. $\mathrm{NH}_{3}$ could be boiled off the precipitate, leaving pure zinc chloride. Bakkar repeated the work of Abbott et al. for choline chloride:urea (1:2) [184] and the 1-M chloride:1.5M urea:0.5-M ethylene glycol systems [185], but provided no additional information.

\section{Miscellaneous Lixiviants}

Halli et al. leached EAF dust with 16 different lixiviants in 27 conditions, focusing on five elements: zinc, iron, lead, chromium, and manganese [186]. The objective was to selectively leach zinc and lead to leave a recyclable Fe-rich material for the steel plant. The four lixiviants with the highest zinc extraction $(>75 \%)$ and the lowest iron extraction $(<10 \%)$ were $10 \%$ aqua regia, $1.2-\mathrm{M} \mathrm{HCl}, 0.94-\mathrm{M}$ citric acid, and 1.5- $\mathrm{M} \mathrm{HNO}_{3}$. There was also partial dissolution of lead, chromium, and manganese. The best for lead removal was $1.75-\mathrm{M}$ acetic acid. The results for zinc and iron are in Figs. 22 and 23, respectively. In a follow-up study, leaching with citric acid, which can dissolve $\mathrm{ZnO}$ but not $\mathrm{ZnFe}_{2} \mathrm{O}_{4}$, was investigated in more detail [187]. Halli et al. alkali roasted with $\mathrm{NaOH}$ at $450{ }^{\circ} \mathrm{C}$ as a pre-treatment for $\mathrm{ZnFe}_{2} \mathrm{O}_{4}$ decomposition, followed by leaching with $0.8-\mathrm{M}$ citric acid at $40{ }^{\circ} \mathrm{C}$ with oxygen purging for $2 \mathrm{~h}$ [187]. All of the zinc was leached, more than $80 \%$ of the lead, and with less than $10 \%$ co-dissolution of iron. A study of leaching EAF dust in organic acids (formic, acetic, and citric acid) confirmed that citric acid had the highest zinc yield ( $>75 \%$ ), with less than $20 \%$ iron co-dissolution [188]. The co-dissolution of lead by citric acid is seen as an advantage. Acetic acid $(1.75 \mathrm{M})$ was the second best. All the organic acids dissolved $\mathrm{ZnO}$, but not $\mathrm{ZnFe}_{2} \mathrm{O}_{4}$. The citric acid needs to be $0.8-0.9 \mathrm{M}$ for good zinc recovery, which means dilute citric acid waste streams (e.g., from fermentation) cannot be used. High concentrations of citric acid (3.0 M) removed $99 \%$ of the lead from EAF dust [189], while removing 54\% of the zinc and $6 \%$ of the iron. In a follow-up study, Halli et al. recovered lead and zinc from a citric acid leach solution [190]. The lead precipitated as $\mathrm{PbSO}_{4}$ by adding $\mathrm{H}_{2} \mathrm{SO}_{4}$ to a pH of 2 . The zinc was extracted with D2EHPA and Cyanex 572. The best results were for D2EHPA.

Wang et al. leached EAF dust with $\left(\mathrm{NH}_{4}\right) \mathrm{Fe}\left(\mathrm{SO}_{4}\right)_{2} \cdot 12 \mathrm{H}_{2} \mathrm{O}$ [191]. The reagent dissolved upon heating in its own crystal water and ionized to $\mathrm{Fe}^{3+}, \mathrm{NH}_{4}^{+}$, and $\mathrm{SO}_{4}{ }^{2-}$. $\mathrm{Fe}^{3+}$ hydrolyses and released $\mathrm{H}^{+}$, and a solution with a high proton concentration was formed. These protons reacted with EAF dust and brought $\mathrm{Zn}^{2+}$ in solution. In the meantime, $\mathrm{NH}_{4}{ }^{+}$, $\mathrm{SO}_{4}{ }^{2-}$, and $\mathrm{Fe}^{3+}$ ions in solution formed a jarosite precipitate, $\left(\mathrm{NH}_{4}\right) \mathrm{Fe}\left(\mathrm{SO}_{4}\right)_{2}(\mathrm{OH})_{6}$. The reaction was for 6 to $12 \mathrm{~h}$ in an autoclave at $180-220^{\circ} \mathrm{C}$. After leaching and cooling to room temperature, the solid and liquid were separated. All the zinc was in solution (93\% recovery). A disadvantage is the high reagent consumption; the mass ratio for the reagent and EAF dust was 1:1 to 7:1.

\section{Bioleaching}

The bioleaching of EAF dust is rare. Bayat et al. bioleached zinc and iron with Acidithiobacillus ferrooxidans [192]. Under optimum conditions, 35\% of the zinc and 37\% of the iron were dissolved, i.e., poor selectivity. The pulp density was $1 \%$ and the process is slow. Carranza et al. treated EAF dust and acid mine drainage (AMD) [193]. First, the EAF dust is leached with AMD water. Next, Fe(II) ions are bioxidized, and iron and aluminum are precipitated. Then, copper, nickel, cobalt, and cadmium are cemented by zinc metal, and finally the zinc is precipitated as zinc hydroxide. Lime is used to neutralize the acidic water, with gypsum precipitating.

\section{Thermal Pre-treatment}

Stopic and Friedrich describe the thermal treatment of $\mathrm{ZnFe}_{2} \mathrm{O}_{4}$ to decompose it into $\mathrm{ZnO}$ and magnetite in nitrogen at $1150{ }^{\circ} \mathrm{C}$ [194]. This avoids the energy intensive $\mathrm{ZnO}$ reduction and $\mathrm{Zn}$ evaporation. The residue was leached with $\mathrm{H}_{2} \mathrm{SO}_{4}$ at $\mathrm{pH} 4.3$ at $60{ }^{\circ} \mathrm{C}$ to dissolve the $\mathrm{ZnO}$, leaving 
Fig. 24 Flow sheet for processing of sinter-plant dust. Adapted from [204]

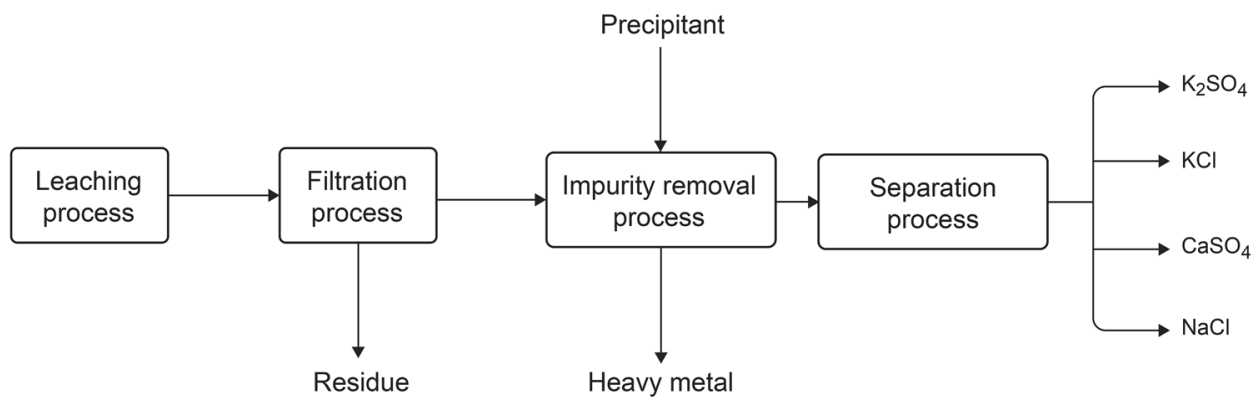

$\mathrm{Fe}_{3} \mathrm{O}_{4}$. $\mathrm{ZnFe}_{2} \mathrm{O}_{4}$ can be decomposed to $\mathrm{ZnO}$ and wüstite $(\mathrm{FeO})$ by a reductive thermal treatment in a $\mathrm{CO} / \mathrm{CO}_{2}$ gas mixture [195]. When iron is present as wüstite, it dissolves with zinc during mild acid leaching. To avoid the unwanted formation of wüstite, it can be reoxidized to magnetite by magnetization roasting in $\mathrm{CO}_{2}$ atmosphere, after which the zinc can be extracted from $\mathrm{ZnO}$ at a low acid concentration [196]. $\mathrm{ZnFe}_{2} \mathrm{O}_{4}$ is decomposed to metallic iron and $\mathrm{ZnO}$ by hydrogen gas at $600{ }^{\circ} \mathrm{C}$ [197]. The main advantages of this are high reaction rates, low energy requirements, and no $\mathrm{CO}_{2}$ emissions. Antrekowitsch and Antrekowitsch decomposed $\mathrm{ZnFe}_{2} \mathrm{O}_{4}$ in a $\mathrm{N}_{2} / \mathrm{H}_{2}$ mixture [198]. The reduction took $30 \mathrm{~min}$ at $350{ }^{\circ} \mathrm{C}$. A $100 \%$ zinc yield was possible by leaching with $\mathrm{H}_{2} \mathrm{SO}_{4}$ or $\mathrm{NaOH}$, when the $\mathrm{ZnFe}_{2} \mathrm{O}_{4}$ was decomposed in a $\mathrm{N}_{2} / \mathrm{H}_{2}$ mix with $>50 \% \mathrm{H}_{2}$. Li et al. decomposed $\mathrm{ZnFe}_{2} \mathrm{O}_{4}$ by roasting with ammonium sulfate [199].

In the section on alkali leaching of EAF dust (vide supra), the decomposition of $\mathrm{ZnFe}_{2} \mathrm{O}_{4}$ by alkali roasting or alkali fusion with $\mathrm{NaOH}$ was discussed. Another approach is to roast EAF dust with $\mathrm{Na}_{2} \mathrm{CO}_{3}$ to form $\mathrm{ZnO}$ and $\mathrm{NaFeO}_{2}$ [200]. After roasting, the residue can be leached with $\mathrm{H}_{2} \mathrm{SO}_{4}$ or $\mathrm{NaOH}$. $\mathrm{H}_{2} \mathrm{SO}_{4}$ brings more iron into solution. The advantage of $\mathrm{Na}_{2} \mathrm{CO}_{3}$ roasting over $\mathrm{NaOH}$ roasting is that a smaller amount of $\mathrm{Na}_{2} \mathrm{CO}_{3}$ is required, compared to $\mathrm{NaOH}$, although $\mathrm{Na}_{2} \mathrm{CO}_{3}$ roasting needs higher temperatures. Typical $\mathrm{Na}_{2} \mathrm{CO}_{3}$ roasting of EAF dust requires $80 \% \mathrm{Na}_{2} \mathrm{CO}_{3}$ at $950{ }^{\circ} \mathrm{C}$.

EAF dust can also be reacted with $\mathrm{CaO}$ at high temperatures. Miki et al. treated EAF dust with $\mathrm{CaO}(\mathrm{Ca} / \mathrm{Fe}$ molar ratio $=1.3$ ) at $1100{ }^{\circ} \mathrm{C}$ for $5 \mathrm{~h} \mathrm{[201]}$. The $\mathrm{ZnFe}_{2} \mathrm{O}_{4}$ is decomposed into $\mathrm{ZnO}$ and $\mathrm{Ca}_{2} \mathrm{Fe}_{2} \mathrm{O}_{5}$. Leaching with $\mathrm{NH}_{4} \mathrm{Cl}$ solution dissolves the $\mathrm{ZnO}$, but not the $\mathrm{Ca}_{2} \mathrm{Fe}_{2} \mathrm{O}_{5}$. The optimum leaching conditions were $70^{\circ} \mathrm{C}, 2-\mathrm{M} \mathrm{NH}_{4} \mathrm{Cl}$, liquid-to-solid ratio $=300,2 \mathrm{~h}$.

\section{Sinter-Plant Dust}

About $0.2-3.6 \mathrm{~kg}$ of sinter-plant dust are produced per ton of sinter. The sinter dust has a high concentration of chloride salts, particularly $\mathrm{KCl}$. The dust contains up to $28.7 \mathrm{wt} \%$ of $\mathrm{K}_{2} \mathrm{O}$, with the potassium mainly in the fine particles. Sinterplant dust could be a source of potassium for the fertilizer industry [202]. Peng et al. recovered $90 \%$ of the potassium in sinter-plant dust by leaching with water in a liquid-to-solid ratio of 2 for $5 \mathrm{~min}$ [203]. With a counter-current process, close to $100 \%$ of the $\mathrm{KCl}$ could be leached, but $40 \%$ of the other components dissolved. The washed residues could be reused. The other compounds in solution were $\mathrm{NaCl}$ and $\mathrm{CaCl}_{2}$. Heavy metals ( $\mathrm{Pb}, \mathrm{Cd}, \mathrm{Zn}, \mathrm{Cu}$ ) were precipitated by adding $\mathrm{Na}_{2} \mathrm{~S}$. $\mathrm{KCl}$ could be obtained by evaporation, followed by fractional crystallization. $\mathrm{K}_{2} \mathrm{SO}_{4}$ was selected as a precipitating agent for $\mathrm{Ca}^{2+}$ ions, and $95 \%$ pure $\mathrm{KCl}$ was obtained.

A potassium chloride plant with a capacity of 10,000 tons/year was built in Tangshan (China) for potassium fertilizer [204]. The flow sheet is shown in Fig. 24. The sinterplant dust is leached with water and filtered, with the residue recycled to the plant. Heavy metals are removed from the filtrate by sulfide precipitation, which is evaporated to obtain high-purity products. In a modified flow sheet, $\mathrm{Ca}^{2+}$ is removed as spherical $\mathrm{CaCO}_{3}$ particles by adding $\mathrm{Na}_{2} \mathrm{CO}_{3}$ before the $\mathrm{CaSO}_{4}$ starts to crystallize [205]. Spherical $\mathrm{CaCO}_{3}$ is used in paint, ink, and other industries. The sulfate will crystallize as $\mathrm{K}_{2} \mathrm{SO}_{4}$.

Sinter-plant dust can also be a source of rubidium $(\mathrm{Rb})$; it contains about $0.30 \mathrm{wt} \% \mathrm{Rb}$ in the form of $\mathrm{RbCl}$ [206], making it richer than any other rubidium resource. Some $95 \%$ of the rubidium could be leached at a liquid-to-solid ratio of 5 , at $25{ }^{\circ} \mathrm{C}$ for $10 \mathrm{~min}$. Also, $93 \%$ of the potassium and $95 \%$ of the sodium in the dust dissolved. In fact, $50 \%$ of the dust dissolved. $\mathrm{Ca}^{2+}$ and $\mathrm{Mg}^{2+}$ impurities could be removed by adding $\mathrm{Na}_{2} \mathrm{CO}_{3}$, precipitating $\mathrm{CaCO}_{3}$ and $\mathrm{MgCO}_{3}$. The concentrations of metal ions in the leachate were $[\mathrm{Na}]=7.76 \mathrm{~g} / \mathrm{L},[\mathrm{K}]=33.85 \mathrm{~g} / \mathrm{L},[\mathrm{Rb}]=0.74 \mathrm{~g} / \mathrm{L}$. Potassium/ rubidium were separated by solvent extraction with 4-tertbutyl-2( $\alpha$-methylbenzyl)phenol (t-BAMBP) in the $\mathrm{Na}^{+}$form. The extraction used counter-current mode, with two mixersettler batteries, each consisting of 4 extraction, 6 washing, and 3 stripping stages. The composition of the eluate was $[\mathrm{Rb}]=11.36 \mathrm{~g} / \mathrm{L},[\mathrm{K}]=0.027 \mathrm{~g} / \mathrm{L},[\mathrm{Na}]=0.013 \mathrm{~g} / \mathrm{L}$. The recovery rate of rubidium was $58 \%$ and the purity of $\mathrm{RbCl}$ after crystallization was $99.5 \%$. 


\section{Oily Mill Sludge}

In hot roll mill (HRM), due to oxidation, mill scale forms on the surface of the steel in reheat furnaces, and on rolling trains and stands [207]. It is removed by a water jet. Oil, used to lubricate rolling equipment, is also removed [208]. The discarded sludge is treated in a series of horizontal settling tanks, and the clarified water is reused. Coarse sediments from the primary tanks (primary mill scale) with particles $>2 \mathrm{~mm}$ and an oil content of $<1 \%$ can be recycled, e.g., as an additive to the iron ore sinter mixture. Fine scale from the secondary tanks (secondary mill scale) has particles $>2 \mathrm{~mm}$, and contains up to $20 \mathrm{wt} \%$ of oil and $10 \mathrm{wt} \%$ of water. Mill scale consists mainly of iron oxides, with small amounts of sulfur, phosphorus, and alkali metals. Depending on the steel grade, it also contains chromium, nickel, vanadium, etc. At the wastewater treatment plant, oil, water, and oily mill sludge are generated. The oily mill sludge is a mixture of mill scale, oil, water, and residual chemicals. It cannot be further separated and so is sent to landfills. The oily mill sludge is a sticky solid that is difficult to handle [209]. Also, during the cold roll mill (CRM), an oily mill sludge is generated.

The recycling of secondary scale is difficult due to the negative effects of oil on the environment and equipment. For instance, if the oiled scale is an additive to the iron ore sinter mixture, it is a problem for gas cleaning and can damage these installations with fires. One option to improve combustion of the scale's oil in the sintering process is to prepare a mixture with peat [208]. The oily mill sludge can be recycled with direct reduction iron (DRI), where the oil participates directly in the reactions for the reduction and conversion of hematite $\left(\mathrm{Fe}_{2} \mathrm{O}_{3}\right)$ and magnetite $\left(\mathrm{Fe}_{3} \mathrm{O}_{4}\right)$ to wüstite $(\mathrm{FeO})[210]$.

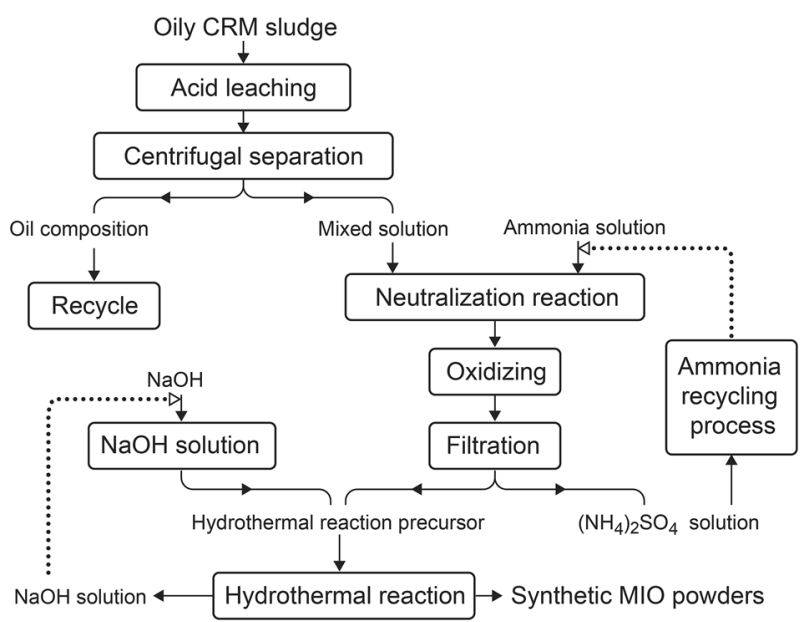

Fig. 25 Flow sheet for the preparation of micaceous iron oxide (MIO) pigment from oily CRM sludge. Adapted from [211]
De-oiling of mill scale and oily mill sludge was studied, but no technology proved to be economic and eco-friendly, and there are presently no de-oiling plants in operation [207]. Biological treatment for oil removal was investigated, but was reported to be difficult and impractical, due to the long treatment time and the low oil-removal efficiency [210]. Microwave heating was used to remove the water and to reduce the oil content in oily mill sludge [209]. Microwave heating speeds up the drying of sludge, saving both energy and time. After the microwave treatment, the material has better rheological properties. The microwaved samples are less oxidized than conventionally heat treated, which is an advantage for recycling sludge because less carbon is required to reduce it to metallic iron. However, the costs of microwave equipment versus gas heating or residual heat can be prohibitive.

To the best of our knowledge, no studies were published on the recovery of metals from oily HRM sludge by hydrometallurgical methods. However, some studies looked at the recovery of oily mill sludge generated by CRM process. Liu et al. investigated the combined recovery of iron and organic materials from oily CRM sludge, and how to prepare micaceous iron oxide (MIO) pigment from the material [211]. This pigment is used in construction materials, paints, and coatings. The oily CRM sludge was leached in $\mathrm{H}_{2} \mathrm{SO}_{4}$, until complete dissolution (6- $\mathrm{M} \mathrm{H}_{2} \mathrm{SO}_{4}, 85^{\circ} \mathrm{C}, 4 \mathrm{~h}$, solid-to-liquid ratio $=1: 5$ ). After leaching, the mixture was centrifuged into an organic part (used as fuel) and a solution. The solution consisted of $\mathrm{FeSO}_{4}$ and $\mathrm{Fe}_{2}\left(\mathrm{SO}_{4}\right)_{3}$. The iron was precipitated as $\mathrm{Fe}(\mathrm{OH})_{2}$ and $\mathrm{Fe}(\mathrm{OH})_{3}$ by an $\mathrm{NH}_{3}$ solution. $\mathrm{Fe}(\mathrm{OH})_{2}$ was oxidized by air to $\mathrm{Fe}(\mathrm{OH})_{3}$. The MIO pigment was prepared by hydrothermal synthesis in alkaline media, starting from the hydroxide precursor. The pigment was metallic gray with uniform flake shape. A flow sheet is shown in Fig. 25. Later, the authors reported an alternative for the preparation of the MIO pigment, using $\mathrm{H}_{2} \mathrm{O}_{2}$ to oxidize $\mathrm{FeSO}_{4}$ to $\mathrm{Fe}_{2}\left(\mathrm{SO}_{4}\right)_{3}$ [212]. Liu et al. removed the oil from oily CRM sludge by vacuum distillation [213]. The oil can be used as fuel or chemical feedstock. The distillation gases can be collected and also reused as fuel. When the distillation residue is oxidized by roasting, high-purity $\mathrm{Fe}_{2} \mathrm{O}_{3}$ is obtained, whereas reduction with $\mathrm{H}_{2}$ leads to the formation of iron powder.

\section{Pickling Sludge}

Pickling is used in steel plants to remove oxide scales from steel. These hydrometallurgical processes utilize mineral acids for leaching. Carbon-steel pickling in hot-dip galvanizing works with $\mathrm{HCl}$ or $\mathrm{H}_{2} \mathrm{SO}_{4}$, whereas stainless-steel pickling in rolling mills is based on mixtures of $\mathrm{HF}$ and $\mathrm{HNO}_{3}$ [214]. $\mathrm{HNO}_{3}$ dissolves and oxidizes the $\mathrm{Fe}(\mathrm{II})$ oxide scale, while HF is used for its reactivity and stabilizing capacity of metals in solution. 


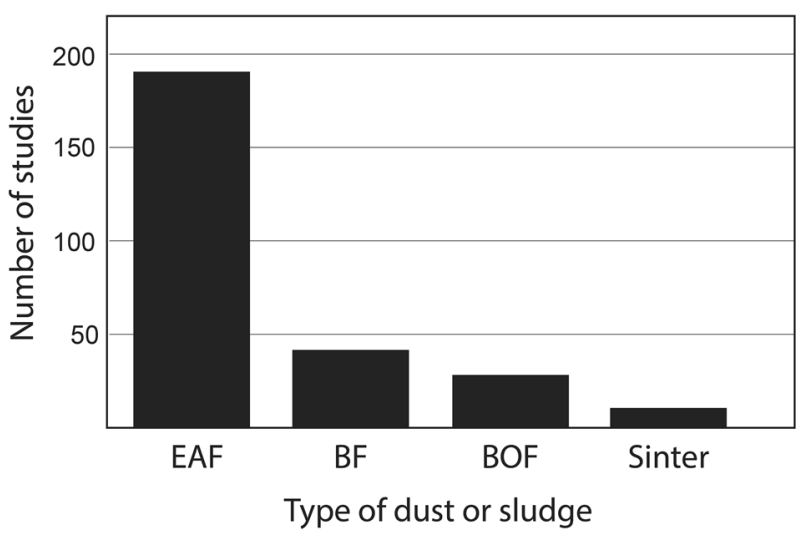

Fig. 26 Comparison of the number of studies devoted to the recovery of metals from different types of dusts and sludges

Most methods for the treatment of spent pickling liquor involve acid recovery $[215,216]$. The methods based on acid retardation or diffusion dialysis only recover the free acid, producing a residual effluent with a high metal content that is treated by solvent extraction or precipitation. The precipitation involves adding lime $(\mathrm{CaO})$ or alkali $(\mathrm{NaOH}$ or $\mathrm{KOH})$. The precipitation generates picking sludge, which is sent to landfills [217]. The metals in the sludge of stainless-steel pickling are iron, chromium, and nickel [218]. If lime is used for neutralization, the sludge will also contain $\mathrm{CaF}_{2}$. A chemical analysis of a pickling sludge yielded the following: $21.68 \mathrm{wt} \% \mathrm{Fe}, 2.42 \mathrm{wt} \% \mathrm{Cr}$, and $2.78 \mathrm{wt} \% \mathrm{Ni}$ [218].

There are few studies on the recovery of metals from pickling sludges, because if the objective is to recover the metals, solvent extraction is used. For a good overview of the treatment of spent pickling liquor by solvent extraction, the reader is referred to a review by Regel-Rosocka [219]. One of the few studies on metal recovery from pickling sludge is by $\mathrm{Ji}$ et al. who recovered nickel by controlled leaching with $\mathrm{H}_{2} \mathrm{SO}_{4}$, followed by solvent extraction [218].

Dufour et al. recovered metals from spent picking liquor by sequential selective precipitation [215]. In the first stage, iron and chromium are precipitated as $\mathrm{K}_{3} \mathrm{MF}_{6}(\mathrm{M}=\mathrm{Fe}$, $\mathrm{Cr}$ ) by adding fluoride ions (as $\mathrm{HF}$ or $\mathrm{KF}$ ) at $\mathrm{pH} 4$. Also, molybdenum will precipitate at this $\mathrm{pH}$. The effluent contains nickel(II) and nitrate ions, and nickel is precipitated in a second precipitation step as $\mathrm{Ni}(\mathrm{OH})_{2}$ at $\mathrm{pH} 7$ to 9 . The $\mathrm{K}_{3} \mathrm{MF}_{6}$ compounds can be re-dissolved and iron and chromium re-precipitated at $\mathrm{pH} 5$. The same authors described the recovery of iron from a spent $\mathrm{H}_{2} \mathrm{SO}_{4}$ pickling liquor as magnetite by oxidation-precipitation [220]. The crystalline magnetite could be used as a pigment in the paint industry. Hermoso et al. described the selective precipitation of $\mathrm{K}_{2} \mathrm{FeF}_{5}, \mathrm{CrF}_{3}$, and $\mathrm{Ni}(\mathrm{OH})_{2}$ [221].

\section{Conclusions and Outlook}

The studies on the recovery of metals by hydrometallurgical methods from steel by-products are very unequally divided among the different by-products. Studies of metal recovery from slags are outnumbered by those on dusts and sludges. There are several reasons for this. Firstly, slags are much easier to valorize. Secondly, the heavy-metal content of slags does not hamper their valorization. There is an exception with EAF slags that are intended for clinker production: in this case the chromium content can be a major problem, because $\mathrm{Cr}(\mathrm{III})$ can oxidize to $\mathrm{Cr}(\mathrm{VI})$ that is soluble in water and toxic. Thirdly, the treatment of slags by hydrometallurgical methods not only generates a residue that is of less commercial value than the original slag, it also yields aqueous waste streams that need further treatment. In contrast, dusts and sludges are much more difficult to valorize than slags and internal recycling in steelmaking is often inhibited by their high zinc content. The number of studies follows this order: EAF dust $>$ BF sludge $>$ BOF sludge $>$ sinter dust (Fig. 26).

In the past 5 years, there has been a sharp increase in research on the recovery of vanadium from vanadium slags, especially in China. This is an important trend, because of the increasing demand for vanadium for use in redox flow batteries. In contrast, the economics of manganese recovery from ferromanganese slags or chromium recovery from $\mathrm{Cr}$ rich stainless-steel slags are much less favorable.

Although the main objectives of the treatment of $\mathrm{BF}$ sludges, BOF sludges, and EAF dust are similar, i.e., the removal of zinc and generating an Fe-rich residue that can be returned to the steel plant, these three classes of by-products exhibit different mineralogical compositions and zinc contents. Moreover, within the same class of materials (e.g., EAF dust), wide variations in composition and zinc content are possible, so that it is not simple to develop a "silver bullet" process with the same set of process conditions.

The majority of the studies described in the review relate to EAF dust. This interest in EAF dust is because of its enhanced zinc content, which is by far the highest of all steel by-products. However, EAF dust is typically of interest to the zinc industry rather than that of steel. This means that the objective is to maximize zinc recovery from EAF dust, using the processes of the zinc industry. Several of the processes proposed for EAF dust treatment are similar to the roast-leach-electrowinning (RLE) process that is state of the art in the zinc industry. In fact, EAF dust is similar to the calcine that is obtained by dead-roasting $\mathrm{ZnS}$ concentrate, with the difference that EAF dust is much richer in lime $(\mathrm{CaO})$. As a consequence, EAF dust will consume more acid during leaching than zinc calcine. Much less emphasis has been paid to the destination of the iron in the process. As 
a result, iron will often be precipitated as jarosite or goethite, which are of little interest to the steel industry. This is because these iron-containing compounds are too contaminated with unwanted metals or their iron content is too low for economic use in the BF.

Many processes for the treatment of EAF dust integrate, as a final step in the targeted flow sheet, the electrowinning of zinc from the leachate (to produce high-quality zinc metal). They do this independently of the lixiviant $\left(\mathrm{H}_{2} \mathrm{SO}_{4}\right.$, $\mathrm{HCl}$, or $\mathrm{NaOH}$ ). However, this is less interesting for steel plants that want to clean up EAF dust and do not have an electrolysis plant on site. On the other hand, zinc electrolyte is less convenient to transport than solid zinc compounds. For this reason, the treatments of EAF dust that are of interest to the zinc industry have a flow sheet that produces a solid zinc compound, e.g., $\mathrm{ZnO}, \mathrm{ZnCO}_{2}$, basic $\mathrm{ZnCO}_{2}$, or $\mathrm{ZnS}$. The latter is usually preferred.

It is very difficult to compare the leaching results and the zinc yields published for EAF dust in different studies, because the composition of the EAF dusts varies widely. Different types of EAF dust not only have different concentrations of zinc, but also show variations in the $\mathrm{ZnO} / \mathrm{ZnFe}_{2} \mathrm{O}_{4}$ ratio (zincite-to-franklinite ratio). In many processes, only the $\mathrm{ZnO}$ is dissolved, while the refractory $\mathrm{ZnFe}_{2} \mathrm{O}_{4}$ phase remains in the residue. $\mathrm{ZnFe}_{2} \mathrm{O}_{4}$ is only dissolved in concentrated acids, or if the EAF dust is pre-treated (e.g., by a reductive roasting step). Furthermore, dissolving $\mathrm{ZnFe}_{2} \mathrm{O}_{4}$ in acidic solutions also brings iron into solution.

Compared to EAF dust, there is much less research on BF sludges, with most of it performed by the steel industry. There has been limited interest in BF sludges from academics, probably due to the low content of non-ferrous metals such as zinc. This limits the value of BF sludge as a potential secondary source of zinc. Very few studies focus on BF sludges with a low zinc content. Some investigations have considered BF sludges with exceptionally high zinc contents, which begs the question about how representative such studies are. In some studies, it is evident that zinc is present in $\mathrm{BF}$ sludges in the form of $\mathrm{ZnS}$ (sphalerite). This requires oxidative leaching, e.g., with $\mathrm{FeCl}_{3}$. It is not clear how general the presence of $\mathrm{ZnS}$ in BF sludges actually is, because many studies did not report the sulfur content in BF sludges or in the minor mineralogical phases. Concurrently, the high carbon content in BF sludges leads to operational problems with hydrometallurgical processes, because of foaming.

The recovery of zinc from BOF dusts and sludges has received little attention so far, and very little information has been published in the literature and as patents.

When treating dusts and sludges, it is recommended to focus on the easily soluble zinc (in the form of $\mathrm{ZnO}$ ), because this needs relatively mild conditions and the dissolution takes just a couple of minutes. However, in general, the selected leaching times are often much too long.
This is unnecessary for the dissolution of $\mathrm{ZnO}$ and leads to unacceptable levels of iron co-dissolution. On the other hand, if the dissolution of the more refractory $\mathrm{ZnFe}_{2} \mathrm{O}_{4}$ (franklinite) phase is targeted, much harsher conditions are required and a lot of iron will co-dissolve. Therefore, it is better to "bleed" the zinc from the system by dissolving the $\mathrm{ZnO}$, and to return the $\mathrm{ZnFe}_{2} \mathrm{O}_{4}$ back to the $\mathrm{BF}$ or $\mathrm{BOF}$. In the $\mathrm{BF}$ or $\mathrm{BOF}$, the $\mathrm{ZnFe}_{2} \mathrm{O}_{4}$ is partly decomposed to $\mathrm{ZnO}$. The removal of zinc via $\mathrm{ZnO}$, therefore, constitutes the "low-hanging fruit." A compromise has to be found between the zinc removal yield and the requirements in terms of OPEX and CAPEX. The maximum permissible value of the zinc concentration in the leaching residues of the dusts and sludges depends on the operational conditions of the $\mathrm{BF}$ or $\mathrm{BOF}$, and in particular on the average zinc content of the regular iron-containing feeds to the furnace. However, as a rule of thumb, the zinc content in the residue that is sent back to the BF or BOF must be below $1 \mathrm{wt} \%$.

Since it is difficult to remove iron from leachates, it is better to avoid bringing iron into solution in the first place. When/if iron has to be precipitated from the solution, the preferred iron phase is hematite $\left(\mathrm{Fe}_{2} \mathrm{O}_{3}\right)$, because hematite is Fe-rich and has a very low level of impurities, in contrast to jarosite or goethite. Unfortunately, hematite can only be formed at elevated temperatures, i.e., above $100{ }^{\circ} \mathrm{C}$, which requires an expensive autoclave. However, there are ways to obtain hematite at lower temperatures, for instance by seeding the iron-containing solution with a high concentration of hematite crystals. There is definitively room for research on the formation of hematite precipitates under milder conditions. Hematite is easier to form from chloride than from sulfate solutions. Also, nitrate media can lead to hematite formation. The precipitation of jarosite or goethite is not sustainable, because it creates a solid-waste problem. It simply transfers the zinc industry's solid-waste problem to the steel industry.

Although this review focused on hydrometallurgical processes, several process flow sheets contain a high-temperature pre-processing step. Examples include alkali roasting with $\mathrm{NaOH}$ or $\mathrm{Na}_{2} \mathrm{CO}_{3}$ to decompose the $\mathrm{ZnFe}_{2} \mathrm{O}_{4}$ phases in $\mathrm{EAF}$ dust, the roasting of vanadium slags with $\mathrm{NaCl}$ to decompose the vanadium spinel phases, and the dry digestion with concentrated $\mathrm{H}_{2} \mathrm{SO}_{4}$ of silicate-rich slags. In all these cases, the thermal pre-processing temperature should be as low as possible, in order to curb the energy consumption. In any case, the reaction temperatures are much lower than those of pyrometallurgical processes. A concern with thermal pre-processing is that often large amounts of chemicals are used for the roasting step. Therefore, it is better to pay more attention to reducing the consumption of chemicals or developing reagent-free roasting processes. 
Acknowledgements The authors acknowledge funding from the European Institute of Innovation and Technology (EIT), a body of the European Union, under Horizon 2020, part of the 'KAVA Call 6,' in the framework of the 'Innovation Theme' No.3 of EIT Raw Materials Project Number 19205 (SAMEX). Alma Capa and Jose Luis García are acknowledged for their contributions during discussions and for editing this paper. Paul McGuiness is acknowledged for his text editing work.

\section{Compliance with Ethical Standards}

Conflict of interest On behalf of all authors, the corresponding author states that there is no conflict of interest.

Open Access This article is licensed under a Creative Commons Attribution 4.0 International License, which permits use, sharing, adaptation, distribution and reproduction in any medium or format, as long as you give appropriate credit to the original author(s) and the source, provide a link to the Creative Commons licence, and indicate if changes were made. The images or other third party material in this article are included in the article's Creative Commons licence, unless indicated otherwise in a credit line to the material. If material is not included in the article's Creative Commons licence and your intended use is not permitted by statutory regulation or exceeds the permitted use, you will need to obtain permission directly from the copyright holder. To view a copy of this licence, visit http://creativecommons.org/licenses/by/4.0/.

\section{References}

1. Stewart D, Barron A (2020) Pyrometallurgical removal of zinc from basic oxygen steelmaking dust - a review of best available technology. Resour Conserv Recycl 157:104746. https://doi. org/10.1016/j.resconrec.2020.104746

2. Zhang H, Hong X (2011) An overview for the utilization of wastes from stainless steel industries. Resour Conserv Recycl 55:745-754. https://doi.org/10.1016/j.resconrec.2011.03.005

3. Candian Lobato NC, Villegas EA, Mansur MB (2015) Management of solid wastes from steelmaking and galvanizing processes: a brief review. Resour Conserv Recycl 102:49-57. https ://doi.org/10.1016/j.resconrec.2015.05.025

4. Fisher LV, Barron AR (2019) The recycling and reuse of steelmaking slags - a review. Resour Conserv Recycl 146:244-255. https://doi.org/10.1016/j.resconrec.2019.03.010

5. Lin X, Peng Z, Yan J et al (2017) Pyrometallurgical recycling of electric arc furnace dust. J Clean Prod 149:1079-1100. https:// doi.org/10.1016/j.jclepro.2017.02.128

6. Yang C, Pan J, Zhu D et al (2019) Pyrometallurgical recycling of stainless steel pickling sludge: a review. J Iron Steel Res Int 26:547-557. https://doi.org/10.1007/s42243-019-00278-y

7. Antunano N, Cambra JF, Arias PL (2019) Hydrometallurgical processes for Waelz oxide valorisation - an overview. Process Saf Environ Prot 129:308-320. https://doi.org/10.1016/j. psep.2019.06.028

8. Das B, Prakash S, Reddy PSR, Misra VN (2007) An overview of utilization of slag and sludge from steel industries. Resour Conserv Recycl 50:40-57. https://doi.org/10.1016/j.resco nrec.2006.05.008

9. Du C, Gao X, Kitamura S (2019) Measures to decrease and utilize steelmaking slag. J Sustain Metall 5:141-153. https://doi. org/10.1007/s40831-018-0202-4

10. Rieger J, Schenk J (2019) Residual processing in the european steel industry: a technological overview. J Sustain Metall 5:295309. https://doi.org/10.1007/s40831-019-00220-2
11. Worldsteel (2010) Steel industry by-products: project group report 2007-2009. World Steel Association, Brussels

12. Ji Y, Shen S, Liu J, Xue Y (2017) Cleaner and effective process for extracting vanadium from vanadium slag by using an innovative three-phase roasting reaction. J Clean Prod 149:1068-1078. https://doi.org/10.1016/j.jclepro.2017.02.177

13. Jiang T, Dong H, Guo Y et al (2010) Study on leaching Ti from Ti bearing blast furnace slag by sulphuric acid. Trans Inst Min Metall Sect C 119:33-38. https://doi.org/10.1179/037195509X 12585446038807

14. Valighazvini F, Rashchi F, Nekouei RK (2013) Recovery of titanium from blast furnace slag. Ind Eng Chem Res 52:1723-1730. https://doi.org/10.1021/ie301837m

15. He S, Sun H, Tan D, Peng T (2016) Recovery of titanium compounds from Ti-enriched product of alkali melting Ti-bearing blast furnace slag by dilute sulfuric acid leaching. Procedia Environ Sci 31:977-984. https://doi.org/10.1016/j.proen v.2016.03.003

16. Mang G, Cheng M (2014) Research of $\mathrm{Al}$ and $\mathrm{Fe}$ leaching rate in the process of slag leaching by hydrochloric acid. Appl Mech Mater 675-677:1417-1420. https://doi.org/10.4028/www.scien tific.net/AMM.675-677.1417

17. Meshram P, Sarkar S, Venugopalan T (2017) Exploring blast furnace slag as a secondary resource for extraction of rare earth elements. Miner Metall Process 34:178-182

18. Huijgen W, Witkamp G, Comans R (2005) Mineral $\mathrm{CO}_{2}$ sequestration by steel slag carbonation. Environ Sci Technol 39:96769682. https://doi.org/10.1021/es050795f

19. Bilen M, Altiner M, Yildirim M (2018) Evaluation of steelmaking slag for $\mathrm{CO}_{2}$ fixation by leaching-carbonation process. Part Sci Technol 36:368-377. https://doi.org/10.1080/02726 351.2016.1267285

20. Hall C, Large DJ, Adderley B, West HM (2014) Calcium leaching from waste steelmaking slag: significance of leachate chemistry and effects on slag grain mineralogy. Miner Eng 65:156-162. https://doi.org/10.1016/j.mineng.2014.06.002

21. Zhang G, Zhang T, Lu G et al (2015) Extraction of vanadium from vanadium slag by high pressure oxidative acid leaching. Int J Miner Metall Mater 22:21-26. https://doi.org/10.1007/s1261 3-015-1038-6

22. Zhang J, Zhang W, Zhang L, Gu S (2014) A critical review of technology for selective recovery of vanadium from leaching solution in $\mathrm{V}_{2} \mathrm{O}_{5}$ production. Solvent Extr Ion Exch 32:221-248. https://doi.org/10.1080/07366299.2013.877753

23. Li M, Zheng S, Liu B et al (2017) A clean and efficient method for recovery of vanadium from vanadium slag: nonsalt roasting and ammonium carbonate leaching processes. Miner Process Extr Metall Rev 38:228-237. https://doi.org/10.1080/08827 508.2017.1288117

24. Zhang J, Zhang W, Xue Z (2019) An environment-friendly process featuring calcified roasting and precipitation purification to prepare vanadium pentoxide from the converter vanadium slag. Metals. https://doi.org/10.3390/met9010021

25. Li H-Y, Wang K, Hua W-H et al (2016) Selective leaching of vanadium in calcification-roasted vanadium slag by ammonium carbonate. Hydrometallurgy 160:18-25. https://doi. org/10.1016/j.hydromet.2015.11.014

26. Li X, Xie B (2012) Extraction of vanadium from high calcium vanadium slag using direct roasting and soda leaching. Int J Miner Metall Mater 19:595-601. https://doi.org/10.1007/s1261 3-012-0600-8

27. Zhang G, Luo D, Deng C et al (2018) Simultaneous extraction of vanadium and titanium from vanadium slag using ammonium sulfate roasting-leaching process. J Alloys Compd 742:504-511. https://doi.org/10.1016/j.jallcom.2018.01.300 
28. Li M, Liu B, Zheng S et al (2017) A cleaner vanadium extraction method featuring non-salt roasting and ammonium bicarbonate leaching. J Clean Prod 149:206-217. https://doi.org/10.1016/j. jclepro.2017.02.093

29. Li M, Du H, Zheng S et al (2017) Extraction of vanadium from vanadium slag via non-salt roasting and ammonium oxalate leaching. JOM 69:1970-1975. https://doi.org/10.1007/s1183 7-017-2494-4

30. Wen J, Jiang T, Zhou W et al (2019) A cleaner and efficient process for extraction of vanadium from high chromium vanadium slag: leaching in $\left(\mathrm{NH}_{4}\right)_{2} \mathrm{SO}_{4}-\mathrm{H}_{2} \mathrm{SO}_{4}$ synergistic system and $\mathrm{NH}_{4}{ }^{+}$recycle. Sep Purif Technol 216:126-135. https://doi. org/10.1016/j.seppur.2019.01.078

31. Zhang G-Q, Zhang T-A, Zhang Y et al (2016) Pressure leaching of converter vanadium slag with waste titanium dioxide. Rare Met 35:576-580. https://doi.org/10.1007/s12598-014-0225-3

32. Zhang Y, Zhang T-A, Dreisinger D et al (2017) Extraction of vanadium from direct acid leach solution of converter vanadium slag. Can Metall Q 56:281-293. https://doi.org/10.1080/00084 433.2017.1327501

33. McIntosh S, Baglin E (1992) Recovery of manganese from steel plant slag by carbamate leaching. US Bur Mines Rep Investig 9400:1-16

34. Krasheninin AG, Khalezov BD, Bornovolokov AS, Ordinartsev DP (2019) Technology for extracting manganese from vanadium converter slag after leaching vanadium. Metallurgist 63:534-542. https://doi.org/10.1007/s11015-019-00854-3

35. Mombelli D, Mapelli C, Barella S et al (2016) The effect of chemical composition on the leaching behaviour of electric arc furnace (EAF) carbon steel slag during a standard leaching test. J Environ Chem Eng 4:1050-1060. https://doi.org/10.1016/j. jece.2015.09.018

36. Mombelli D, Barella S, Gruttadauria A et al (2019) Effects of basicity and mesh on $\mathrm{Cr}$ leaching of EAF carbon steel slag. Appl Sci 9:1-12. https://doi.org/10.3390/app9010121

37. Yu Y, Wang D, Li J et al (2018) Effect of cooling conditions on the leachability of chromium in $\mathrm{Cr}_{2} \mathrm{O}_{3}$-containing steelmaking slag. J South Afr Inst Min Metall 118:539-543

38. Wang X, Geysen D, Van Gerven T et al (2017) Characterization of landfilled stainless steel slags in view of metal recovery. Front Chem Sci Eng 11:353-362. https://doi.org/10.1007/s1170 5-017-1656-9

39. Kim E, Spooren J, Broos K et al (2015) Selective recovery of $\mathrm{Cr}$ from stainless steel slag by alkaline roasting followed by water leaching. Hydrometallurgy 158:139-148. https://doi. org/10.1016/j.hydromet.2015.10.024

40. Kim E, Spooren J, Broos K et al (2016a) Valorization of stainless steel slag by selective chromium recovery and subsequent carbonation of the matrix material. J Clean Prod 117:221-228. https://doi.org/10.1016/j.jclepro.2016.01.032

41. Kim E, Spooren J, Broos K et al (2016b) New method for selective $\mathrm{Cr}$ recovery from stainless steel slag by $\mathrm{NaOCl}$ assisted alkaline leaching and consecutive $\mathrm{BaCrO}_{4}$ precipitation. Chem Eng J 295:542-551. https://doi.org/10.1016/j.cej.2016.03.073

42. Spooren J, Kim E, Horckmans L et al (2016) In-situ chromium and vanadium recovery of landfilled ferrochromium and stainless steel slags. Chem Eng J 303:359-368. https://doi.org/10.1016/j. cej.2016.05.128

43. Baumgartner S, Groot D (2014) The recovery of manganese products from ferromanganese slag using a hydrometallurgical route. J South Afr Inst Min Metall 114:331-340

44. Mohanty J, Sahoo P, Nathsarma K et al (1998) Characterization and leaching of ferromanganese slag. Miner Metall Process 15:30-33. https://doi.org/10.1007/BF03403221

45. Naganoor P, Prasanna A, Shivaprasad K, Bhat K (2000) Extraction of manganese from Ferro-manganese slag. Int Symp Process
Fines Jamshedpur India 2-3 Novemb 2000 Natl Metall Lab Jamshedpur 300-306

46. Kazadi DM, Groot DR, Steenkamp JD, Poellmann H (2016) Control of silica polymerisation during ferromanganese slag sulphuric acid digestion and water leaching. Hydrometallurgy 166:214-221. https://doi.org/10.1016/j.hydromet.2016.06.024

47. Kazadi D, Groot D, Pöllmann H et al (2013) Utilization of Ferromanganese slags for manganese extraction and as a cement additive. Proceedings of the Advances in Cement and Concrete Technology in Africa conference, Emperor's Palace, Johannesburg (South Africa), 28- 30 January 2013, 983-995

48. Hocheng H, Su C, Jadhav UU (2014) Bioleaching of metals from steel slag by Acidithiobacillus thiooxidans culture supernatant. Chemophere 117:652-657. https://doi.org/10.1016/j.chemospher e.2014.09.089

49. Andersson A, Ahmed H, Rosenkranz J et al (2017) Characterization and upgrading of a low zinc-containing and fine blast furnace sludge - a multi-objective analysis. ISIJ Int 57:262-271. https://doi.org/10.2355/isijinternational.ISIJINT-2016-512

50. Li B, Wei Y, Wang $\mathrm{H}$ et al (2019) Preparation of $\mathrm{ZnSO}_{4} .7 \mathrm{H}_{2} \mathrm{O}$ and separation of zinc from blast furnace sludge by leachingpurification-crystallization method. ISIJ Int 59:201-207. https ://doi.org/10.2355/isijinternational.ISIJINT-2018-401

51. Kretzschmar R, Mansfeldt T, Mandaliev PN et al (2012) Speciation of $\mathrm{Zn}$ in blast furnace sludge from former sedimentation ponds using synchrotron X-ray diffraction, fluorescence, and absorption spectroscopy. Environ Sci Technol 46:1238112390. https://doi.org/10.1021/es302981v

52. Steer JM, Griffiths AJ (2013) Investigation of carboxylic acids and non-aqueous solvents for the selective leaching of zinc from blast furnace dust slurry. Hydrometallurgy 140:34-41. https://doi.org/10.1016/j.hydromet.2013.08.011

53. Van Herck P, Vandecasteele C, Swennen R, Mortier R (2000) Zinc and lead removal from blast furnace sludge with a hydrometallurgical process. Environ Sci Technol 34:3802-3808. https://doi.org/10.1021/es9910331

54. Schrama F, Beunder E, Van den Berg B et al (2017) Sulphur removal in ironmaking and oxygen steelmaking. Ironmak Steelmak 44:333-343. https://doi.org/10.1080/03019 233.2017.1303914

55. Trinkel V, Mallow O, Thaler C et al (2015) Behavior of chromium, nickel, lead, zinc, cadmium, and mercury in the blast furnace-a critical review of literature data and plant investigations. Ind Eng Chem Res 54:11759-11771. https://doi. org/10.1021/acs.iecr.5b03442

56. Trinkel V, Mallow O, Aschenbrenner P et al (2016) Characterization of blast furnace sludge with respect to heavy metal distribution. Ind Eng Chem Res 55:5590-5597. https://doi. org/10.1021/acs.iecr.6b00617

57. Foeldi C, Dohrmann R, Mansfeldt T (2015) Volatilization of elemental mercury from fresh blast furnace sludge mixed with basic oxygen furnace sludge under different temperatures. Environ Sci Process Impacts 17:1915-1922. https://doi. org/10.1039/c5em00403a

58. Foeldi C, Dohrmann R, Mansfeldt T (2014) Mercury in dumped blast furnace sludge. Chemophere 99:248-253. https ://doi.org/10.1016/j.chemosphere.2013.11.007

59. Ma N (2014) In-Process Separation of Zinc From Blast Furnace Offgas Solid Wastes. In: AISTech 2014 Proceedings. Association for Iron \& Steel Technology, pp 623-634

60. Zeydabadi B, Mowla D, Shariat M, Kalajahi J (1997) Zinc recovery from blast furnace flue dust. Hydrometallurgy 47:113-125. https://doi.org/10.1016/S0304-386X(97)00039-X

61. Havlik T, Kukurugya F, Orac D, Parilak L (2012) Acidic leaching of EAF steelmaking dust. World Metall - ERZMETALL 65:48-56 
62. Banerjee D (2007) Metal recovery from blast furnace sludge and flue dust using leaching technologies. Res J Chem Environ $11: 18-21$

63. Soria-Aguilar MJ, Davila-Pulido GI, Carrillo-Pedroza FR et al (2019) Oxidative leaching of zinc and alkalis from iron blast furnace sludge. METALS. https://doi.org/10.3390/met9091015

64. Veres J, Lovas M, Jakabsky S et al (2012) Characterization of blast furnace sludge and removal of zinc by microwave assisted extraction. Hydrometallurgy 129:67-73. https://doi. org/10.1016/j.hydromet.2012.09.008

65. Mikhailov I, Komarov S, Levina V et al (2017) Nanosized zero-valent iron as Fenton-like reagent for ultrasonic-assisted leaching of zinc from blast furnace sludge. J Hazard Mater 321:557-565. https://doi.org/10.1016/j.jhazmat.2016.09.046

66. SIDMAR (1999) Werkwijze voor het behandelen van gecontamineerd ijzerhoudend slib. Belgian Patent 1011619A3

67. Mortier R (1999) Oxidising elutriation of contaminated sludge containing iron with separation of zinc and lead. Patent WO 9931285

68. Josis C, Hissel J (1988) Procédé de traitement des matières contenant des metaux lourds par lixiviation acide. Belgian Patent 1001781A6

69. Giordana S (2016) Method for the treatment of iron-containing sludge, and associated equipment. Canadian Patent CA 2985027 A1

70. Flock J, Mittelstädt H, Pappert E, Tebeck A (2018) Integrated process for recycling washing tower sludge for recovery of iron oxide and carbon. Patent WO 2018219464

71. Peters R (1999) Chelant extraction of heavy metals from contaminated soils. J Hazard Mater 66:151-210. https://doi.org/10.1016/ S0304-3894(99)00010-2

72. Wasay S, Barrington S, Tokunaga S (1998) Remediation of soils polluted by heavy metals using salts of organic acids and chelating agents. Environ Technol 19:369-379. https://doi. org/10.1080/09593331908616692

73. Voglar D, Lestan D (2014) Chelant soil-washing technology for metal-contaminated soil. Environ Technol 35:1389-1400. https ://doi.org/10.1080/09593330.2013.869265

74. Chen Y, Zhang S, Xu X et al (2016) Effects of surfactants on low-molecular-weight organic acids to wash soil zinc. Environ Sci Pollut Res 23:4629-4638. https://doi.org/10.1007/s1135 6-015-5700-3

75. Cheikh M, Magnin J, Gondrexon N et al (2010) Zinc and lead leaching from contaminated industrial waste sludges using coupled processes. Environ Technol 31:1577-1585. https://doi. org/10.1080/09593331003801548

76. Peeters T, Xiao Y, Yang Y (2018) Process for selective removal of zinc from metallurgical plant waste. European Patent EP 3333 272 A1

77. Cantarino M, de Carvalho FC, Mansur M (2012) Selective removal of zinc from basic oxygen furnace sludges. Hydrometallurgy 111:124-128. https://doi.org/10.1016/j.hydro met.2011.11.004

78. Ma N (2016) Recycling of basic oxygen furnace steelmaking dust by in-process separation of zinc from the dust. J Clean Prod 112:4497-4504. https://doi.org/10.1016/j.jclepro.2015.07.009

79. Jalkanen H, Oghbasilasie H, Raipala K (2005) Recycling of steelmaking dusts - the Radust concept. J Min Metall 41B:1-16. https ://doi.org/10.2298/JMMB0501001J

80. Sammut ML, Rose J, Masion A et al (2008) Determination of zinc speciation in basic oxygen furnace flying dust by chemical extractions and X-ray spectroscopy. Chemophere 70:1945-1951. https://doi.org/10.1016/j.chemosphere.2007.09.063

81. Veres J, Sepelak V, Hredzak S (2015) Chemical, mineralogical and morphological characterisation of basic oxygen furnace dust. Trans Inst Min Metall Sect C 124:1-8. https://doi. org/10.1179/1743285514Y.0000000069

82. Wang L, Lu X, Huang Y (2013) Determination of Zn distribution and speciation in basic oxygen furnace sludge by synchrotron radiation induced $\mu$-XRF and $\mu$-XANES microspectroscopy. X-Ray Spectrom 42:423-428. https://doi.org/10.1002/xrs.2494

83. Wang L, Huang Y, Lu X (2013) Zn distribution and speciation in zinc-containing steelmaking wastes by synchrotron radiation induced $\mu$-XRF and $\mu$-XANES spectroscopy. J Phys Conf Ser 430:012097. https://doi.org/10.1088/1742-6596/430/1/012097

84. Singh AKP, Raju MT (2011) Recycling of basic oxygen furnace (BOF) sludge in iron and steel works. Int J Environ Technol Manag 14:19-32. https://doi.org/10.1504/IJETM.2011.039255

85. Kelebek S, Yoruk S, Davis B (2004) Characterization of basic oxygen furnace dust and zinc removal by acid leaching. Miner Eng 17:285-291. https://doi.org/10.1016/j.mineng.2003.10.030

86. Trung Z, Kukurugya H, Takáčová Z et al (2010) Leaching of basic oxygen furnace sludge with sulphuric acid. Acta Montan Slovaca 15:200-203

87. Trung ZH, Kukurugya F, Takacova Z et al (2011) Acidic leaching both of zinc and iron from basic oxygen furnace sludge. J Hazard Mater 192:1100-1107. https://doi.org/10.1016/j.jhazm at.2011.06.016

88. Veres J, Jakabsky S, Lovas M, Hredzak S (2010) Non-isothermal microwave leaching kinetics of zinc removal from basic oxygen furnace dust. Acta Montan Slovaca 15:204-211

89. Duval L (1968) Process for removing zinc oxid from iron oxide flue dist by the use of spent pickle liquor. US Patent 3375069

90. Wang J, Wang Z, Zhang Z, Zhang G (2019a) Zinc removal from basic oxygen steelmaking filter cake by leaching with organic acids. Metall Mater Trans B 50:480-490. https://doi.org/10.1007/ s11663-018-1440-3

91. Wang J, Wang Z, Zhang Z, Zhang G (2019b) Removal of zinc from basic oxygen steelmaking filter cake by selective leaching with butyric acid. J Clean Prod 209:1-9. https://doi. org/10.1016/j.jclepro.2018.10.253

92. Wang J, Wang Z, Zhang Z, Zhang G (2019c) Comparison of butyric acid leaching behaviors of zinc from three basic oxygen steelmaking filter cakes. Metals 9:417-428. https://doi. org/10.3390/met 9040417

93. Wang J, Wang Z, Zhang Z, Zhang G (2019d) Effect of addition of other acids into butyric acid on selective leaching of zinc from basic oxygen steelmaking filter cake. Metall Mater Trans B 50:1378-1386. https://doi.org/10.1007/s11663-019-01563-7

94. Gargul K, Jarosz P, Malecki S (2016) Alkaline leaching of low zinc content iron-bearing sludges. Arch Metall Mater 61:43-49. https://doi.org/10.1515/amm-2016-0013

95. Petranikova M, Ssenteza V, Lousada CM et al (2020) Novel process for decontamination and additional valorization of steel making dust processing using two-step correlative leaching. J Hazard Mater. https://doi.org/10.1016/j.jhazmat.2019.121442

96. Gargul K, Boryczko B (2015) Removal of zinc from dusts and sludges from basic oxygen furnaces in the process of ammoniacal leaching. Arch Civ Mech Eng 15:179-187. https://doi. org/10.1016/j.acme.2014.08.004

97. Al-Harahsheh M, Al-Nuairat J, Al-Otoom A et al (2019) Treatments of electric arc furnace dust and halogenated plastic wastes: a review. J Environ Chem Eng. https://doi.org/10.1016/j. jece.2018.102856

98. Keglevich W, de Buzin PJ, Heck NC, Faria Vilela AC (2017) EAF dust: an overview on the influences of physical, chemical and mineral features in its recycling and waste incorporation routes. J Mater Res Technol 6:194-202. https://doi.org/10.1016/j. jrnxt.2016.10.002 
99. Antrekowitsch J, Roesler G, Steinacker S (2015) State of the art in steel mill dust recycling. Chem Ing Tech 87:1498-1503. https ://doi.org/10.1002/cite.201500073

100. Montenegro V, Oustadakis P, Tsakiridis PE, Agatzini-Leonardou $S$ (2013) Hydrometallurgical treatment of steelmaking electric arc furnace dusts (EAFD). Metall Mater Trans B 44:1058-1069. https://doi.org/10.1007/s11663-013-9874-0

101. Bruckard W, Davey K, Rodopoulos T et al (2005) Water leaching and magnetic separation for decreasing the chloride level and upgrading the zinc content of EAF steelmaking baghouse dusts. Int J Miner Process 75:1-20. https://doi.org/10.1016/j.minpr o.2004.04.007

102. Chen W-S, Shen Y-H, Tsai M-S, Chang F-C (2011) Removal of chloride from electric arc furnace dust. J Hazard Mater 190:639644. https://doi.org/10.1016/j.jhazmat.2011.03.096

103. Chmielarz A, Gnot W (2001) Conversion of zinc chloride to zinc sulphate by electrodialysis - a new concept for solving the chloride ion problem in zinc hydrometallurgy. Hydrometallurgy 61:21-43. https://doi.org/10.1016/S0304-386X(01)00153-0

104. Langova S, Matysek D (2010) Zinc recovery from steel-making wastes by acid pressure leaching and hematite precipitation. Hydrometallurgy 101:171-173. https://doi.org/10.1016/j.hydro met.2010.01.003

105. Cruells M, Roca A, Nunez C (1992) Electric arc furnace flue dusts: characterization and leaching with sulphuric acid. Hydrometallurgy 31:213-231. https://doi.org/10.1016/0304386X(92)90119-K

106. Kukurugya F, Vindt T, Havlik T (2015) Behavior of zinc, iron and calcium from electric arc furnace (EAF) dust in hydrometallurgical processing in sulfuric acid solutions: thermodynamic and kinetic aspects. Hydrometallurgy 154:20-32. https://doi. org/10.1016/j.hydromet.2015.03.008

107. Havlik T, Turzakova M, Stopic S, Friedrich B (2005) Atmospheric leaching of EAF dust with diluted sulphuric acid. Hydrometallurgy 77:41-50. https://doi.org/10.1016/j.hydro met.2004.10.008

108. Havlik T, Vidor e Souza B, Bernandes AM et al (2006) Hydrometallurgical processing of carbon steel EAF dust. J Hazard Mater 135:311-318. https://doi.org/10.1016/j.jhazm at.2005.11.067

109. Langova S, Riplova J, Vallova S (2007) Atmospheric leaching of steel-making wastes and the recipitation of goethite from the ferric sulphate solution. Hydrometallurgy 87:157-162. https:// doi.org/10.1016/j.hydromet.2007.03.002

110. Havlik T, Friedrich B, Stopic S (2004) Pressure leaching of EAF dust with sulphuric acid. World Metall-Erzmetall $57: 83-90$

111. Havlik T, Miskufova A, Turek P, Kobialkova IU (2019) Considering the influence of calcium on EAF dust acid leaching. Physicochem Probl Miner Process 55:528-536. https://doi.org/10.5277/ ppmp18164

112. Pazdej R (1982) Hydrometallurgical treatment of metallurgical dust. US Patent 4332777

113. Duyvesteyn W, Jha M (1986) Two-stage leaching process for steel plant dusts. US Patent 4610721

114. Zaromb S, Lawson D (1994) Hydrometallurgical process for recovering iron sulfate and zinc sulfate from baghouse dust. US Patent 5286465

115. Diaz G, Martin D (1994) Modified zincex process - the clean, safe and profitable solution to the zinc secondaries treatment. Resour Conserv Recycl 10:43-57. https://doi.org/10.1016/09213449(94)90037-X

116. Oustadakis P, Tsakiridis PE, Katsiapi A, Agatzini-Leonardou S (2010) Hydrometallurgical process for zinc recovery from electric arc furnace dust (EAFD) part i: characterization and leaching by diluted sulphuric acid. J Hazard Mater 179:1-7. https://doi. org/10.1016/j.jhazmat.2010.01.059

117. Tsakiridis PE, Oustadakis P, Katsiapi A, Agatzini-Leonardou S (2010) Hydrometallurgical process for zinc recovery from electric arc furnace dust (EAFD). Part II: downstream processing and zinc recovery by electrowinning. J Hazard Mater 179:8-14. https ://doi.org/10.1016/j.jhazmat.2010.04.004

118. Gotfryd L, Chmielarz A, Szolomicki Z (2011a) Recovery of zinc from arduous wastes using solvent extraction technique part I. Preliminary laboratory studies. Physicochem Probl Miner Process 47:149-158

119. Gotfryd L, Chmielarz A, Szolomicki Z (2011b) Recovery of zinc from arduous wastes using solvent extraction technique part II. Pilot plant tests. Physicochem Probl Miner Process 47:249-258

120. Montenegro V, Agatzini-Leonardou S, Oustadakis P, Tsakiridis P (2016) Hydrometallurgical treatment of EAF dust by direct sulphuric acid leaching at atmospheric pressure. Waste Biomass Valoriz 7:1531-1548. https://doi.org/10.1007/s1264 9-016-9543-z

121. Xanthopoulos $P$, Agatzini-Leonardou S, Oustadakis P, Tsakiridis PE (2017) Zinc recovery from purified electric arc furnace dust leach liquors by chemical precipitation. J Environ Chem Eng 5:3550-3559. https://doi.org/10.1016/j.jece.2017.07.023

122. Brunelli K, Dabala M (2015) Ultrasound effects on zinc recovery from EAF dust by sulfuric acid leaching. Int J Miner Metall Mater 22:353-362. https://doi.org/10.1007/s12613-015-1080-4

123. Winand R (1991) Chloride hydrometallurgy. Hydrometallurgy 27:285-316. https://doi.org/10.1016/0304-386X(91)90055-Q

124. Van Weert G, Peek E (1992) Reagent recovery in chloride hydrometallurgy - some missing links. Hydrometallurgy 29:513-526. https://doi.org/10.1016/0304-386X(92)90030-4

125. Baik D, Fray D (2000) Recovery of zinc from electric-are furnace dust by leaching with aqueous hydrochloric acid, plating of zinc and regeneration of electrolyte. Trans Inst Min Metall Sect C 109:C121-C128. https://doi.org/10.1179/ mpm.2000.109.3.121

126. Duyvesteyn W, Jha M (1986) Zinc recovery from steel plant dusts and other zinciferous materials. US Patent 4572771

127. Duyvesteyn W, Hogsett R (1986) Process for metal recovery from steel plant dust. US Patent 4610722

128. McElroy R (1994) Process for the treatment of electric arc furnace dust. US Patent 5336297

129. McElroy R (1994) Processing of electric arc furnace dust via chloride hydrometallurgy. Hydrometallurgy 94:993-1010. https://doi.org/10.1007/978-94-011-1214-7_68

130. Cashman J (1998) Hydrometallurgical processing of flue dust. US Patent 5709730

131. Lee H, Baik D, Jo H (2002) Hydrometallurgical method for recovery of zinc from electric arc furnace dust. US Patent 6338748

132. Barrera-Godinez J, O'Keefe T, Watson J (1992) Effect of ultrasound on acidified brine leaching of double-kiln treated EAF dust. Miner Eng 5:1365-1373. https://doi.org/10.1016/08926875(92)90172-6

133. Prater J, Queneau P, Hudson T (1973) Nitric acid route to processing copper concentrates. AIME Trans 254:117-122

134. Drinkard Jr. W (2001) Nitric acid production and recycle. US Patent 6264909

135. Matsuoka S, Kodama T, Kumagai M et al (2003) Development of adsorption process for NOx recycling in a reprocessing plant. J Nucl Sci Technol 40:410-416. https://doi. org/10.1080/18811248.2003.9715373

136. Matsuoka S, Kodama T, Izumi J et al (2004) Development of $\mathrm{NO}_{x}$ recycle process for practical use at reprocessing plant. $\mathrm{J}$ Nucl Sci Technol 41:466-472. https://doi.org/10.1080/18811 248.2004.9715509 
137. Ma B, Yang W, Yang B et al (2015) Pilot-scale plant study on the innovative nitric acid pressure leaching technology for laterite ores. Hydrometallurgy 155:88-94. https://doi. org/10.1016/j.hydromet.2015.04.016

138. Shang Y, Van Weert G (1993) Iron control in nitrate hydrometallurgy by autoclave hydrolysis of iron(III) nitrate. Hydrometallurgy 33:273-290. https://doi.org/10.1016/0304386X(93)90067-N

139. Drinkard Jr. W, Woerner H (1999) Metallurgical dust recycling process. US Patent 5912402

140. Koningen D, Freund W (2008) Metallurgical dust reclamation process. US Patent 7399454

141. Dreisinger D, Peters E, Morgan G (1990) The hydrometallurgical treatment of carbon-steel electric-arc furnace dusts by the UBC-Chaparral process. Hydrometallurgy 25:137-152. https ://doi.org/10.1016/0304-386X(90)90035-Z

142. Barrett E, Nenniger E, Dziewinski J (1992) A hydrometallurgical process to treat carbon-steel electric-arc furnace dust. Hydrometallurgy 30:59-68. https://doi.org/10.1016/0304386X(92)90077-D

143. Barrett E, Nenniger E (1992) Processing of carbon steel furnace dusts. US Patent 5082493

144. Siebenhofer M, Zapfel W, Luttenberger H (1999) Method for processing residues containing at least one non-ferrous metal and/or compounds thereof. Patent WO 9960176

145. Hilber T, Marr R, Siebenhofer M, Zapfel W (2001) Solid/liquid extraction of zinc from EAF-dust. Sep Sci Technol 36:13231333. https://doi.org/10.1081/SS-100103652

146. Hilber T, Marr R, Siebenhofer M, Simon V (2003) Extractive separation of zinc from oxidic solid bulk feed. Sep Sci Technol 38:2867-2880. https://doi.org/10.1081/SS-120022576

147. Thorsen G (1977) Extraction and separation of metals from solids using liquid cation exchangers. US Patent 4008134

148. Thorsen G, Grislingas A, Steintveit G (1981) Recovery of zinc from zinc ash and flue dusts by hydrometallurgical processing. JOM 33:24-29. https://doi.org/10.1007/BF03354397

149. Thorsen G, Svendsen H, Grislingas A (1984) The integrated organic leaching - solvent extraction operation in hydrometallurgy. In: Hydrometallurgical Process Fundamentals, Proceedings of a NATO Advanced Research Institute on Hydrometallurgical Process Fundamentals, held July 25 - 31 , 1982, in Churchill College, Cambridge University, Cambridge, United Kingdom, Editor: R.G. Bautista. Springer, New York, pp 269-292

150. Filippou D (2004) Innovative hydrometallurgical processes for the primary processing of zinc. Miner Process Extr Metall Rev 25:205-252. https://doi.org/10.1080/08827500490441341

151. Olper M, Maccagni M (1993) Process for recovering zinc and lead from flue dusts from electrical steel works and for recycling said purified metals to the furnace, and installation for implementing said process. European Patent EP 0551155 A1

152. Olper M, Maccagni M (2000) Electrolytic zinc production from crude zinc oxides with the EZINEX process. In: Recycling of Metals and Engineered Materials, Edited by D.L. Stewart, Jr., J.C. Daley and R.L. Stephens. TMS (The Minerals, Metals \& Materials Society), pp 379-396

153. Olper M, Maccagni M (2008) From C.Z.O. to zinc cathode without any pretreatment. The EZINEX process. In: Lead and Zinc 2008. The Southern African Institute of Mining and Metallurgy, pp 85-98

154. Maccagni MG (2016) INDUTEC/EZINEX integrate process on secondary zinc-bearing materials. J Sustain Metall 2:133-140. https://doi.org/10.1007/s40831-016-0041-0

155. Pedrosa F, Cabral M, Margarido F, Nogueira CA (2013) Recycling of exhausted batteries and EAF dusts by leaching with several aqueous media. Mater Sci Forum 730-732:636-641. https://doi.org/10.4028/www.scientific.net/MSF.730-732.636

156. Rao S, Yang T, Zhang D et al (2015) Leaching of low grade zinc oxide ores in $\mathrm{NH}_{4} \mathrm{Cl}-\mathrm{NH}_{3}$ solutions with nitrilotriacetic acid as complexing agents. Hydrometallurgy 158:101-106. https://doi. org/10.1016/j.hydromet.2015.10.013

157. Harvey TG (2006) The hydrometallurgical extraction of zinc by ammonium carbonate: a review of the Schnabel process. Miner Process Extr Metall Rev 27:231-279. https://doi. org/10.1080/08827500600815271

158. Peters M (1978) Process for recovering of zinc from steel-making flue dust. US Patent 4075357

159. Keegel Jr. J (1996) Methods for recycling electric arc furnace dust. US Patent 5538532

160. Bucket G, Fountain C, Sinclair R (1998) Refining of zinc sulphides. World Patent WO1998036102A1

161. Antunano N, Cambra JF, Arias PL (2017) Development of a combined solid and liquid wastes treatment integrated into a high purity $\mathrm{ZnO}$ hydrometallurgical production process from Waelz oxide. Hydrometallurgy 173:250-257. https://doi.org/10.1016/j. hydromet.2017.09.002

162. Varga T, Torok T (2013) Experimental investigation of zinc precipitation from EAF dust leaching solutions. Mater Sci Eng 38:61-71

163. Ruiz O, Clemente C, Alonso M, Alguacil FJ (2007) Recycling of an electric arc furnace flue dust to obtain high grade $\mathrm{ZnO}$. J Hazard Mater 141:33-36. https://doi.org/10.1016/j.jhazm at.2006.06.079

164. Wylock C, Antuñano N, Arias P, Haut B (2014) Analysis of the simultaneous gas-liquid $\mathrm{CO}_{2}$ absorption and liquid-gas $\mathrm{NH}_{3}$ desorption in a hydrometallurgical waelz oxides purification process. Int J Chem React Eng 12:1-14

165. Xia D (1997) Recovery of zinc from zinc ferrite and electric arc furnace dust. PhD Thesis Queens University of Kingston, Ontario, Canada

166. Mordogan H, Cicek T, Isik A (1999) Caustic soda leach of electric arc furnace dust. Turk J Eng Environ Sci 23:199-207

167. Dutra A, Paiva P, Tavares L (2006) Alkaline leaching of zinc from electric arc furnace steel dust. Miner Eng 19:478-485. https ://doi.org/10.1016/j.mineng.2005.08.013

168. Orhan $\mathrm{G}$ (2005) Leaching and cementation of heavy metals from electric arc furnace dust in alkaline medium. Hydrometallurgy 78:236-245. https://doi.org/10.1016/j.hydromet.2005.03.002

169. Palimaka P, Pietrzyk S, Stepien M et al (2018) Zinc recovery from steelmaking dust by hydrometallurgical methods. Metals. https://doi.org/10.3390/met8070547

170. Xia D, Pickles C (1999) Caustic roasting and leaching of electric arc furnace dust. Can Metall Q 38:175-186. https://doi. org/10.1016/S0008-4433(99)00014-2

171. Youcai Z, Stanforth R (2000) Extraction of zinc from zinc ferrites by fusion with caustic soda. Miner Eng 13:1417-1421. https:// doi.org/10.1016/S0892-6875(00)00123-0

172. Zhao Y, Stanforth R (2000) Integrated hydrometallurgical process for production of zinc from electric arc furnace dust in alkaline medium. J Hazard Mater 80:223-240. https://doi. org/10.1016/S0304-3894(00)00305-8

173. Lenz D, Martins F (2007) Lead and zinc selective precipitation from leach electric arc furnace dust solutions. Rev Matér 12:503-509

174. Xie Z, Guo Y, Jiang T et al (2017) The Extraction of Zinc from Zinc Ferrite by Calcified-Roasting and Ammonia-Leaching Process. In: Hwang, JY and Jiang, T and Kennedy, MW and Yucel, $\mathrm{O}$ and Pistorius, $\mathrm{PC}$ and Seshadri, V and Zhao, B and Gregurek, D and Keskinkilic, E (ed) 8th International Symposium on Hightemperature Metallurgical Processing. pp 485-493 
175. Yakornov SA, Panshin AM, Grudinsky PI et al (2018) Method of electric arc furnace dust processing by calcination with lime with following alkaline leaching. Russ Metall. https://doi.org/10.1134/ S0036029518130268

176. Chairaksa-Fujimoto R, Maruyama K, Miki T, Nagasaka T (2016) The selective alkaline leaching of zinc oxide from Electric Arc Furnace dust pre-treated with calcium oxide. Hydrometallurgy 159:120-125. https://doi.org/10.1016/j.hydromet.2015.11.009

177. Zhang C, Zhuang L, Wang J et al (2016) Extraction of zinc from zinc ferrites by alkaline leaching: enhancing recovery by mechanochemical reduction with metallic iron. J South Afr Inst Min Metall 116:1111-1114

178. Xia D, Pickles C (2000) Microwave caustic leaching of electric arc furnace dust. Miner Eng 13:79-94. https://doi.org/10.1016/ S0892-6875(99)00151-X

179. Abbott A, Capper G, Davies D et al (2003) Novel solvent properties of choline chloride/urea mixtures. Chem Commun. https:// doi.org/10.1039/b210714g

180. Smith EL, Abbott AP, Ryder KS (2014) Deep eutectic solvents (DESs) and their applications. Chem Rev 114:11060-11082. https://doi.org/10.1021/cr300162p

181. Abbott AP, Frisch G, Hartley J, Ryder KS (2011) Processing of metals and metal oxides using ionic liquids. Green Chem 13:471-481. https://doi.org/10.1039/c0gc00716a

182. Abbott A, Capper G, Davies D, Shikotra P (2006) Processing metal oxides using ionic liquids. Miner Process Extr Metall 115:15-18. https://doi.org/10.1179/174328506X91293

183. Abbott A, Collins J, Dalrymple I et al (2009) Processing of electric arc furnace dust using deep eutectic solvents. Aust J Chem 62:341-347. https://doi.org/10.1071/CH08476

184. Bakkar A (2014) Recycling of electric arc furnace dust through dissolution in deep eutectic ionic liquids and electrowinning. J Hazard Mater 280:191-199. https://doi.org/10.1016/j.jhazm at.2014.07.066

185. Bakkar A, Neubert V (2019) Recycling of cupola furnace dust: extraction and electrodeposition of zinc in deep eutectic solvents. J Alloys Compd 771:424-432. https://doi.org/10.1016/j.jallc om.2018.08.246

186. Halli P, Hamuyuni J, Revitzer H, Lundstrom M (2017) Selection of leaching media for metal dissolution from electric arc furnace dust. J Clean Prod 164:265-276. https://doi.org/10.1016/j.jclep ro.2017.06.212

187. Halli P, Hamuyuni J, Leikola M, Lundstrom M (2018) Developing a sustainable solution for recycling electric arc furnace dust via organic acid leaching. Miner Eng 124:1-9. https://doi. org/10.1016/j.mineng.2018.05.011

188. Hamuyuni J, Halli P, Tesfaye F et al (2018) A sustainable methodology for recycling electric arc furnace dust. In: Sun Z, Wang C, Guillen DP, Neelameggham NR, Zhang L, Howarter JA, Wang T, Olivetti E, Zhang M, Verhulst D, Guan X, Anderson A, Ikhmayies S, Smith YR, Pandey A, Pisupati S, Lu H (eds) Energy technology 2018: carbon dioxide management and other technologies. Springer, Cham, pp 233-240

189. Forrester K, Francis A (1998) Extraction of metals from heavy metal-bearing wastes. Patent WO 9824938

190. Halli P, Agarwal V, Partinen J, Lundstrom M (2020) Recovery of $\mathrm{Pb}$ and $\mathrm{Zn}$ from a citrate leach liquor of a roasted EAF dust using precipitation and solvent extraction. Sep Purif Technol. https:// doi.org/10.1016/j.seppur.2019.116264

191. Wang H, Jia N, Liu W et al (2016) Efficient and selective hydrothermal extraction of zinc from zinc-containing electric arc furnace dust using a novel bifunctional agent. Hydrometallurgy 166:107-112. https://doi.org/10.1016/j.hydromet.2016.10.013

192. Bayat O, Sever E, Bayat B et al (2009) Bioleaching of zinc and iron from steel plant waste using Acidithiobacillus ferrooxidans.
Appl Biochem Biotechnol 152:117-126. https://doi.org/10.1007/ s12010-008-8257-5

193. Carranza F, Romero R, Mazuelos A, Iglesias N (2016) Recovery of $\mathrm{Zn}$ from acid mine water and electric arc furnace dust in an integrated process. J Environ Manage 165:175-183. https://doi. org/10.1016/j.jenvman.2015.09.025

194. Stopic S, Friedrich B (2009) Kinetics and mechanism of thermal zinc-ferrite phase decomposition. Proceedings of the EMC 2009 conference, June 28-July 1, 2009, Innsbruck, Austria, 1-14

195. Offenthaler D, Ludewig F, Antrekowitsch J (2009) Avoiding the hot acid leaching process in zinc metallurgy by reduction of calcine. World Metall - ERZMETALL 62:376-384

196. Han J, Liu W, Qin W et al (2016) Thermodynamic and kinetic studies for intensifying selective decomposition of zinc ferrite. JOM 68:2543-2550. https://doi.org/10.1007/s11837-015-1807-8

197. Kazemi M, Sichen D (2016) Investigation of selective reduction of iron oxide in zinc ferrite by carbon and hydrogen. J Sustain Metall 2:73-78. https://doi.org/10.1007/s40831-015-0037-1

198. Antrekowitsch J, Antrekowitsch H (2001) Hydrometallurgically recovering zinc from electric arc furnace dusts. JOM 53:26-28. https://doi.org/10.1007/s11837-001-0008-9

199. Li Y, Liu H, Peng B et al (2015) Study on separating of zinc and iron from zinc leaching residues by roasting with ammonium sulphate. Hydrometallurgy 158:42-48. https://doi.org/10.1016/j. hydromet.2015.10.004

200. Holloway PC, Etsell TH, Murland AL (2007) Roasting of La Oroya zinc ferrite with $\mathrm{Na}_{2} \mathrm{CO}_{3}$. Metall Mater Trans B 38:781791. https://doi.org/10.1007/s11663-007-9082-x

201. Miki T, Chairaksa-Fujimoto R, Maruyama K, Nagasaka T (2016) Hydrometallurgical extraction of zinc from $\mathrm{CaO}$ treated EAF dust in ammonium chloride solution. J Hazard Mater 302:90-96. https://doi.org/10.1016/j.jhazmat.2015.09.020

202. Lanzerstorfer C (2019) Potential of industrial de-dusting residues as a source of potassium for fertilizer production - a mini review. Resour Conserv Recycl 143:68-76. https://doi.org/10.1016/j. resconrec.2018.12.013

203. Peng C, Zhang F, Guo Z (2009) Separation and recovery of potassium chloride from sintering dust of ironmaking works. ISIJ Int 49:735-742. https://doi.org/10.2355/isijinternational.49.735

204. Zhan G, Guo Z (2013) Basic properties of sintering dust from iron and steel plant and potassium recovery. J Environ Sci 25:1226-1234. https://doi.org/10.1016/S1001-0742(12)60168-5

205. Zhan G, Guo Z (2015) Preparation of potassium salt with joint production of spherical calcium carbonate from sintering dust. Trans Nonferrous Met Soc China 25:628-639. https://doi. org/10.1016/S1003-6326(15)63646-9

206. Tang H, Zhao L, Sun W et al (2018) Extraction of rubidium from respirable sintering dust. Hydrometallurgy 175:144-149. https:// doi.org/10.1016/j.hydromet.2017.11.003

207. Ma N, McDowell BJ, Houser JB et al (2019) Separation of mill scale from flume wastewater using a dynamic separator toward zero wastes in the steel hot-rolling process. J Sustain Metall 5:97-106. https://doi.org/10.1007/s40831-018-0203-3

208. Shatokha VI, Gogenko OO, Kripak SM (2011) Utilising of the oiled rolling mills scale in iron ore sintering process. Resour Conserv Recycl 55:435-440. https://doi.org/10.1016/j.resco nrec.2010.11.006

209. Gomez V, Wright K, Esquenazi GL, Barron AR (2019) Microwave treatment of a hot mill sludge from the steel industry: en route to recycling an industrial waste. J Clean Prod 207:182-189. https://doi.org/10.1016/j.jclepro.2018.08.294

210. Park J, Ahn J, Song H et al (2002) Reduction characteristics of oily hot rolling mill sludge by direct reduced iron method. Resour Conserv Recycl 34:129-140. https://doi.org/10.1016/ S0921-3449(01)00098-2 
211. Liu B, Zhang S, Tian J et al (2013a) New technology for recycling materials from oily cold rolling mill sludge. Int J Miner Metall Mater 20:1141-1147. https://doi.org/10.1007/s1261 3-013-0847-8

212. Liu B, Zhang S, Pan D, Chang C (2016) Synthesis and characterization of micaceous iron oxide pigment from oily cold rolling mill sludge. Procedia Environ Sci 31:653-661. https://doi. org/10.1016/j.proenv.2016.02.121

213. Liu B, Zhang S, Tian J et al (2013b) Recycle of valuable products from oily cold rolling mill sludge. Int J Miner Metall Mater 20:941-946. https://doi.org/10.1007/s12613-013-0818-0

214. Devi A, Singhal A, Gupta R, Panzade P (2014) A study on treatment methods of spent pickling liquor generated by pickling process of steel. Clean Technol Environ Policy 16:1515-1527. https ://doi.org/10.1007/s10098-014-0726-7

215. Dufour J, Negro C, Heras F, Lopez-Mateos F (2001) Recovery of the metals from pickling liquors of stainless steel by precipitation methods. ISIJ Int 41:801-806. https://doi.org/10.2355/isijintern ational.41.801

216. Heras F, Dufour J, Lopez-Delgado A et al (2004) Feasibility study of metals recycling from nitric-hydrofluoric waste pickle baths. Environ Eng Sci 21:583-590. https://doi.org/10.1089/ ees.2004.21.583
217. Galvez JL, Dufour J, Negro C, Lopez-Mateos F (2009) Routine to estimate composition of concentrated metal-nitric-hydrofluoric acid pickle liquors. Hydrometallurgy 96:88-94. https://doi. org/10.1016/j.hydromet.2008.08.007

218. Ji Z, Lou X, Wang W et al (2017) Recovery of nickel from stainless steelmaking sludge by circular leaching and extraction. AIP Conf Proc 1794:030011. https://doi.org/10.1063/1.4971933

219. Regel-Rosocka M (2010) A review on methods of regeneration of spent pickling solutions from steel processing. J Hazard Mater 177:57-69. https://doi.org/10.1016/j.jhazmat.2009.12.043

220. Dufour J, Lopez L, Negro C et al (2002) Mathematical model of magnetite synthesis by oxidation of sulfuric pickling liquors from steelmaking. Chem Eng Commun 189:285-297. https://doi. org/10.1080/00986440212080

221. Hermoso J, Dufour J, Galvez J et al (2005) Nickel hydroxide recovery from stainless steel pickling liquors by selective precipitation. Ind Eng Chem Res 44:5750-5756. https://doi. org/10.1021/ie050422n

Publisher's Note Springer Nature remains neutral with regard to jurisdictional claims in published maps and institutional affiliations.

\section{Affiliations}

\section{Koen Binnemans ${ }^{1}\left[\right.$ [ $\cdot$ Peter Tom Jones ${ }^{2}$ (1) $\cdot$ Álvaro Manjón Fernández ${ }^{3} \cdot$ Victoria Masaguer Torres $^{3}$}

Koen Binnemans

Koen.Binnemans@kuleuven.be

1 Department of Chemistry, KU Leuven, Celestijnenlaan 200F - box 2404, 3001 Leuven, Belgium
2 Department of Materials Engineering, KU Leuven, Kasteelpark Arenberg 44 - box 2450, 3001 Leuven, Belgium

3 Global R\&D Asturias, ArcelorMittal, P.O. Box 90, 33400 Avilés, Spain 